\title{
A Visible and Near-Infrared Light Activatable Diazo-Coumarin Probe for Fluorogenic Protein Labeling in Living Cells
}

\author{
Sheng-Yao Dai, Dan Yang* \\ Supporting Information Placeholder
}

\begin{abstract}
Chemical modification of proteins in living cells permits valuable glimpses into the molecular interactions that underpin dynamic cellular events. While genetic engineering methods are often preferred, selective labeling of endogenous proteins in a complex intracellular milieu with chemical approaches represents a significant challenge. In this study, we report novel diazo-coumarin compounds that can be photo-activated by visible $(430-490 \mathrm{~nm})$ and near-infrared light $(800 \mathrm{~nm})$ irradiation to photo-uncage reactive carbene intermediates, which could subsequently undergo insertion reaction with concomitant fluorescence "turned-on". With these new molecules in hand, we have developed a new approach for rapid, selective and fluorogenic labeling of endogenous protein in living cells. By using CA-II and eDHFR as model proteins, we demonstrated that subcellular localization of proteins can be precisely visualized by live-cell imaging and protein levels can be reliably quantified in multiple cell types using flow cytometry. Dynamic protein regulations such as hypoxia induced CA-IX accumulation can also be detected. In addition, by two-photon excitation with an $800 \mathrm{~nm}$ laser, cell-selective labeling can also be achieved with spatially controlled irradiation. Our method circumvents the cytotoxicity of UV light and obviates the need for introducing external reporters with "click chemistries". We believe that this approach of fluorescence labeling of endogenous protein by bioorthogonal photo-irradiation opens up exciting opportunities for discoveries and mechanistic interrogation in chemical biology.
\end{abstract}

\section{INTRODUCTION}

Chemical modification of proteins is a powerful method for protein engineering and conjugation to construct biopharmatheuticals $^{1-3}$. The ability to selectively label proteins, particularly in living cells, is critical for characterizing protein function, localization and dynamics, but is challenging for chemical biology and drug development $t^{4-7}$. Precise protein labeling can be achieved by genetic engineering approaches, such as fusion with fluorescent proteins, self-labeling $\operatorname{tags}^{8}$ (e.g. SNAP-tag ${ }^{9}$, CLIP-tag ${ }^{10}$ and HaloTag ${ }^{11}$ ) or incorporation of unnatural amino acids (UAAs) by amber codon suppression $^{12}$. However, the considerably large fusion proteins (19-33 kDa) may perturb the functions of POIs. The challenges of UAA incorporation in mammalian cells also hindered its wide applications ${ }^{13}$. Most importantly, these methods can only be applied to cell types that are amenable to genetic manipulation. Direct chemical modification of endogenous proteins with small molecules is a prevailing avenue, as it minimally perturbs protein functions owing to the small sizes and bypasses the need for genetic manipulation. However, small molecule-based live-cell protein labeling was only achieved by limited examples including ligand-directed chemistry developed by Hamachi group and others ${ }^{14-19}$. Their strategies rely on nucleophilic residues on proteins to react with the electrophilic moiety of affinity-based probes, which may intrinsically compromise the labeling efficiency due to restricted amino-acid coverage and competing hydrolysis reaction. Developing new chemistries for selective modification of native endogenous proteins has thus become one of the most important challenges.

Carbene-mediated insertion reactions have been demonstrated to be versatile methods in protein labeling because of their ability to modify a broad scope of residues. One of the most well-known carbene precursors are diazo compounds, which have recently been employed extensively in chemical biology ${ }^{20}$. For instance, it have been demonstrated that purified peptides or proteins can be labeled in vitro by metallocarbenoid with the use of dirhodium(II)metallopeptides ${ }^{21-29}$ and ruthenium(II)-porphyrin ${ }^{30}$ catalysts. Reactive carbene intermediates can also be photochemically generated from diazo and diazirine compounds to label proteins in cells for photoaffinity protein profiling ${ }^{31}$. However, their activation requires UV irradiation that is detrimental to biomolecules and cells via DNA damage ${ }^{32-34}$ and generation of reactive oxygen species ${ }^{35}$, which hindered the subsequent live-cell applications. How to design new diazo compounds for specific protein modification in live cells in a bioorthogonal manner is still challenging.

Here we present a new photochemical approach by connecting a diazo group to an extended $\pi$ conjugation system, such as a fluorophore, which allows the excitation wavelength of the diazo group to be drastically red-shifted from $254 \mathrm{~nm}^{36-37}$ to visible light region and enables specific intracellular protein labeling in a biocompatible manner without click-chemistry (Scheme 1a). Such protein modification strategy presents several advantages. Firstly, compared to methods utilizing diazirine ${ }^{38-39}$, benzophenone ${ }^{40}$, arylazide $^{41-44}$, tetrazole ${ }^{45-50}$ and $\alpha$-ketoamide ${ }^{51}$, the use of long-wavelength $(400-800 \mathrm{~nm})$ irradiation can avoid the cytotoxicity of UV light. Secondly, copper(I)-catalyzed azide-alkyne cycloaddition (CuAAC) or other reactions that are often required to introduce fluorescence reporters can be obviated, which allows real-time report of labeled proteins. Furthermore, photochemical method provides rapid and non-invasive controls for labeling with spatiotemporal precision $^{52-55}$.

In our studies, we first analyzed the photolysis reaction of diazocoumarins under visible light irradiation and further optimized the structure by introducing a trifluoromethyl substituent adjacent to the diazo group to improve the carbene insertion propensity. Covalent modification of purified proteins by diazo-coumarin can be accomplished with mild irradiation of blue LED lamp. It was con- 
firmed that a range of amino acids can be covalently modified. Directed by small-molecule ligands, labeling of specific proteins was further advanced into living cells. Notably, the protein labeling in cells was found to be rapid, mild and specific. The coumarin fluorescence was recovered upon photo-irradiation to facilitate the instant report of labeled proteins in a variety of analyses, including SDS-PAGE, confocal microscopy and flow cytometry. Furthermore, in situ two-photon labeling was achieved in cells with a nearinfrared laser, providing an exciting potential for achieving protein labeling with spatiotemporal control. Collectively, we envision that diazo-coumarin probes can be exploited as a new photochemical tool for live-cell protein modifications to facilitate the future biological studies, and also provide useful templates for the rational design of next generation protein modification reactions.

Scheme 1. (a) Schematic illustration of light-induced fluorogenic labeling of protein-of-interest (POI). (b) Photo-induced carbene insertion reaction of diazo-coumarins 1 and 2.

a)

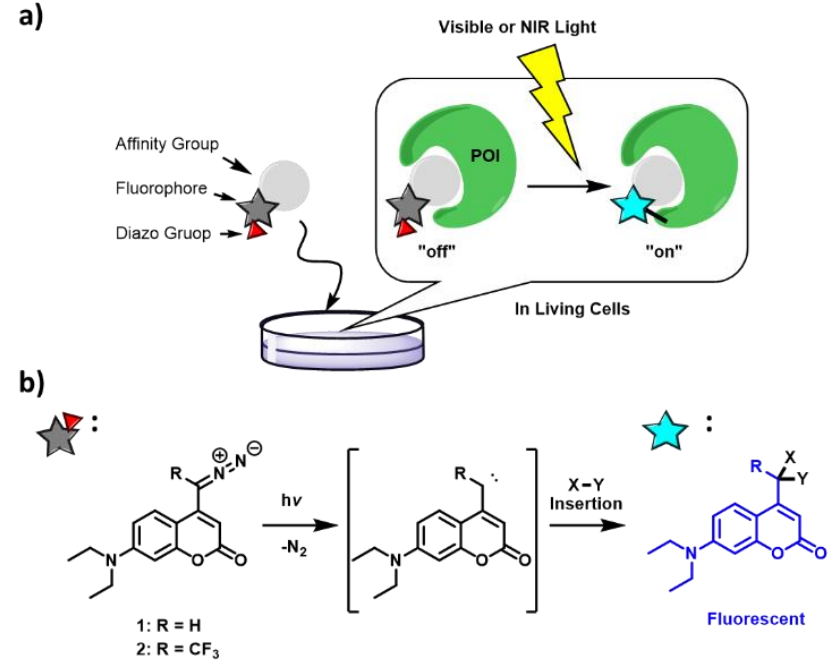

b)

\section{RESULTS AND DISCUSSION}

Photochemical Characterization of Diazo-coumarins Under Blue Light. In the course of surveying different combinations of diazo group and fluorophores, we found that 4-diazomethylcoumarins $^{56-59}$ were used as precursors for photo-releasing of compounds ${ }^{60}$, but the photochemistry of those diazo compounds has been unexplored. We hypothesize that diazo-coumarin compounds can be activated by photo-irradiation with long-wavelength light to "uncage" reactive carbene species for covalent modification of proximal proteins (Scheme 1b). To test whether diazo-coumarins can be photo-activated by visible light, we synthesized compound $\mathbf{1}$ according to procedures reported in the literature (Scheme $\mathrm{S} 1)^{58}$. It was found that a large portion of the longest absorption peak fell into the visible light region (> $400 \mathrm{~nm}$ ) (Figure S1a). Unlike ordinary coumarins, the fluorescence of $\mathbf{1}$ was found to be quenched by the diazo group, presumably via internal charge transfer (ICT) ${ }^{61}$. Consequently, photolysis of $\mathbf{1}$ was first carried out in methanol by irradiation with a household blue LED lamp (430-490 nm). Upon irradiation, changes in absorption and fluorescence spectra were observed (Figure S1a-b), indicating a photochemical transformation of $\mathbf{1}$ under blue light as we anticipated. It is highly conceivable that a carbene intermediate is formed and trapped by methanol. The reaction mixture was analyzed by LCMS, and multiple products were observed (Figure S1c). To identify these products, a large scale photolysis reaction was performed. The photolysis mixture was found to include several solvent insertion products (Scheme 2, Figure $\mathrm{S} 1 \mathrm{~d})$, such as the methanol $\mathrm{C}-\mathrm{H}$ insertion product 1a $(2.3 \%)$, the water insertion product $\mathbf{1 b}(3.3 \%)$ and the methanol $\mathrm{O}$ $\mathrm{H}$ insertion product 1d (19\%). While an aldehyde product 1cresulting from the carbene oxidation by oxygen ${ }^{62}$ was isolated in $35 \%$ yield, the major product was found to be a non-fluorescent ring expansion product 1e $(38 \%)^{63}$, formed by Wolff rearrangement of the carbene intermediate to an allene ${ }^{64}$ followed by methanol addition. This process is undesirable since the allene intermediate has a long lifetime and preferentially reacts with nucleophiles to give non-fluorescent products.

Scheme 2. Photolysis of $2(30 \mu \mathrm{M})$ in methanol upon blue LED irradiation and the isolated yields of photolysis products.

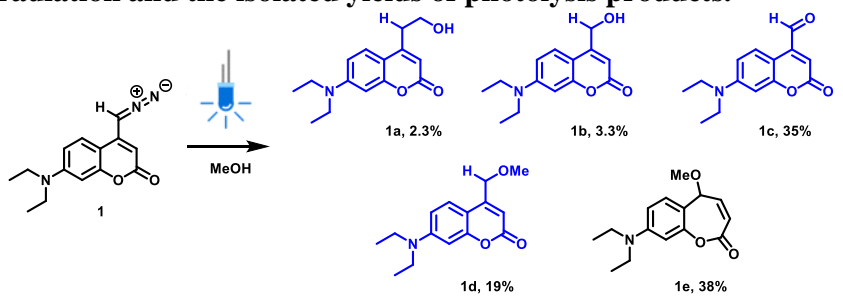

Since trifluoromethyl substituent can prevent intramolecular rearrangement of carbene intermediate generated from trifluoromethylaryldiazirine ${ }^{65}$, we designed and synthesized a trifluoromethyl analog 2 (Scheme S2). Compound 2 was found to have a longer absorption maximum positioned at $408 \mathrm{~nm}$ (extinction coefficient $\varepsilon$ of $2259 \mathrm{M}^{-1} \mathrm{~cm}^{-1}$, Table S1) and was non-fluorescent (quantum yield $\Phi_{\mathrm{fl}}$ of 0.003 ). When 2 was subjected to blue LED irradiation, the peak at $408 \mathrm{~nm}$ only underwent a slight blue-shift and that at $\sim 300 \mathrm{~nm}$ dropped sharply. This indicates the coumarin chromophore was preserved, whereas the diazo moiety that usually absorbs below $300 \mathrm{~nm}$ underwent decomposition. A significant fluorescence enhancement of 135-fold was also detected (Figure $1 \mathrm{~b}, \mathrm{c}$ ). Subsequent analyses (Figure 1d,e) revealed that most products were fluorescent, including insertion products $\mathbf{2 b}(17 \%)$ and 2d $\left(43 \%\right.$; $\Phi_{\mathrm{fl}}$ of 0.22$)$, ketone product $\mathbf{2 a}(15 \%)$, and cyclized ${ }^{66}$ byproduct 2c (10\%) (Figure S2, Table S1). Most importantly, no ringexpansion was found.
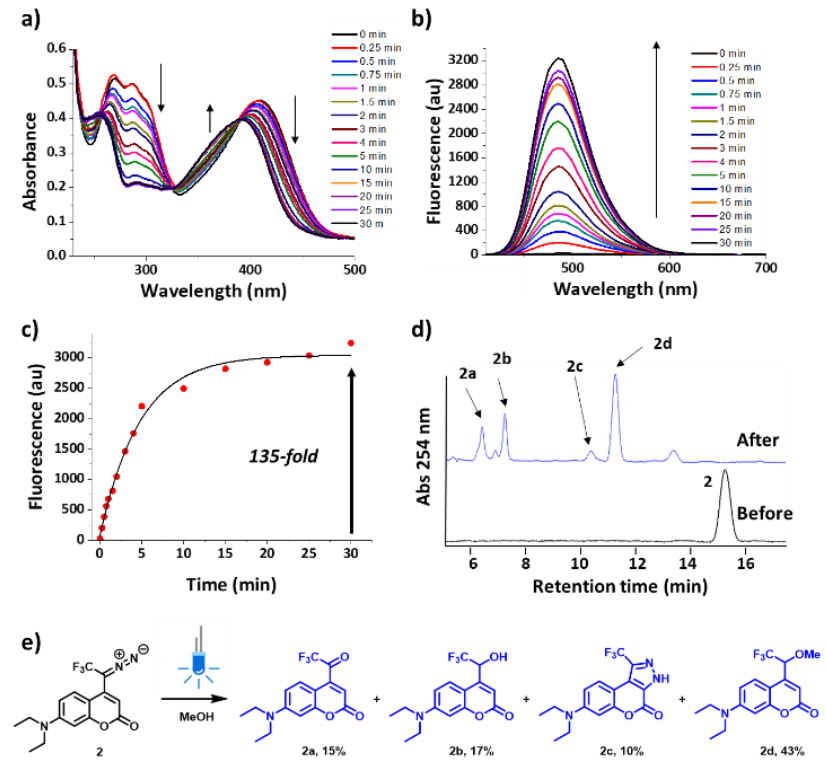

Figure 1. Photo-chemical characterizations of diazo-coumarins. (a)-(b) Change in absorption and emission spectra of $2(30 \mu \mathrm{M})$ in methanol upon blue LED irradiation. $\lambda_{\mathrm{ex}}=400 \mathrm{~nm}$. (c) Change in fluorescence intensity at $\lambda_{\mathrm{em}}=484 \mathrm{~nm}$ upon blue LED irradiation. (d) HPLC analysis of $\mathbf{2}$ before and after photolysis. (e) Isolated yields of photolysis products.

Reactivity and Stability of Diazo-coumarins in Biologically Relevant Conditions. Encouraged by these results, we performed the blue light-prompted reaction of model protein bovine serum albumin (BSA) with 1 or $\mathbf{2}$. The fluorogenic property of coumarin facilitated the visualization of proteins during in-gel fluorescence scanning without the need for "click" chemistry. While both compounds can covalently label BSA at high concentrations, 2 ap- 
peared to be more efficient (Figure 2a) than 1. Through tryptic digestion and tandem mass spectrometry (LC/MS/MS) analysis (Figures 2 b, c, and S3), 35 and 8 modification sites by $\mathbf{1}$ and $\mathbf{2}$ were identified on BSA, respectively. It was found that although the two compounds modified similar regions, 2 labeled neutral and polar side-chains without strong preference, suggesting the formation of a reactive carbene intermediate. However, 1 additionally reacted with a large number of nucleophilic residues, such as His, Lys, Ser, Arg, Thr and Tyr, indicative of the generation of ketene intermediate along with the reactive carbene, which could potentially lead to non-specific labeling ${ }^{67}$ in a more complex environment. These results suggested that $\mathbf{2}$ is superior to $\mathbf{1}$ in terms of sensitivity and selectivity in protein labeling. Since diazo groups are prone to decomposition, especially towards thiols ${ }^{68}$ and acids ${ }^{69}$, the stability of 2 was further examined. When 2 was incubated with an equal amount of reduced glutathione (GSH), an intracellularly abundant nucleophile and reductant, in phosphate buffer for $24 \mathrm{~h}$ in dark, no reaction was observed by NMR analysis (Figure $2 \mathrm{~d}$ ). In addition, as shown in Figure 2e, $\mathbf{2}$ was stable across a wide range of $\mathrm{pH}$; the fluorescence increased only when the compound was exposed to light.

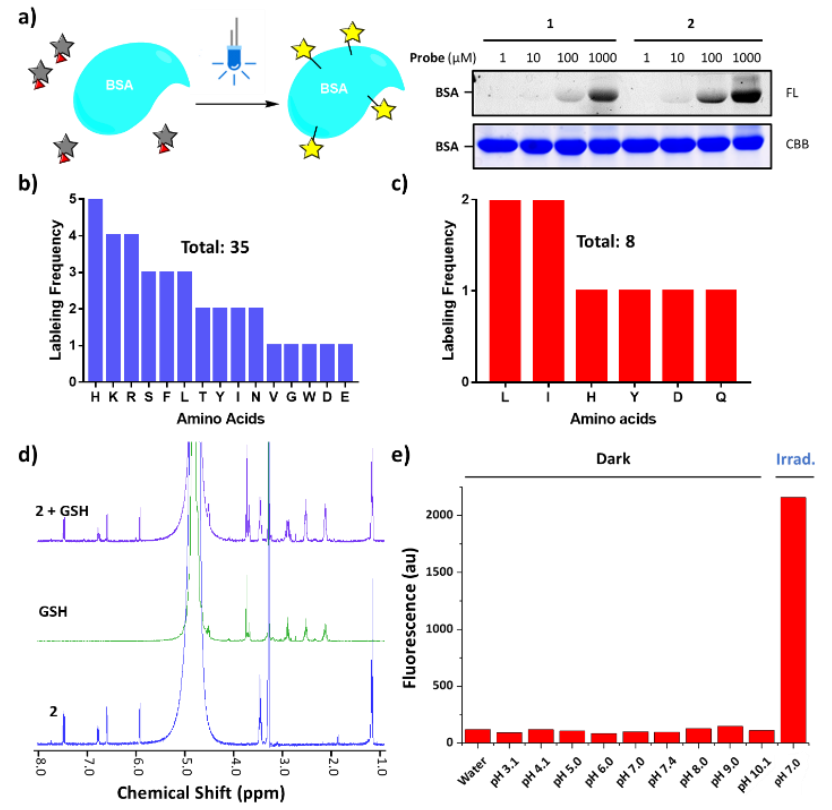

Figure 2. Reactivity and stability of diazo-coumarins. (a) SDSPAGE of BSA $(15 \mu \mathrm{M})$ labeled by $\mathbf{1}$ and $\mathbf{2}$ of various concentrations. (b)-(c) Bar chart showing the amino acid labeling frequencies of $\mathbf{1}$ and $\mathbf{2}$ obtained from tryptic peptide LC/MS/MS analysis of BSA. (d) Comparison of ${ }^{1} \mathrm{H}$ NMR spectra of $2(5 \mathrm{mM})$ before and after $24 \mathrm{~h}$ incubation in sodium phosphate buffer $(10 \mathrm{mM}), \mathrm{pH}$ $7.4\left(\mathrm{D}_{2} \mathrm{O}\right) / \mathrm{CD}_{3} \mathrm{OD} 1: 1$, in the dark at room temperature, in the presence of reduced glutathione $(5 \mathrm{mM})$. (e) Fluorescence intensity of $2\left(\lambda_{\mathrm{ex}}=400 \mathrm{~nm}, \lambda_{\mathrm{em}}=510 \mathrm{~nm}\right)$ in sodium phosphate buffer of various $\mathrm{pH}$ values incubated in dark or under blue LED irradiation as indicated.

Labeling of Recombinant CA-II with Blue Light. The affinity-based approach was then employed to achieve specific protein labeling using small-molecule ligands. Carbonic anhydrase-II (CAII, $29 \mathrm{kDa}$ ) was chosen as a target for selective labeling as it has been widely adopted in studies of affinity-based probes ${ }^{70}$. CA-II can be reversibly inhibited by aromatic primary sulfonamides ${ }^{71}$, such as 4-carboxybenzene-sulfonamide $(\mathbf{C B S})\left(K_{\mathrm{d}} \sim 3.2 \mu \mathrm{M}\right)^{72}$. Accordingly, we designed and synthesized 3 (Figure 3a, Scheme S2) by modifying one of the ethyl substituents on the 7-amino group to connect $\mathbf{C B S}$ through a simple amide linker. In vitro labeling of recombinant CA-II was then performed by mixing with 3 followed by blue LED irradiation (Figure $3 b$ ). As visualized by the resulting SDS-PAGE, labeling of CA-II by 3 was furnished in both concentration (Figure 3c, EC $50: 2.48 \mu \mathrm{M}$ ) and time (Figure 3d) dependent manner, and was diminished by competition with an excess of CBS (Figure 3e, IC50: $182 \mu \mathrm{M}$ ). An enzyme activity assay was performed, which showed that $\mathbf{3}$ has an $\mathrm{IC}_{50}$ value comparable to that of CBS (Figure 3f, IC 50 of 3: $0.90 \mu \mathrm{M}$, IC 50 of CBS: 2.14 $\mu \mathrm{M})$. These results showed that the binding property of the sulfonamide was not disrupted despite its modest interaction with CA-II. Further, LC/MS/MS analysis revealed that 3 labeled His 2 and Trp4 residues of the $N$-terminal peptide of CA-II (Figure $3 \mathrm{~g}$, Figure S4). Both residues were located at the entrance of the ligand-binding pocket (Figure $3 \mathrm{~h}$ ), suggesting that labeling is induced by the specific interaction between CA-II and 3. Consistently, exclusive labeling of $29 \mathrm{kDa}$ CA-II could also be observed in HeLa cell lysates spiked with the recombinant protein (Figure S5a). a)

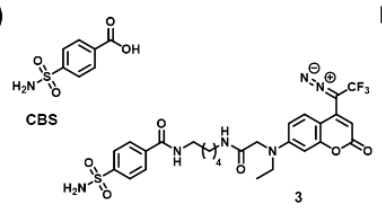

)

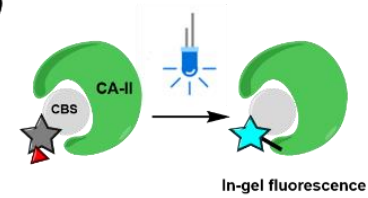

c)

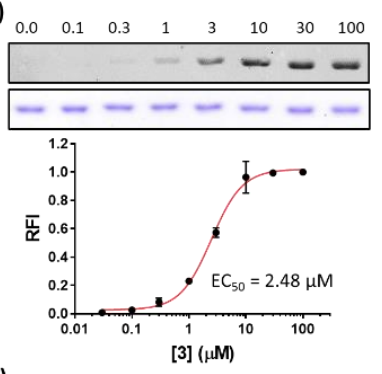

d)

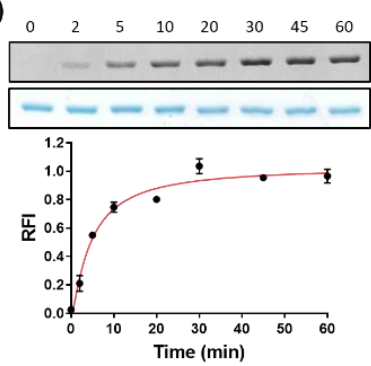

e)

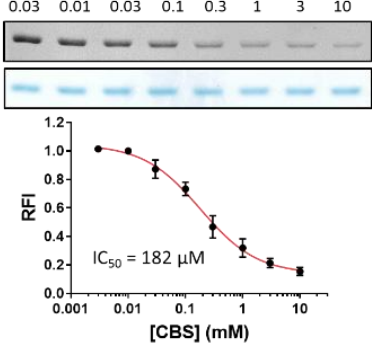

g)
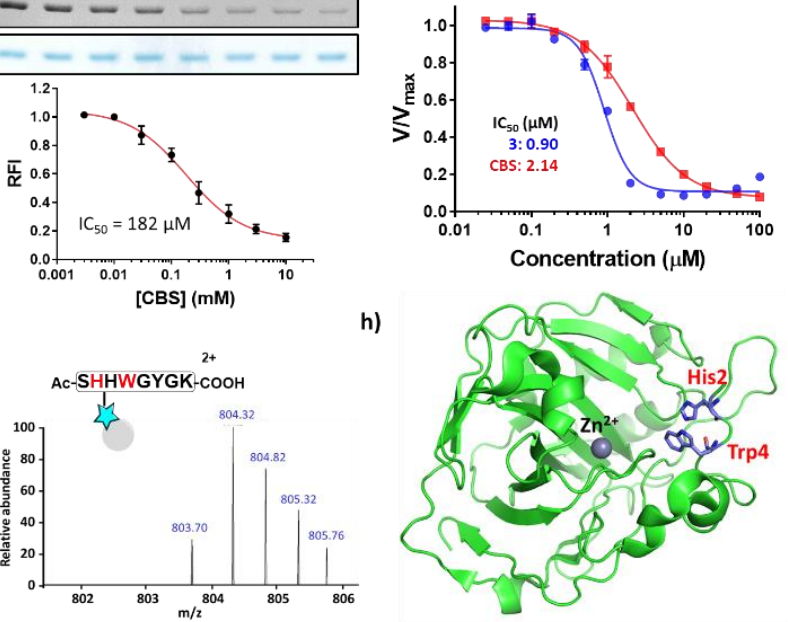

Figure 3. Fluorescence labeling of recombinant CA-II with blue light. (a) Structures of 4-carbonxybenzenesulfonamide (CBS) and 3. (b) Schematic illustration of blue LED light-induced labeling of recombinant CA-II. (c)-(e) SDS-PAGE of recombinant CA-II (1.7 $\mu \mathrm{M})$ labeled by $3(10 \mu \mathrm{M}$ in (d) and (e)) under blue LED irradiation. (f) Enzymatic activity assay of CA-II catalyzed the hydrolysis of $p$-nitrophenyl acetate. Error bar indicates SD, $\mathrm{n}=3$. (g) Mass spectrum of modified CA-II tryptic peptide by 3. (h) Crystal structure of CA-II showing $\mathrm{Zn}^{2+}$ ion and the two labeled residues.

Labeling of Endogenous CA-II in Living Cells. Our ultimate goal is to label endogenously expressed proteins in living cells. Therefore, labeling was attempted with live MCF7 human breast cancer cells ${ }^{73}$ and HCT116 human colorectal cancer cells ${ }^{74}$, which endogenously express CA-II. After incubation with $\mathbf{3}$, cells were irradiated with the blue LED lamp (Figure 4a). Subsequently, cell lysates were harvested and separated by SDS-PAGE to visualize the fluorescent signal. A strong single fluorescent band corresponds to CA-II was observed in SDS-PAGE of MCF7 cells, but 
was blocked by CBS co-treatment (Figure 4b, lanes 3 and 4). A weaker band was observed without irradiation (Figure 4b, lane 2), suggesting that a minor reaction occurred in the dark. Western blot analysis confirms that CA-II was evenly expressed among the four groups and matched the molecular weight of fluorescent bands. Similar results were obtained in HCT116 cells (Figure S5b,c). Surprisingly, in the live-cell time-dependent experiments, the labeling was found to complete within 2 mins under irradiation (Figure S5d). The faster labeling in living cells is presumably attributed to the enriched concentrations of $\mathbf{3}$ and the intracellular proteins when confined within cells. When the CA-II expression of MCF7 cells was knocked down by siRNA, the in-gel fluorescent signal disappeared (Figure 4c). Taken altogether, these results convincingly demonstrated the visible-light-induced specific and rapid labeling of CA-II by diazo-coumarin in living cells.

a)
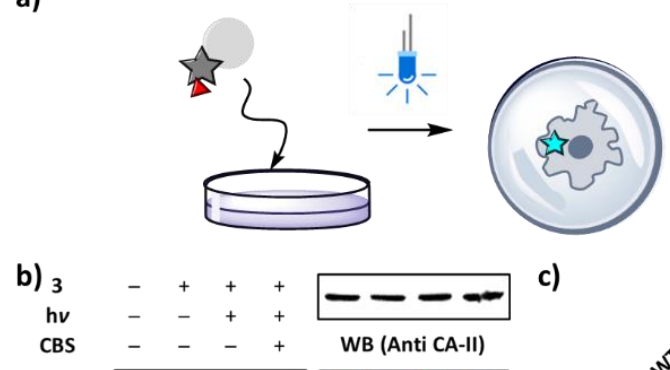

c)
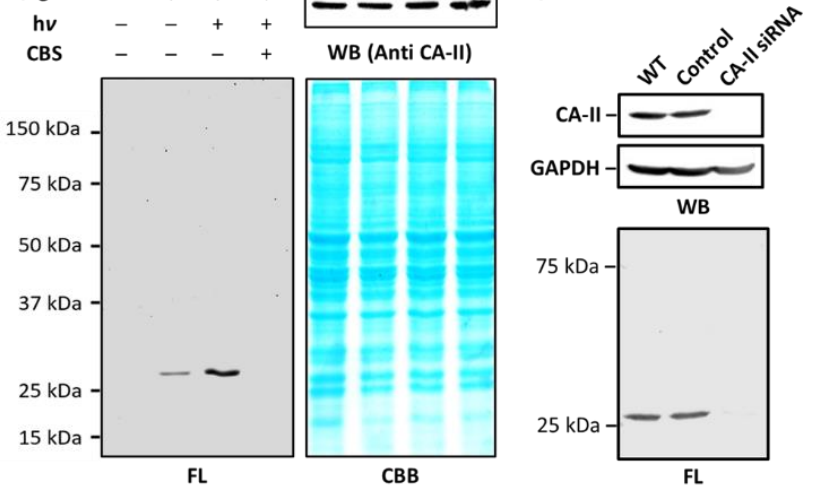

d)

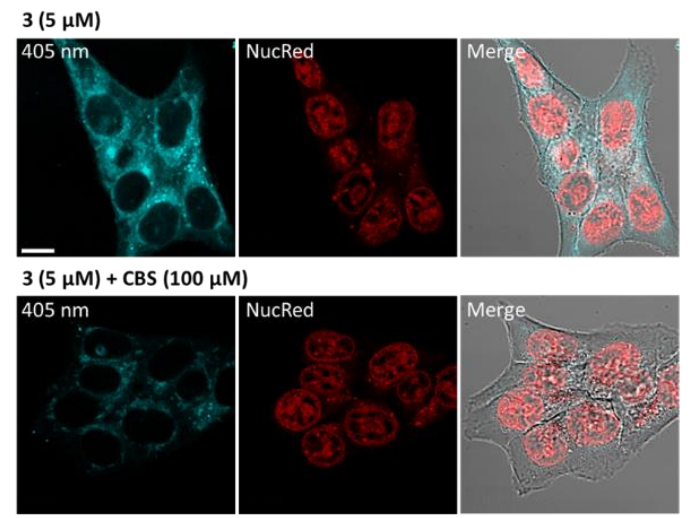

Figure 4. Fluorescence labeling of endogenously CA-II in cells. (a) Schematic illustration of live-cell labeling. (b) SDS-PAGE of MCF7 live-cell labeling by $3(10 \mu \mathrm{M})$ in the presence/absence of CBS $(200 \mu \mathrm{M})$. (c) SDS-PAGE and western blot of MCF7 live-cell labeling by $3(10 \mu \mathrm{M})$ after CA-II knockdown by siRNA. (d) Livecell confocal imaging of HCT116 cells treated with $3(5 \mu \mathrm{M})$, followed by blue LED irradiation. 3: $\lambda_{\mathrm{ex}}=405 \mathrm{~nm}$, NucRed: $\lambda_{\mathrm{ex}}=633$ $\mathrm{nm}$. Scale bar $=10 \mu \mathrm{m}$.

Due to the unique fluorogenic property of the diazo-coumarin probe 3 and biocompatibility of the labeling condition, live-cell imaging of the intracellular CA-II can be performed, which is otherwise difficult to achieve with other methods. After the treatment of 3 with blue LED irradiation, strong fluorescence was observed in the cytosolic region of HCT116 cells (Figure 4d) and MCF7 cells (Figure S6a). In addition, the fluorescent signal was diminished when $\mathbf{C B S}$ was added to compete with $\mathbf{3}$. When a washout step was performed prior to the irradiation, minimal labeling was observed (Figure S6b). The fluorescence signals were clearly excluded from the nucleus that was stained by the red nucleus probe (NucRed), which was consistent with the reported cytosolic distribution of $\mathrm{CA}-\mathrm{II}^{75}$. Immunofluorescence staining showed that the signal from 3 was highly co-localized with that of CA-II antibody (Figure S6c). Moreover, the fact that the fluorescence signal of $\mathbf{3}$ was retained after cell permeabilization is also an evidence that the covalent bonding was established in response to light.

By using fluorescence-activated cell sorting (FACS) analysis, the fluorogenic effect and competition can be quantitatively assessed (Figure 5a). As recent work has demonstrated the assessment of the expression level of the cannabinoid receptors by tandem live-cell photoaffinity labeling and click chemistry on fixed cells $^{76}$, we envisage that such an assessment can be carried out in living cells with our approach. As shown in Figure 5b, the strongest specific labeling for CA-II was obtained in MCF7 cells, followed by HCT116 cells, whereas HeLa cells showed minimal labeling. This result suggests that the expression level of CA-II should follow this order: MCF7 > HCT116 > HeLa, which was validated by Western blot analysis (Figure 5c).

a)

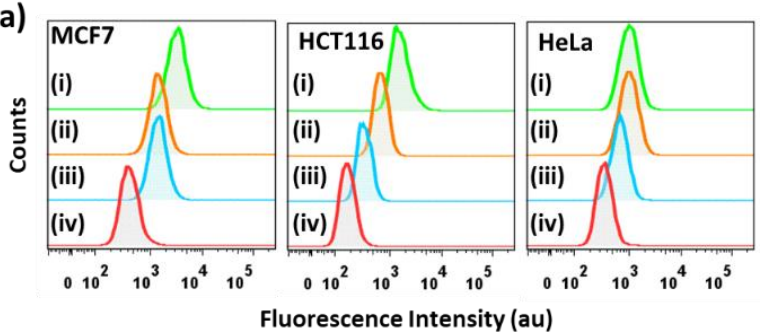

b)

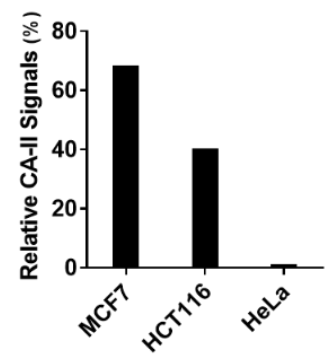

c)

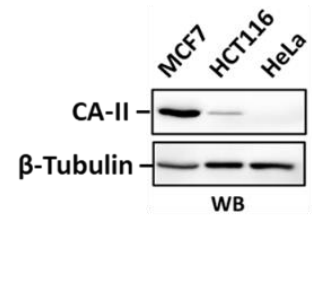

Figure 5. FACS analysis of CA-II expression in different cell types. (a) FACS analysis of cells treated with: (i) $3(5 \mu \mathrm{M})$, blue LED irradiation; (ii) $\mathbf{3}(5 \mu \mathrm{M})$ and $\mathbf{C B S}(100 \mu \mathrm{M})$, blue LED irradiation; (iii) $3(5 \mu \mathrm{M})$, no irradiation; (iv) untreated. (b) Relative CA-II signals obtained from FACS analysis in MCF7, HCT116 and HeLa cells. (c) Western blot of CA-II in three cell lines.

Labeling of CA-IX under Hypoxia-mimetic Condition. CAIX is a membrane-associated isoform of CAs, which is markedly overexpressed in hypoxic tumor cells ${ }^{77}$. As it plays a pivot role in malignant progression, especially in regulating $\mathrm{pH}$ homeostasis under acidic extracellular matrix, CA-IX is thus regarded as a valuable biomarker as well as an attractive target in cancer therapy ${ }^{78}$. The expression of CA-IX is modulated by hypoxia-inducible factor 1 (HIF-1), which under normoxia condition is hydroxylated at proline residues by prolyl hydroxylase domain-containing protein 2 (PHD2) and subsequently ubiquitinated by Von Hippel-Lindau (VHL) E3 ligase for proteasome degradation (Figure 6a) ${ }^{79}$. Since oxygen-sensing of PHD2 relies on its catalytic iron(II) center, iron chelator deferoxamine mesylate (DFO) can inhibit PHD2 to stabilize HIF-1, thus acting as a hypoxia-mimetic agent ${ }^{80}$. In our experiment, HeLa cells, which has no CA-II expression, were cultured under normal or hypoxia-mimetic conditions (treated with DFO). From the western blot result shown in Figure 6b, it can be observed that CA-IX was upregulated as a result of HIF-1 accumulation. After that, these cells were treated with $\mathbf{3}$ and followed by irradiation with blue LED light. The resulting live-cell confocal images 
showed that substantial signals accumulated on the plasma membrane in cells treated with DFO, while untreated cells displayed minimal signal (Figure 6c). The majority of the signals could be displaced by co-treatment of CBS. This evidently indicated that 3 could fluorescently label the membrane-bound CA-IX under hypoxia-mimetic condition. Our results demonstrated that our visible light activated probe could be used for labeling proteins that are dynamically expressed under specific condition, which is otherwise hard to be accomplished with overexpression system of genetically modification approach.

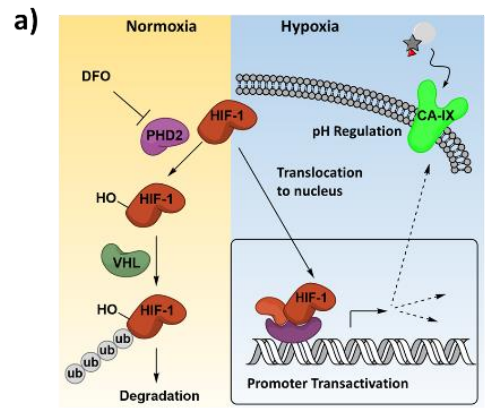

b)

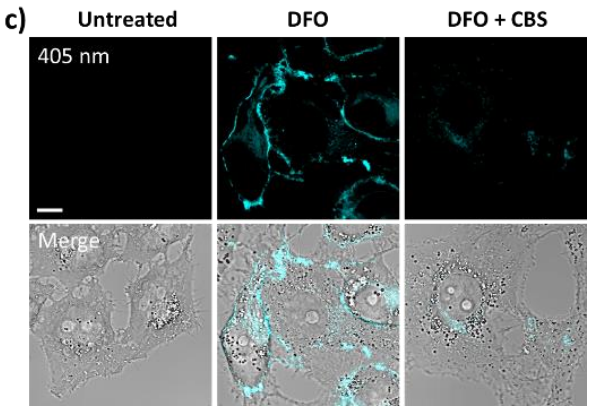

Figure 6. Fluorescence labeling of CA-IX in cells under hypoxiamimetic condition. (a) Schematic illustration of inducible CA-IX expression under hypoxia or treatment by DFO. (b) Western blot of HeLa cells cultured under normal or hypoxia-mimetic (DFO, $100 \mu \mathrm{M}$ for $24 \mathrm{~h}$ ) conditions. (c) Live-cell confocal imaging of HeLa cells cultured under normal or hypoxia-mimetic (DFO, $100 \mu \mathrm{M}$ for $24 \mathrm{~h})$ conditions. Cells were treated with $3(5 \mu \mathrm{M})$ in the presence/absence of CBS $(100 \mu \mathrm{M})$, followed by blue LED irradiation. 3: $\lambda_{\mathrm{ex}}$ $=405 \mathrm{~nm}$. Scale bar $=10 \mu \mathrm{m}$.

In situ Two-photon Labeling and Imaging. Since 7-aminocoumarin has been applied in two-photon uncaging ${ }^{81}$, we wonder if two-photon protein labeling can be performed. In principle, the ability of two-photon activation would potentially lead to reduced photo-toxicity, better spatial control, and deeper tissue penetration $^{82}$. We, therefore, tested the feasibility of two-photon activation of 2 to form carbene with the use of near-infrared (NIR) light to initiate the reaction ${ }^{83-84}$. When 2 was exposed to the femtosecond pulses of an $800 \mathrm{~nm}$ focused laser beam, a similar photo-chemical response to that of blue light irradiation was observed (Figure 7a). Dependence of the fluorescence increase on the focused laser power was recorded, however, no reaction occurred when the laser was unfocused (Figure 7b). These results suggest that 2 can be twophoton activated by NIR light. As a proof-of-concept experiment, in situ two-photon labeling and imaging of CA-II was performed in living cells with 3 (Figure 7c). In this experiment, MCF7 cells were treated with $\mathbf{3}$ and the cell location was first tracked with $\mathrm{Nu}$ cRed under confocal microscopy. Next, only selected cells were irradiated with a laser at $800 \mathrm{~nm}$ of the microscope. Followed by the washing of excess probes, the cells were imaged. As shown in Figure 7c, stronger fluorescence signals were detected in cells exposed to NIR light, indicating that two-photon activated labeling of CA-II can be achieved in live cells.
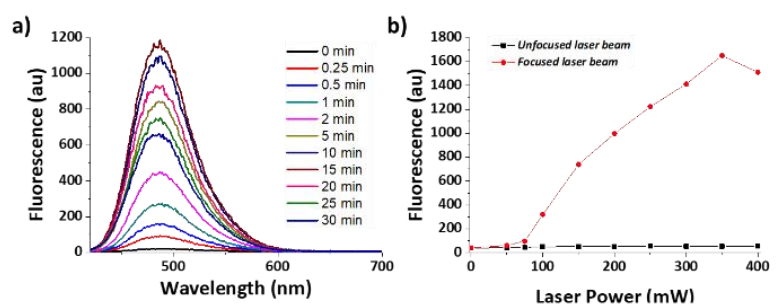

c)

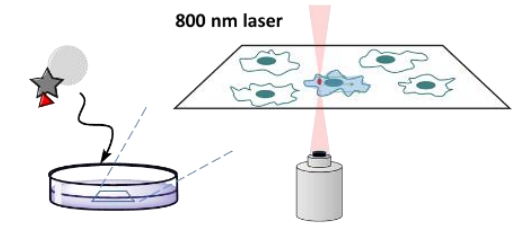

Before $800 \mathrm{~nm}$

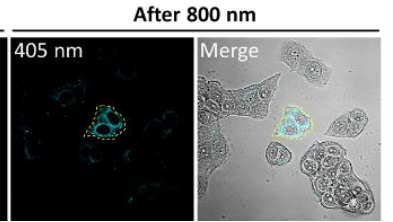

Figure 7. In situ two-photon labeling and imaging of CA-II. (a) Change in emission spectra of $2(30 \mu \mathrm{M})$ upon two-photon photolysis with a mode-locked Ti:sapphire $800 \mathrm{~nm}$ femtosecond pulses focused laser at $200 \mathrm{~mW}$. Emission was measured at $\lambda_{\mathrm{ex}}=400 \mathrm{~nm}$. (b) Fluorescence intensity $\left(\lambda_{\mathrm{ex}}=400 \mathrm{~nm}, \lambda_{\mathrm{ex}}=484 \mathrm{~nm}\right.$ ) measured at $30 \mathrm{~min}$ after irradiation with focused or unfocused laser beam of varying laser power. (c) Schematic illustration of two-photon induced labeling of CA-II with $3(5 \mu \mathrm{M})$ in living cells and confocal imaging of MCF7 cells before and after two-photon activation with $800 \mathrm{~nm}$. Scale bar $=20 \mu \mathrm{m}$.

a)

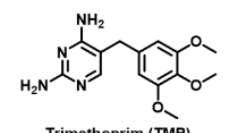

b)
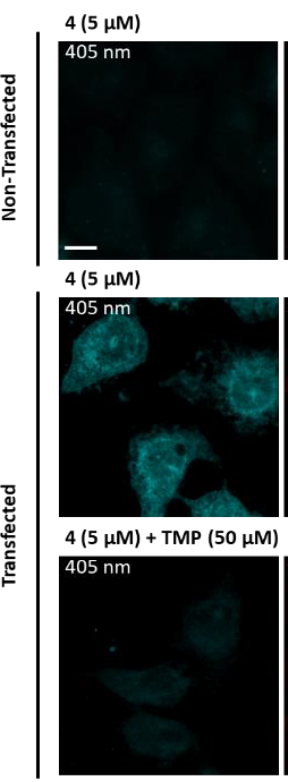
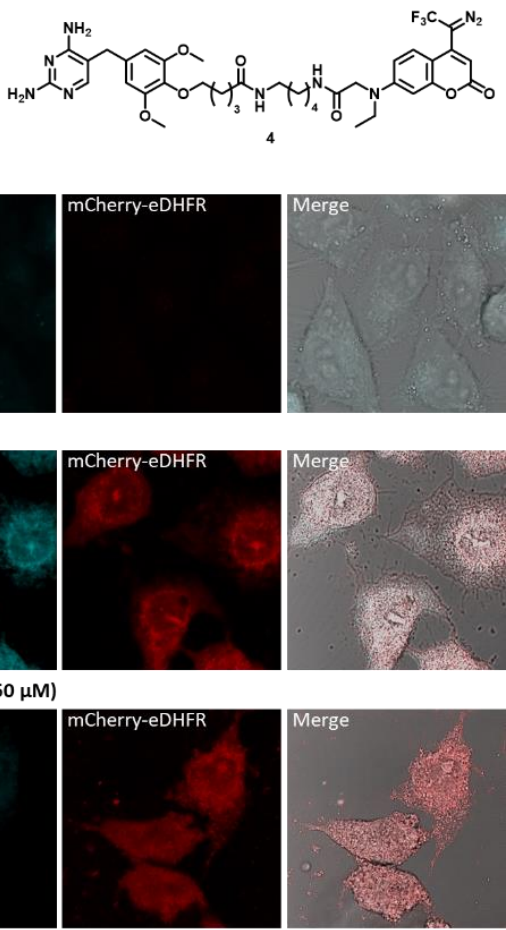
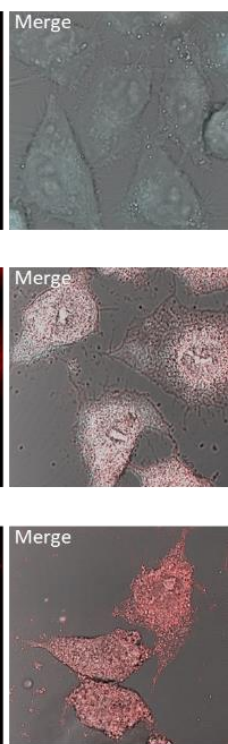

Figure 8. Fluorescence labeling of mCherry-eDHFR in HeLa cells. (a) Chemical Structures of TMP and 4. (b) Live-cell confocal imaging of HeLa cells with or without transient expression of mCherry-eDHFR, treated with $4(5 \mu \mathrm{M})$ and TMP $(50 \mu \mathrm{M})$ after blue LED irradiation. 4: $\lambda_{\mathrm{ex}}=405 \mathrm{~nm}$, mCherry: $\lambda_{\mathrm{ex}}=561 \mathrm{~nm}$. Scale bar $=10 \mu \mathrm{m}$.

Labeling of eDHFR in Living Cells. To demonstrate that our labeling strategy can be applied to other target proteins, $\mathbf{4}$ was synthesized by incorporating trimethoprim (TMP, $K_{\mathrm{d}} \sim 10 \mathrm{nM}$ ) as a 
ligand moiety (Figure 8a) ${ }^{85}$, which can selectively bind E. coli dihydrofolate reductase (eDHFR). HeLa cells were transfected plasmid DNA to overexpress eDHFR fused with a red fluorescent protein (mCherry-eDHFR). The transfection of this fusion protein helps to confirm the co-localization with diazo-coumarin in living cells under confocal microscopy. When the cells were treated with $4(5 \mu \mathrm{M})$ and irradiated with blue light, co-localization of the probe signal and mCherry was observed in live-cell imaging (Figure $8 b$ ). While the cells without transfection did not show any staining, the addition of TMP also predictably perturbed the labeling in transfected cells.

\section{CONCLUSION}

In the investigation described above, we have demonstrated that diazo-coumarin can be activated by visible light to "photo-uncage" reactive carbene intermediate, which can subsequently undergo insertion reaction with biomolecules. Through detailed chemical analysis, the structure of diazo-coumarin was optimized by the introduction of a trifluoromethyl group to improve the carbene insertion propensity. Moreover, we showed that efficient visible light photo-activation and fluorogenic property of diazo-coumarin can be exploited as a biorthogonal tool in endogenous protein labeling. As a result, proteins-of-interest can be covalently modified after mild blue LED irradiation, with instant fluorescence report bypassing the need to perform "click" chemistry. We demonstrated the applications of diazo-coumarin in affinity labeling of endogenous proteins in living cells using CA-II as a model protein. Remarkable labeling speed and specificity of endogenous CA-II has been achieved, which enables reliable visualization of localization by live-cell imaging and quantitative assessment of expression level among different cell types by flow cytometry. Live-cell imaging also allowed monitoring of protein dynamics as proved by hypoxia induced CA-IX accumulation. Furthermore, diazo-coumarin can be photo-activated by two-photon excitation, which allows spatiotemporally controlled protein labeling in living cells with the least phototoxic NIR light. As a further illustration, this strategy can also be successfully applied to the labeling of eDHFR. We believe that this photo-chemical approach should expand the chemical repertoire of the covalent labeling of biomolecules in living cells to facilitate biological discoveries.

\section{ASSOCIATED CONTENT}

\section{Supporting Information}

Supporting figures, tables, experimental procedures, synthesis, characterization of compounds, LC/MS/MS spectra and NMR spectra.

\section{AUTHOR INFORMATION}

\section{Corresponding Author}

Dan Yang - Morningside Laboratory for Chemical Biology, Department of Chemistry, The University of Hong Kong, Pokfulam Road, Hong Kong, China; Email: yangdan@ @ku.hk

\section{Authors}

Sheng-Yao Dai - Morningside Laboratory for Chemical Biology, Department of Chemistry, The University of Hong Kong, Pokfulam Road, Hong Kong, China

\section{ACKNOWLEDGMENT}

We thank Dr. Ming-De Li (Shantou University) and Prof. David Philip (The University of Hong Kong) for help in the two-photon photolysis experiment setup. We thank Dr. Fang-Fang Shen and Dr. Xiang David Li (The University of Hong Kong) as well as Dr.
Nai-Kei Wong (The Second Hospital Affiliated to Southern University of Science and Technology) for helpful advice on experiments and critical reading of the manuscript. We thank The University of Hong Kong Li Ka Shing Faculty of Medicine Faculty Core Facility for support in confocal microscopy and flow cytometry. We thank Dr. Ruijun Tian (Southern University of Science and Technology) for assistance in LC/MS/MS experiment. This work was supported by The University of Hong Kong, the University Development Fund, the Morningside Foundation, and the Hong Kong Research Grants Council under the Area of Excellence Scheme (AoE/P-705/16).

\section{REFERENCES}

1. Hoyt, E. A.; Cal, P. M. S. D.; Oliveira, B. L.; Bernardes, G. J. L., Contemporary approaches to site-selective protein modification. Nat. Rev. Chem. 2019, 3, 147-171.

2. Krall, N.; da Cruz, F. P.; Boutureira, O.; Bernardes, G. J. L., Siteselective protein-modification chemistry for basic biology and drug development. Nat. Chem. 2015, 8, 103-113.

3. Boutureira, O.; Bernardes, G. J., Advances in chemical protein modification. Chem. Rev. 2015, 115, 2174-95.

4. Tamura, T.; Hamachi, I., Chemistry for Covalent Modification of Endogenous/Native Proteins: From Test Tubes to Complex Biological Systems. J. Am. Chem. Soc. 2019, 141, 2782-2799.

5. Amaike, K.; Tamura, T.; Hamachi, I., Recognition-driven chemical labeling of endogenous proteins in multi-molecular crowding in live cells. Chem. Commun. 2017, 53, 11972-11983.

6. Kubota, R.; Hamachi, I., Protein recognition using synthetic small-molecular binders toward optical protein sensing in vitro and in live cells. Chem. Soc. Rev. 2015, 44, 4454-71.

7. Zhang, G.; Zheng, S.; Liu, H.; Chen, P. R., Illuminating biological processes through site-specific protein labeling. Chem. Soc. Rev. 2015, 44, 3405-17.

8. Wang, Z.; Ding, X.; Li, S.; Shi, J.; Li, Y., Engineered fluorescence tags for in vivo protein labelling. $R S C A d v$. 2014, 4, 7235-7245.

9. Juillerat, A.; Gronemeyer, T.; Keppler, A.; Gendreizig, S.; Pick, H.; Vogel, H.; Johnsson, K., Directed Evolution of O6Alkylguanine-DNA Alkyltransferase for Efficient Labeling of Fusion Proteins with Small Molecules In Vivo. Chem. Biol. 2003, 10, 313-317.

10. Gautier, A.; Juillerat, A.; Heinis, C.; Corrêa, I. R.; Kindermann, M.; Beaufils, F.; Johnsson, K., An Engineered Protein Tag for Multiprotein Labeling in Living Cells. Chem. Biol. 2008, 15, 128136.

11. Los, G. V.; Encell, L. P.; McDougall, M. G.; Hartzell, D. D.; Karassina, N.; Zimprich, C.; Wood, M. G.; Learish, R.; Ohana, R. F.; Urh, M.; Simpson, D.; Mendez, J.; Zimmerman, K.; Otto, P.; Vidugiris, G.; Zhu, J.; Darzins, A.; Klaubert, D. H.; Bulleit, R. F.; Wood, K. V., HaloTag: A Novel Protein Labeling Technology for Cell Imaging and Protein Analysis. ACS Chem. Biol. 2008, 3, 373382.

12. Lang, K.; Chin, J. W., Cellular incorporation of unnatural amino acids and bioorthogonal labeling of proteins. Chem. Rev. 2014, 114, 4764-806.

13. Lin, X.; Yu, A. C.; Chan, T. F., Efforts and Challenges in Engineering the Genetic Code. Life (Basel) 2017, 7.

14. Tamura, T.; Ueda, T.; Goto, T.; Tsukidate, T.; Shapira, Y.; Nishikawa, Y.; Fujisawa, A.; Hamachi, I., Rapid labelling and covalent inhibition of intracellular native proteins using liganddirected N-acyl-N-alkyl sulfonamide. Nat. Commun. 2018, 9, 1870 .

15. Matsuo, K.; Nishikawa, Y.; Masuda, M.; Hamachi, I., Live-Cell Protein Sulfonylation Based on Proximity-driven N-Sulfonyl Pyridone Chemistry. Angew. Chem. Int. Ed. 2018, 57, 659-662.

16. Yamaguchi, T.; Asanuma, M.; Nakanishi, S.; Saito, Y.; Okazaki, M.; Dodo, K.; Sodeoka, M., Turn-ON fluorescent affinity 
labeling using a small bifunctional O-nitrobenzoxadiazole unit. Chem. Sci. 2014, 5, 1021-1029.

17. Fujishima, S. H.; Yasui, R.; Miki, T.; Ojida, A.; Hamachi, I., Ligand-directed acyl imidazole chemistry for labeling of membrane-bound proteins on live cells. J. Am. Chem. Soc. 2012, 134, 3961-4.

18. Tsukiji, S.; Miyagawa, M.; Takaoka, Y.; Tamura, T.; Hamachi, I., Ligand-directed tosyl chemistry for protein labeling in vivo. Nat. Chem. Biol. 2009, 5, 341-3.

19. Hughes, C. C.; Yang, Y.-L.; Liu, W.-T.; Dorrestein, P. C.; Clair, J. J. L.; Fenical, W., Marinopyrrole A Target Elucidation by Acyl Dye Transfer. J. Am. Chem. Soc. 2009, 131, 12094-12096.

20. Mix, K. A.; Aronoff, M. R.; Raines, R. T., Diazo Compounds: Versatile Tools for Chemical Biology. ACS Chem. Biol. 2016, 11, 3233-3244.

21. Ohata, J.; Ball, Z. T., A Hexa-rhodium Metallopeptide Catalyst for Site-Specific Functionalization of Natural Antibodies. J. Am. Chem. Soc. 2017, 139, 12617-12622.

22. Martin, S. C.; Vohidov, F.; Wang, H.; Knudsen, S. E.; Marzec, A. A.; Ball, Z. T., Designing Selectivity in Dirhodium Metallopeptide Catalysts for Protein Modification. Bioconjug. Chem. 2017, 28, 659-665.

23. Vohidov, F.; Coughlin, J. M.; Ball, Z. T., Rhodium(II) metallopeptide catalyst design enables fine control in selective functionalization of natural SH3 domains. Angew. Chem. Int. Ed. 2015, 54, 4587-91.

24. Minus, M. B.; Liu, W.; Vohidov, F.; Kasembeli, M. M.; Long, X.; Krueger, M. J.; Stevens, A.; Kolosov, M. I.; Tweardy, D. J.; Sison, E. A. R.; Redell, M. S.; Ball, Z. T., Rhodium(II) ProximityLabeling Identifies a Novel Target Site on STAT3 for Inhibitors with Potent Anti-Leukemia Activity. Angew. Chem. Int. Ed. 2015, 54, 13085-13089.

25. Kundu, R.; Ball, Z. T., Rhodium-catalyzed cysteine modification with diazo reagents. Chem. Commun. 2013, 49, 41668.

26. Chen, Z.; Vohidov, F.; Coughlin, J. M.; Stagg, L. J.; Arold, S. T.; Ladbury, J. E.; Ball, Z. T., Catalytic protein modification with dirhodium metallopeptides: specificity in designed and natural systems. J. Am. Chem. Soc. 2012, 134, 10138-45.

27. Popp, B. V.; Ball, Z. T., Proximity-driven metallopeptide catalysis: Remarkable side-chain scope enables modification of the Fos bZip domain. Chem. Sci. 2011, 2, 690-695.

28. Chen, Z.; Popp, B. V.; Bovet, C. L.; Ball, Z. T., Site-specific protein modification with a dirhodium metallopeptide catalyst. ACS Chem. Biol. 2011, 6, 920-5.

29. Popp, B. V.; Ball, Z. T., Structure-Selective Modification of Aromatic Side Chains with Dirhodium Metallopeptide Catalysts. $J$. Am. Chem. Soc. 2010, 132, 6660-6662.

30. Ho, C.-M.; Zhang, J.-L.; Zhou, C.-Y.; Chan, O.-Y.; Yan, J. J.; Zhang, F.-Y.; Huang, J.-S.; Che, C.-M., A Water-Soluble Ruthenium Glycosylated Porphyrin Catalyst for Carbenoid Transfer Reactions in Aqueous Media with Applications in Bioconjugation Reactions. J. Am. Chem. Soc. 2010, 132, 18861894.

31. Ge, S.-S.; Chen, B.; Wu, Y.-Y.; Long, Q.-S.; Zhao, Y.-L.; Wang, P.-Y.; Yang, S., Current advances of carbene-mediated photoaffinity labeling in medicinal chemistry. RSC Advances $\mathbf{2 0 1 8}$, 8, 29428-29454.

32. Ridley, A. J.; Whiteside, J. R.; McMillan, T. J.; Allinson, S. L., Cellular and sub-cellular responses to UVA in relation to carcinogenesis. Int. J. Radiat Biol. 2009, 85, 177-95.

33. McMillan, T. J.; Leatherman, E.; Ridley, A.; Shorrocks, J.; Tobi, S. E.; Whiteside, J. R., Cellular effects of long wavelength UV light (UVA) in mammalian cells. J. Pharm. Pharmacol. 2008, 60, 969-76.

34. Barlev, A.; Sen, D., DNA's Encounter with Ultraviolet Light: An Instinct for Self-Preservation? Acc. Chem. Res. 2018, 51, 526533.
35. Bai, X.; Huang, Y.; Lu, M.; Yang, D., HKOH-1: A Highly Sensitive and Selective Fluorescent Probe for Detecting Endogenous Hydroxyl Radicals in Living Cells. Angew. Chem. Int. Ed. 2017, 56, 12873-12877.

36. Chowdhry, V.; Vaughan, R.; Westheimer, F. H., 2-diazo-3,3,3trifluoropropionyl chloride: reagent for photoaffinity labeling. Proc. Natl. Acad. Sci. U.S.A 1976, 73, 1406-1408.

37. Singh, A.; Thornton, E. R.; Westheimer, F. H., The Photolysis of Diazoacetylchymotrypsin. J. Biol. Chem. 1962, 237, 3006-3008. 38. Tomohiro, T.; Morimoto, S.; Shima, T.; Chiba, J.; Hatanaka, Y., An Isotope-Coded Fluorogenic Cross-Linker for HighPerformance Target Identification Based on Photoaffinity Labeling. Angew. Chem. Int. Ed. 2014, 53, 13502-5.

39. Tomohiro, T.; Yamamoto, A.; Tatsumi, Y.; Hatanaka, Y., [3(Trifluoromethyl)-3H-diazirin-3-yl]coumarin as a carbenegenerating photocross-linker with masked fluorogenic beacon. Chem. Commun. 2013, 49, 11551-3.

40. Murale, D. P.; Hong, S. C.; Yun, J.; Yoon, C. N.; Lee, J. S., Rational design of a photo-crosslinking BODIPY for in situ protein labeling. Chem. Commun. 2015, 51, 6643-6.

41. Wang, Y.; Hu, L.; Xu, F.; Quan, Q.; Lai, Y.-T.; Xia, W.; Yang, Y.; Chang, Y.-Y.; Yang, X.; Chai, Z.; Wang, J.; Chu, I. K.; Li, H.; Sun, H., Integrative approach for the analysis of the proteome-wide response to bismuth drugs in Helicobacter pylori. Chem. Sci. 2017, $8,4626-4633$.

42. Chao, A.; Jiang, N.; Yang, Y.; Li, H.; Sun, H., A Ni-NTA-based red fluorescence probe for protein labelling in live cells. J. Mater. Chem. B 2017, 5, 1166-1173.

43. Lai, Y. T.; Chang, Y. Y.; Hu, L.; Yang, Y.; Chao, A.; Du, Z. Y.; Tanner, J. A.; Chye, M. L.; Qian, C.; Ng, K. M.; Li, H.; Sun, H., Rapid labeling of intracellular His-tagged proteins in living cells. Proc Natl Acad Sci U S A 2015, 112, 2948-53.

44. Chiba, K.; Asanuma, M.; Ishikawa, M.; Hashimoto, Y.; Dodo, K.; Sodeoka, M.; Yamaguchi, T., Specific fluorescence labeling of target proteins by using a ligand-4-azidophthalimide conjugate. Chem. Commun. 2017, 53, 8751-8754.

45. Tian, Y.; Lin, Q., Genetic encoding of 2-aryl-5carboxytetrazole-based protein photo-cross-linkers. Chem. Commun. 2018, 54, 4449-4452.

46. Tian, Y.; Jacinto, M. P.; Zeng, Y.; Yu, Z.; Qu, J.; Liu, W. R.; Lin, Q., Genetically Encoded 2-Aryl-5-carboxytetrazoles for SiteSelective Protein Photo-Cross-Linking. J. Am. Chem. Soc. 2017, 139, 6078-6081.

47. Cheng, K.; Lee, J. S.; Hao, P.; Yao, S. Q.; Ding, K.; Li, Z., Tetrazole-Based Probes for Integrated Phenotypic Screening, Affinity-Based Proteome Profiling, and Sensitive Detection of a Cancer Biomarker. Angew. Chem. Int. Ed. 2017, 56, 15044-15048. 48. Zhao, S.; Dai, J.; Hu, M.; Liu, C.; Meng, R.; Liu, X.; Wang, C.; Luo, T., Photo-induced coupling reactions of tetrazoles with carboxylic acids in aqueous solution: application in protein labelling. Chem. Commun. 2016, 52, 4702-5.

49. Li, Z.; Qian, L.; Li, L.; Bernhammer, J. C.; Huynh, H. V.; Lee, J. S.; Yao, S. Q., Tetrazole Photoclick Chemistry: Reinvestigating Its Suitability as a Bioorthogonal Reaction and Potential Applications. Angew. Chem. Int. Ed. 2016, 55, 2002-6.

50. Herner, A.; Marjanovic, J.; Lewandowski, T.; Marin, V. L.; Patterson, M. J.; Miesbauer, L.; Ready, D.; Williams, J.; Vasudevan, A.; Lin, Q., 2-Aryl-5-carboxytetrazole as a New Photoaffinity Label for Drug Target Identification. J. Am. Chem. Soc. 2016, 138, 14609-14615.

51. Ota, E.; Usui, K.; Oonuma, K.; Koshino, H.; Nishiyama, S.; Hirai, G.; Sodeoka, M., Thienyl-Substituted alpha-Ketoamide: A Less Hydrophobic Reactive Group for Photo-Affinity Labeling. ACS Chem. Biol. 2018, 13, 876-880.

52. Ankenbruck, N.; Courtney, T.; Naro, Y.; Deiters, A., Optochemical Control of Biological Processes in Cells and Animals. Angew. Chem. Int. Ed. 2018, 57, 2768-2798. 
53. Sato, S.; Morita, K.; Nakamura, H., Regulation of target protein knockdown and labeling using ligand-directed $\mathrm{Ru}(\mathrm{bpy}) 3$ photocatalyst. Bioconjug Chem 2015, 26, 250-6.

54. Sato, S.; Nakamura, H., Ligand-directed selective protein modification based on local single-electron-transfer catalysis. Angew. Chem. Int. Ed. 2013, 52, 8681-4.

55. Geri, J. B.; Oakley, J. V.; Reyes-Robles, T.; Wang, T.; McCarver, S. J.; White, C. H.; Rodriguez-Rivera, F. P.; Parker, D. L.; Hett, E. C.; Fadeyi, O. O.; Oslund, R. C.; MacMillan, D. W. C., Microenvironment mapping via Dexter energy transfer on immune cells. Science 2020, 367, 1091.

56. Ito, K.; Sawanobori, J., 4-Diazomethyl-7-Methoxycoumarin as a New Type of Stable Aryldiazomethane Reagent. Synth. Commun. 1982, 12, 665-671.

57. Takadate, A.; Tamura, T.; Fujino, H.; Goya, S., Synthesis and Properties of 4-Diazomethyl-7-methoxycoumarin as a New Fluorescent Labeling Reagent for Alchohols and Carboxyacids. Chem. Pharm. Bull. 1982, 30, 4120-4125.

58. Ito, K.; Maruyama, J., Studies on Stable Diazoalkanes as Potential Fluorogenic Reagents. I. 7-Substituted 4Diazomethylcoumarins. Chem. Pharm. Bull. 1983, 31, 3012-3014. 59. Ito, K.; Maruyama, J., Studies on Stable Diazoalkanes as Potential Fluorogenic Reagents. II. : Ring-Fused 4Diazomethylcoumarins. Chem. Pharm. Bull. 1986, 34, 390-395.

60. Ando, H.; Furuta, T.; Tsien, R. Y.; Okamoto, H., Photomediated gene activation using caged RNA/DNA in zebrafish embryos. Nat. Genet. 2001, 28, 317-25.

61. Sivakumar, K.; Xie, F.; Cash, B. M.; Long, S.; Barnhill, H. N.; Wang, Q., A Fluorogenic 1,3-Dipolar Cycloaddition Reaction of 3Azidocoumarins and Acetylenes. Org. Lett. 2004, 6, 4603-4606.

62. Bethell, D.; Stevens, G.; Tickle, P., The reaction of diphenylmethylene with isopropyl alcohol and oxygen: the question of reversibility of singlet-triplet interconversion of carbenes. J. Chem. Soc. D 1970, 792 b-794.

63. Dean, F. M.; Park, B. K., Activating groups for the ring expansion of coumarin by diazoethane: benzoyl, pivaloyl, arylsulphonyl, arylsulphinyl, and nitro. J. Chem. Soc., Perkin Trans. 1 1976, 1260-1268.

64. McMahon, R. J.; Abelt, C. J.; Chapman, O. L.; Johnson, J. W.; Kreil, C. L.; LeRoux, J. P.; Mooring, A. M.; West, P. R., 1,2,4,6Cycloheptatetraene: the key intermediate in arylcarbene interconversions and related C7H6 rearrangements. J. Am. Chem. Soc. 1987, 109, 2456-2469.

65. Dubinsky, L.; Krom, B. P.; Meijler, M. M., Diazirine based photoaffinity labeling. Bioorg. Med. Chem. 2012, 20, 554-70.

66. Ito, K.; Maruyama, J., A Facile Intramolecular Cyclization of 4-Diazomethylcoumarins. A Convenient Route to Benzopyrano[3,4-c]pyrazol-4(3H)-ones. Heterocycles 1984, 22, 1057-1059.

67. Preston, G. W.; Wilson, A. J., Photo-induced covalent crosslinking for the analysis of biomolecular interactions. Chem. Soc. Rev. 2013, 42, 3289-3301.

68. Takagaki, Y.; Gupta, C. M.; Khorana, H. G., Thiols and the diazo group in photoaffinity labels. Biochem. Biophys. Res. Commun. 1980, 95, 589-595.

69. McGrath, N. A.; Andersen, K. A.; Davis, A. K.; Lomax, J. E.; Raines, R. T., Diazo compounds for the bioreversible esterification of proteins. Chem. Sci. 2015, 6, 752-755.

70. Teruya, K.; Tonissen, K. F.; Poulsen, S.-A., Recent developments of small molecule chemical probes for fluorescencebased detection of human carbonic anhydrase II and IX. Med. Chem. Commun. 2016, 7, 2045-2062.

71. Supuran, C. T., How many carbonic anhydrase inhibition mechanisms exist? J. Enzyme Inhib. Med. Chem. 2016, 31, 345-60. 72. Li, G.; Liu, Y.; Liu, Y.; Chen, L.; Wu, S.; Liu, Y.; Li, X., Photoaffinity labeling of small-molecule-binding proteins by DNA-templated chemistry. Angew. Chem. Int. Ed. 2013, 52, 95449.
73. Mallory, J. C.; Crudden, G.; Oliva, A.; Saunders, C.; Stromberg, A.; Craven, R. J., A novel group of genes regulates susceptibility to antineoplastic drugs in highly tumorigenic breast cancer cells. Mol. Pharmacol. 2005, 68, 1747-56.

74. Hulikova, A.; Aveyard, N.; Harris, A. L.; Vaughan-Jones, R. D.; Swietach, P., Intracellular carbonic anhydrase activity sensitizes cancer cell $\mathrm{pH}$ signaling to dynamic changes in $\mathrm{CO} 2$ partial pressure. J. Biol. Chem. 2014, 289, 25418-30.

75. Supuran, C. T., Carbonic Anhydrases - An Overview. Curr. Pharm. Des. 2008, 14, 603-614.

76. Soethoudt, M.; Stolze, S. C.; Westphal, M. V.; van Stralen, L.; Martella, A.; van Rooden, E. J.; Guba, W.; Varga, Z. V.; Deng, H.; van Kasteren, S. I.; Grether, U.; AP, I. J.; Pacher, P.; Carreira, E. M.; Overkleeft, H. S.; Ioan-Facsinay, A.; Heitman, L. H.; van der Stelt, M., Selective Photoaffinity Probe That Enables Assessment of Cannabinoid CB2 Receptor Expression and Ligand Engagement in Human Cells. J. Am. Chem. Soc. 2018, 140, 6067-6075.

77. Yang, J.-S.; Lin, C.-W.; Chuang, C.-Y.; Su, S.-C.; Lin, S.-H.; Yang, S.-F., Carbonic anhydrase IX overexpression regulates the migration and progression in oral squamous cell carcinoma. Tumor Biol. 2015, 36, 9517-9524.

78. Tafreshi, N. K.; Lloyd, M. C.; Bui, M. M.; Gillies, R. J.; Morse, D. L., Carbonic Anhydrase IX as an Imaging and Therapeutic Target for Tumors and Metastases. In Carbonic Anhydrase: Mechanism, Regulation, Links to Disease, and Industrial Applications, Frost, S. C.; McKenna, R., Eds. Springer Netherlands: Dordrecht, 2014; pp 221-254.

79. Benej, M.; Pastorekova, S.; Pastorek, J., Carbonic Anhydrase IX: Regulation and Role in Cancer. In Carbonic Anhydrase: Mechanism, Regulation, Links to Disease, and Industrial Applications, Frost, S. C.; McKenna, R., Eds. Springer Netherlands: Dordrecht, 2014; pp 199-219.

80. An, W. G.; Kanekal, M.; Simon, M. C.; Maltepe, E.; Blagosklonny, M. V.; Neckers, L. M., Stabilization of wild-type p53 by hypoxia-inducible factor 1 a . Nature 1998, 392, 405-408.

81. Geißler, D.; Antonenko, Y. N.; Schmidt, R.; Keller, S.; Krylova, O. O.; Wiesner, B.; Bendig, J.; Pohl, P.; Hagen, V., (Coumarin - 4 - yl)methyl Esters as Highly Efficient, Ultrafast Phototriggers for Protons and Their Application to Acidifying Membrane Surfaces. Angew. Chem. Int. Ed. 2005, 44, 1195-1198. 82. Bort, G.; Gallavardin, T.; Ogden, D.; Dalko, P. I., From onephoton to two-photon probes: "caged" compounds, actuators, and photoswitches. Angew. Chem. Int. Ed. 2013, 52, 4526-37.

83. Dyer, J.; Jockusch, S.; Balsanek, V.; Sames, D.; Turro, N. J., Two-Photon Induced Uncaging of a Reactive Intermediate. Multiphoton In Situ Detection of a Potentially Valuable Label for Biological Applications. J. Org. Chem. 2005, 70, 2143-2147.

84. Urdabayev, N. K.; Popik, V. V., Wolff Rearrangement of 2Diazo-1(2H)-Naphthalenone Induced by Nonresonant Two-Photon Absorption of NIR Radiation. J. Am. Chem. Soc. 2004, 126, 40584059 .

85. Miller, L. W.; Cai, Y.; Sheetz, M. P.; Cornish, V. W., In vivo protein labeling with trimethoprim conjugates: a flexible chemical tag. Nat. Methods 2005, 2, 255-257. 


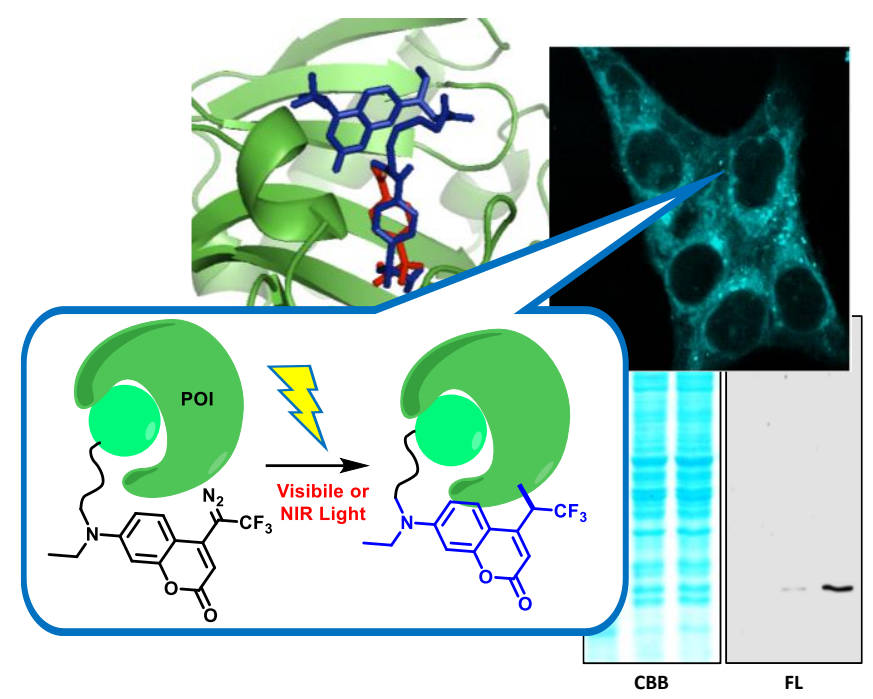


Supporting information for

\title{
A Visible and Near-Infrared Light Photoactivatable Diazo-Coumarin Probe for Fluorogenic Protein Labeling in Living Cells
}

\author{
Sheng-Yao Dai, Dan Yang* \\ Morningside Laboratory for Chemical Biology, Department of Chemistry, The University of Hong Kong, Pokfulam Road, \\ Hong Kong, P. R. China.
}

\section{Table of content}

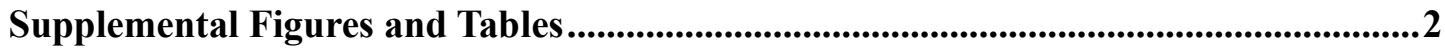

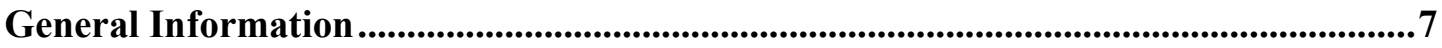

Experimental Procedures ...................................................................................................9

Chemical synthesis .....................................................................................................................................16

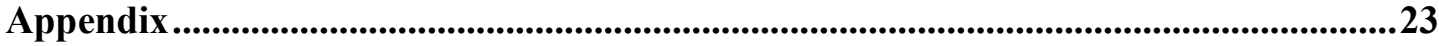

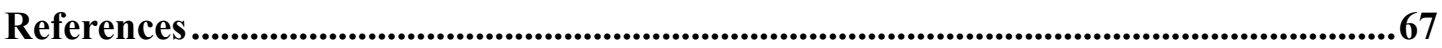




\section{Supplemental Figures and Tables}
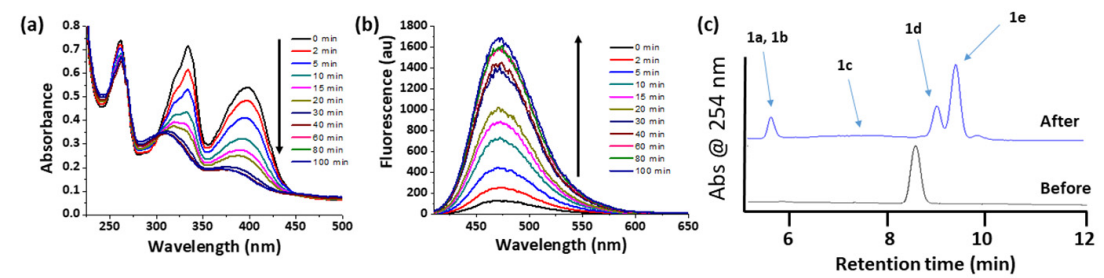

(d)

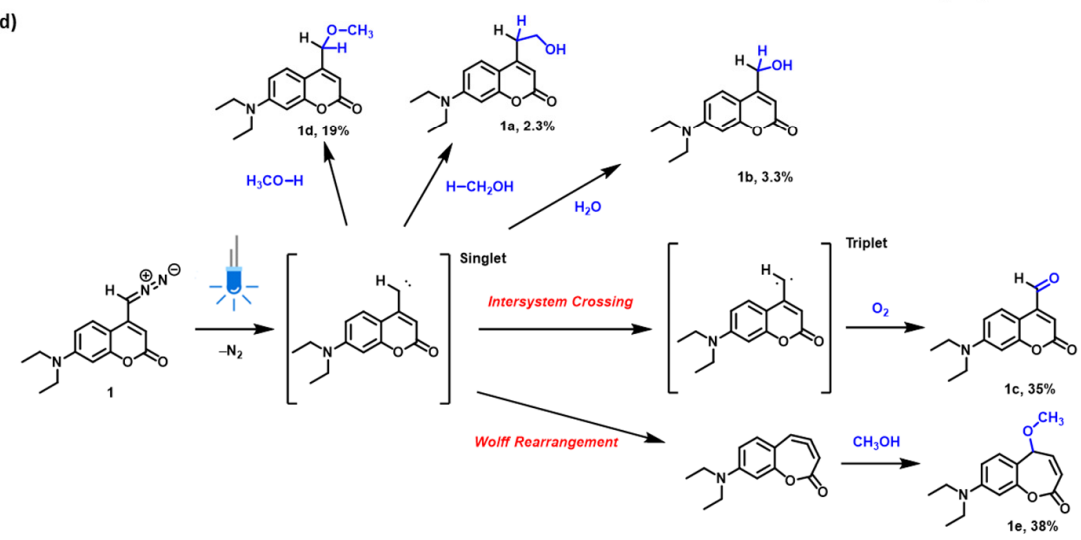

Figure S1. (a)-(b) Change in absorption and emission spectra of $1(30 \mu \mathrm{M})$ in methanol upon irradiation with a blue LED lamp. $\lambda_{\mathrm{ex}}=400 \mathrm{~nm}$. (c) HPLC analysis of 1 before and after photolysis. (d) Proposed mechanism of formation of each product and isolated yields from photolysis of $\mathbf{1}$.

(a)
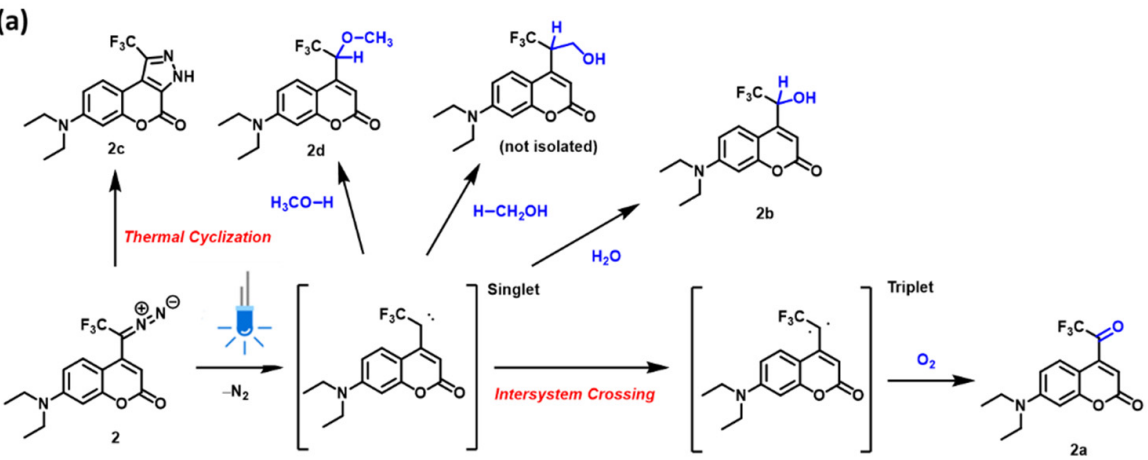

(b)

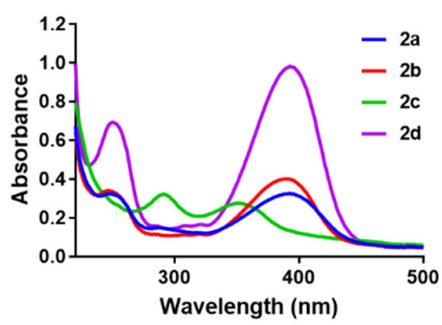

(c)

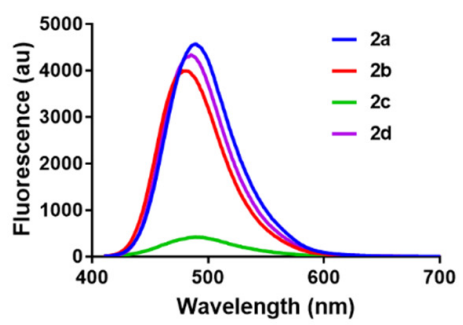

Figure S2. (a) Proposed mechanism of formation of each product from photolysis of 2. (b)-(c) Absorption and emission spectra of $2 \mathbf{a}-\mathbf{d}(30 \mu \mathrm{M})$ in methanol. $\lambda_{\mathrm{ex}}=400 \mathrm{~nm}$. 
Table S1. Summary of photophysical properties of $\mathbf{2}$ and $\mathbf{2 a - d . ~}$

\begin{tabular}{cccccc}
\hline Compound & Solvent & $\lambda_{\max }(\mathrm{nm})^{a}$ & $\varepsilon\left(10^{4} \mathrm{M}^{-1} \mathrm{~cm}^{-1}\right)^{b}$ & $\lambda_{\mathrm{em}}(\mathrm{nm})^{c}$ & $\Phi_{\mathrm{fl}}{ }^{d}$ \\
\hline $\mathbf{2}$ & $\mathrm{CH}_{3} \mathrm{OH}$ & 408 & 2.26 & 490 & 0.003 \\
$\mathbf{2 a}$ & $\mathrm{CH}_{3} \mathrm{OH}$ & 392 & 1.17 & 489 & 0.23 \\
$\mathbf{2 b}$ & $\mathrm{CH}_{3} \mathrm{OH}$ & 392 & 1.34 & 481 & 0.20 \\
$\mathbf{2 c}$ & $\mathrm{CH}_{3} \mathrm{OH}$ & 351 & 0.92 & 489 & 0.02 \\
$\mathbf{2 d}$ & $\mathrm{CH}_{3} \mathrm{OH}$ & 393 & 3.12 & 485 & 0.22 \\
$\mathbf{2}$ & $\mathrm{H}_{2} \mathrm{O}$ & 414 & 1.93 & 500 & 0.0002 \\
$\mathbf{2 d}$ & $\mathrm{H}_{2} \mathrm{O}$ & 402 & 2.89 & 500 & 0.015 \\
\hline
\end{tabular}

All the measurements were obtained at $25{ }^{\circ} \mathrm{C}$ with $10 \mu \mathrm{M}$ of compounds. ${ }^{a}$ Wavelength of the longest absorption maxima. ${ }^{b}$ Molar extinction coefficient, calculated from the equation $\mathrm{A}=$ $\varepsilon l c$, where $\mathrm{A}$ is the absorbance, $c$ is the concentration of the compound, and $l$ is the path length ( $1 \mathrm{~cm}$ of the cuvette). ${ }^{c}$ Wavelength of the emission maxima. ${ }^{d}$ Fluorescence quantum yield, measured by using 7-diethylamino-4-methylcoumarin as reference $\left(\Phi_{\mathrm{fl}}=0.73\right.$ in EtOH$)$. 


\begin{tabular}{|c|c|c|c|c|c|c|c|}
\hline \multicolumn{2}{|c|}{ - : Compound 1} & \multirow[b]{2}{*}{30} & \multirow[b]{2}{*}{40} & \multirow[b]{2}{*}{50} & \multirow[b]{2}{*}{60} & \multirow[b]{2}{*}{70} & \multirow[b]{2}{*}{80} \\
\hline 10 & 20 & & & & & & \\
\hline MKWVTFISLL & LLFSSAYSRG & VFRRDTHKSE & IAHRFKDLGE & EHFKGLVLIA & FSQYLQQCPF & DEHVKLVNEL & TEFAKTCVAD \\
\hline 90 & 100 & 110 & 120 & 130 & 140 & 150 & 160 \\
\hline ESHAGCEKSL & $\begin{array}{l}\text { HTLFGDELCK } \\
:\end{array}$ & VASLRETYGD & MADCCEKQEP & ERNECFLSHK & DDSPDLPKLLK & PDPNTLCDEF & KADEKKFWGK \\
\hline 170 & 180 & 190 & 200 & 210 & 220 & 230 & 240 \\
\hline YLYEIARRHP & YFYAPELLYYY & ANKYNGVFQE & CCQAEDKGAC & LLPKIETMRE & KVLASSARQR & LRCASIQKFG & ERALKAWSVA \\
\hline 250 & 260 & 270 & 280 & 290 & 300 & 310 & 320 \\
\hline RLSQKFPKAE & FVEVTKLVTD & LTKVHKECCH & GDLLECADDR & $\begin{array}{l}\text { ADLAKYICDN } \\
\because: \vdots\end{array}$ & QDTISSKLKE & CCDKPLLEKS & $\begin{array}{l}\text { HCIAEVEKDA } \\
:\end{array}$ \\
\hline 330 & 340 & 350 & 360 & 370 & 380 & 390 & 400 \\
\hline IPENLPPLTA & DFAEDKDVCK & NYQEAKDAFL & GSFLYEYSRR & HPEYAVSVLL & RLAKEYEATL & EECCAKDDPH & ACYSTVFDKL \\
\hline 410 & 420 & 430 & 440 & 450 & 460 & 470 & 480 \\
\hline KHLVDEPQNL & IKQNCDQFEK & LGEYGFONAL & IVRYTRKVPQ & VSTPTLVEVS & RSLGKVGTRC & CTKPESERMP & CTEDYLSLIL \\
\hline 490 & 500 & 510 & 520 & 530 & 540 & 550 & 560 \\
\hline NRLCVLHEKT & PVSEKVTKCC & $\begin{array}{l}\text { TESLVNRRPC } \\
\because\end{array}$ & FSALTPDETY & VPKAFDEKLF & TFHADICTLP & DTEKQIKKQT & ALVELLKHKP \\
\hline 570 & 580 & 590 & 600 & 610 & & & \\
\hline KATEEQLKTV & MENFVAFVDK & CCAADDKEAC & FAVEGPKLVV & STQTALA & & & \\
\hline
\end{tabular}

Figure S3. Identified modification sites on BSA $(15 \mu \mathrm{M})$ by 1 and $\mathbf{2}(1 \mathrm{mM})$ under blue LED irradiation with tryptic peptide LC/MS/MS.
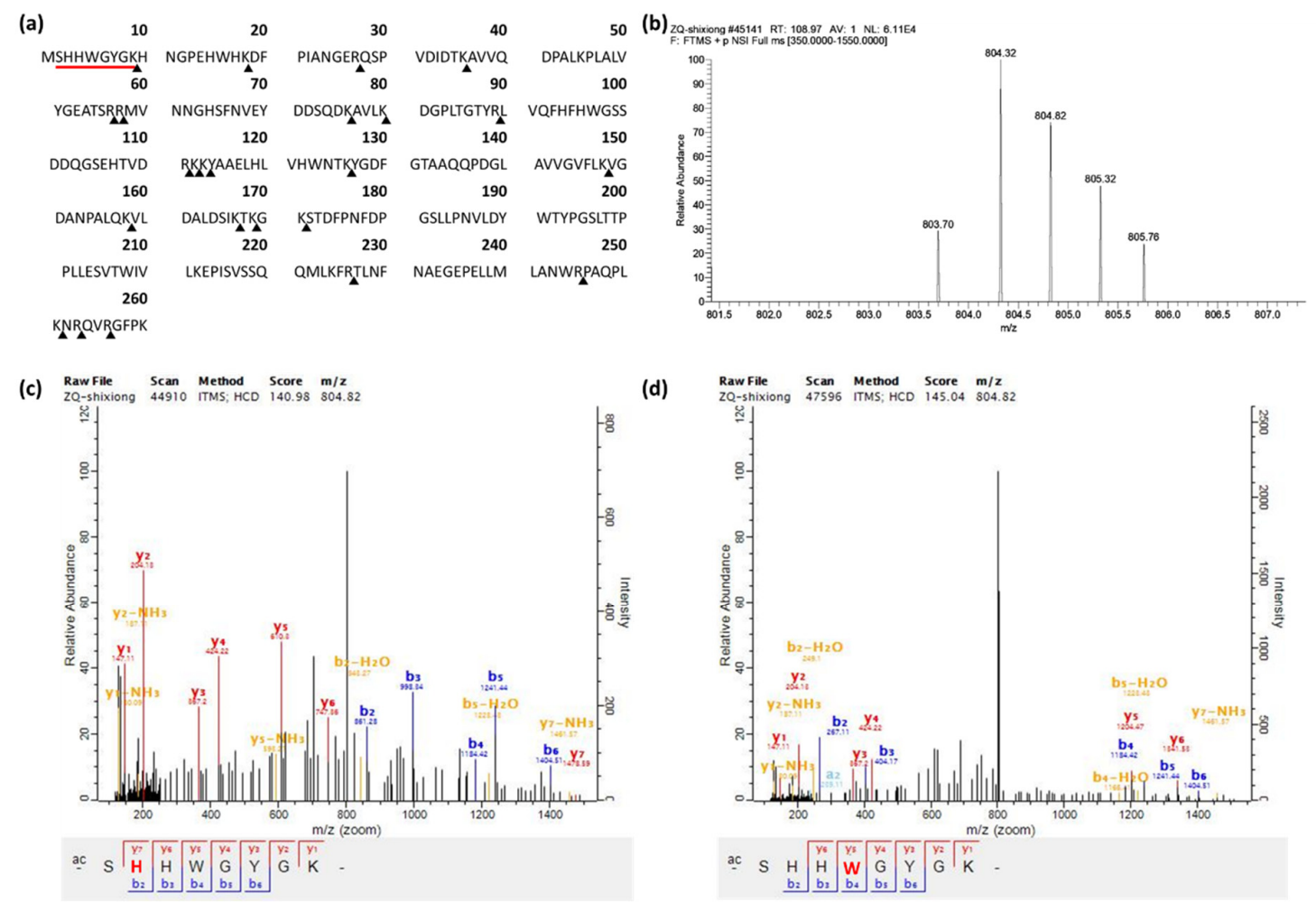

Figure S4. (a) Primary sequence of CA-II and the sites of cleavage by tryptic digestion ( $\mathbf{\Delta})$. The identified peptide that is labeled with $\mathbf{3}$ was underlined in red. (b) Mass spectrum of the labeled peptide. (c)-(d) MS/MS analysis of the labeled peptide. Two labeled residues (His2 and Trp4) were identified. 
a)

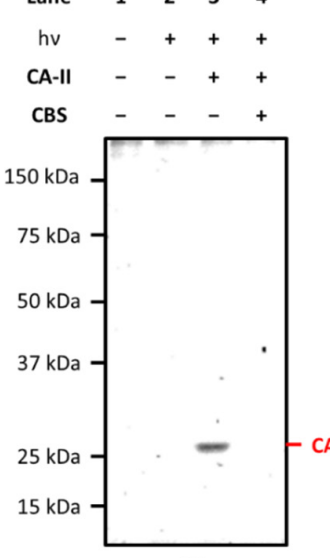

FL

c)
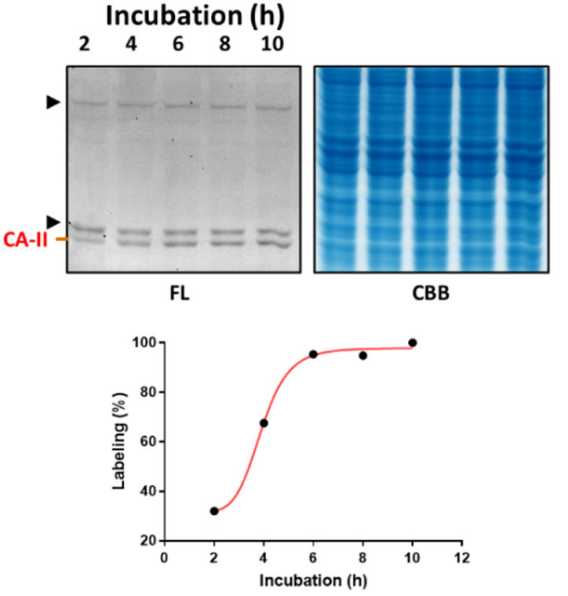

b)

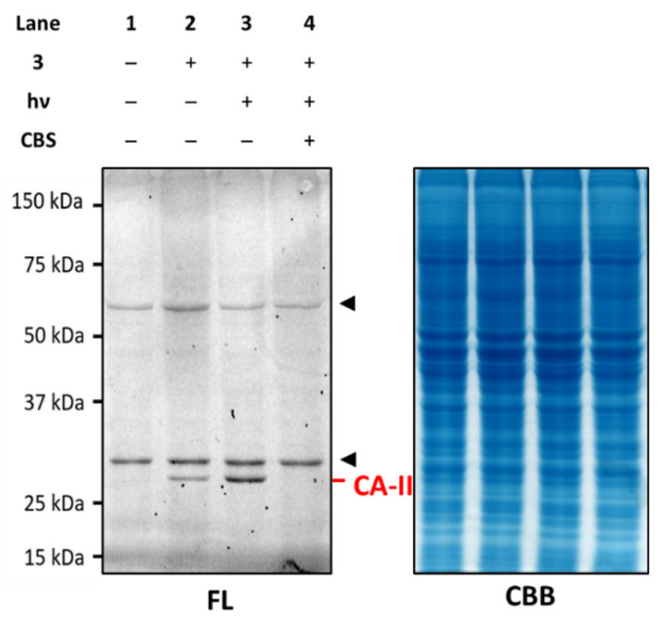

d)
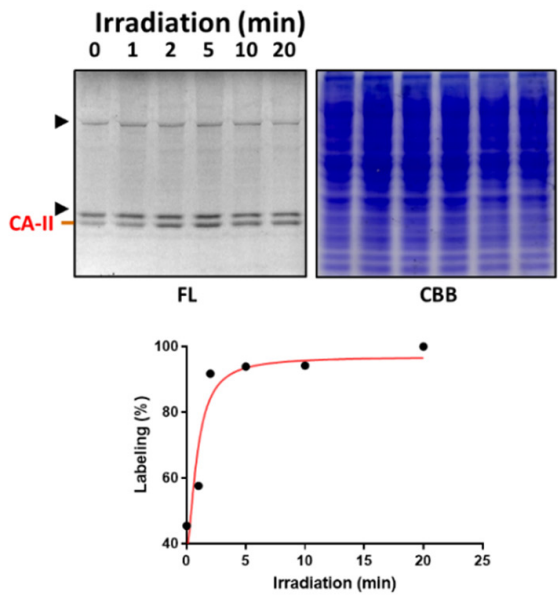

Figure S5. (a) SDS-PAGE of recombinant CA-II labeled by 3 in cell lysates. Each lane contains $10 \mu \mathrm{g}$ HeLa cell lysate proteins, $3(10 \mu \mathrm{M})$, recombinant CA-II $(1 \mu \mathrm{g})$ and CBS (100 $\mu \mathrm{M}$ ) as indicated. (b) SDS-PAGE of endogenous CA-II labeled by 3 in live HCT116 cells. (c) SDS-PAGE of endogenous CA-II labeled by $3(10 \mu \mathrm{M})$ in live HCT116 cells with varying incubated time. (d) SDS-PAGE of endogenous CA-II labeled by $3(10 \mu \mathrm{M})$ in HCT116 cells with varying irradiation time. (b)-(d) Each lane contains $50 \mu \mathrm{g}$ of total proteins.

Endogenous fluorescence band in HCT116 cell lysate under $473 \mathrm{~nm}$. FL: in-gel fluorescence, CBB: Coomassie brilliant blue staining. 
a)

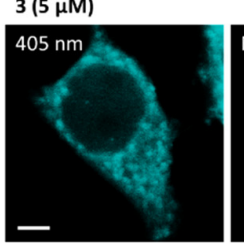

$3(5 \mu \mathrm{M})+\mathrm{CBS}(100 \mu \mathrm{M})$

\section{$405 \mathrm{~nm}$}

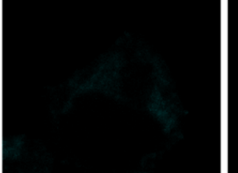

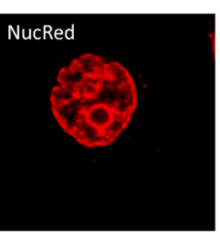

NucRed

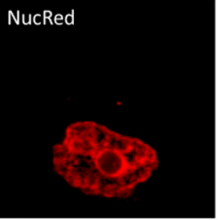

b) $3(5 \mu \mathrm{M})$ without blue LED irradiation
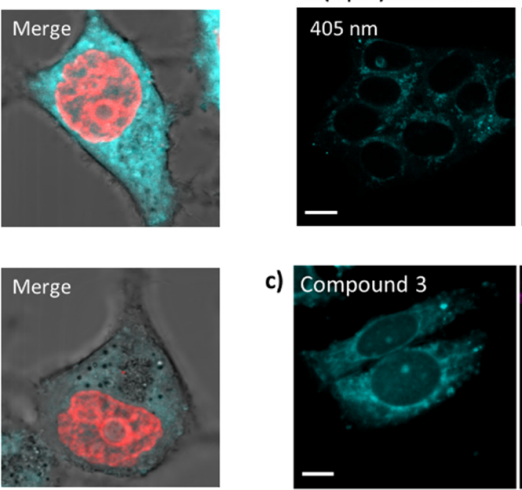

c) Compound 3
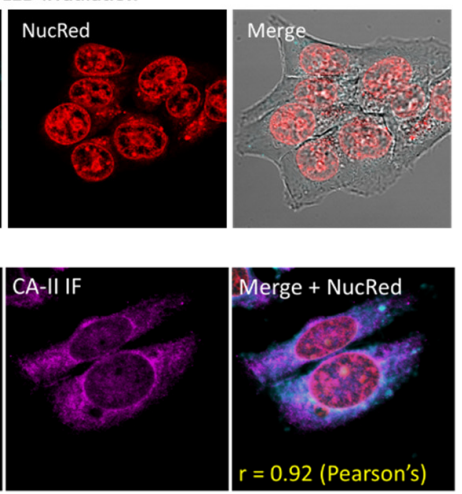

Figure S6. (a) Live-cell confocal imaging of MCF7 cells labeled with $3(5 \mu \mathrm{M})$ with or without CBS $(200 \mu \mathrm{M})$. Scale bar $=5 \mu \mathrm{m}$. (b) Live-cell confocal imaging of HCT116 cells treated with $3(5 \mu \mathrm{M})$ and vigorously washed with HBSS for 3 times prior to blue LED irradiation. The imaging setting was identical to Figure $3 \mathrm{c}$. Scale bar $=10 \mu \mathrm{m}$. (c) Confocal imaging of fixed MCF7 cells labeled with $3(5 \mu \mathrm{M})$ and immunofluorescence (IF) stained with CA-II antibody. Scale bar $=10 \mu \mathrm{m}$. 


\section{General Information}

All chemicals were purchased from commercial vendors and used without further purification unless indicated otherwise. All reactions requiring anhydrous conditions were carried out under argon atmosphere using oven-dried glassware. AR-grade solvents were used for all reactions. Dichloromethane, DMF, and trimethylamine were distilled from calcium hydride. THF was distilled from sodium. Air and moisture sensitive compounds were introduced via syringes through rubber septa under argon atmosphere. Reaction progress was monitored by TLC on pre-coated silica plates (Merck $60 \mathrm{~F} 254 \mathrm{~nm}, 0.25 \mu \mathrm{m}$ ) and spots were visualized by $\mathrm{UV}$ and/or staining in phosphomolybdic acid (PMA) or $\mathrm{KMnO}_{4}$ solution followed by heating. Flash column chromatography was carried out using silica gel (Merck 60 F254 nm, 0.040-0.063 $\mu \mathrm{m})$.

NMR spectra were acquired on Bruker Avance DPX 300 Fourier Transform Spectrometer operating at $300 \mathrm{MHz}$ for ${ }^{1} \mathrm{H}$ and at $75 \mathrm{MHz}$ for ${ }^{13} \mathrm{C}$, Bruker Avance DPX 400 Fourier Transform Spectrometer operating at $400 \mathrm{MHz}$ for ${ }^{1} \mathrm{H}, 100 \mathrm{MHz}$ for ${ }^{13} \mathrm{C}, 376 \mathrm{MHz}$ for ${ }^{19} \mathrm{~F}$ and Bruker Avance III HD 500 Spectrometer operating at $500 \mathrm{MHz}$ for ${ }^{1} \mathrm{H}, 125 \mathrm{MHz}$ for ${ }^{13} \mathrm{C}, 470$ $\mathrm{MHz}$ for ${ }^{19} \mathrm{~F}$. Chemical shifts were reported in parts per million (ppm) referenced with respect to appropriate internal standards or residual solvent peaks $\left(\mathrm{CDCl}_{3}=7.26 \mathrm{ppm}, \mathrm{DMSO}-d_{6}=\right.$ $2.50 \mathrm{ppm}, \mathrm{CD}_{3} \mathrm{OD}=3.31 \mathrm{ppm}$ for ${ }^{1} \mathrm{H} ; \mathrm{CDCl}_{3}=77.16 \mathrm{ppm}, \mathrm{DMSO}-d_{6}=39.52 \mathrm{ppm}, \mathrm{CD}_{3} \mathrm{OD}$ $=49.00 \mathrm{ppm}$ for ${ }^{13} \mathrm{C}$ ). The following abbreviations were used in reporting spectra, br s (broad singlet), s (singlet), d (doublet), $\mathrm{t}$ (triplet), q (quartet), dd (doublet of doublets) and $\mathrm{m}$ (multiplet). High-resolution mass spectra were obtained on Bruker maXis II High-Resolution QTOF using ESI mode. All LCMS analysis was carried out on Agilent 1100 HPLC system equipped with an auto-sampler using reverse-phase Phenomenex Luna $5 \mu \mathrm{m}$ C18(2) $100 \AA 50$ $\times 3.0 \mathrm{~mm}$ columns. Water and acetonitrile containing $0.1 \%$ TFA were used as eluents and the flow rate was $0.4 \mathrm{~mL} / \mathrm{min}$. Ultraviolet absorption spectra were recorded on a Cary $50 \mathrm{UV}$ visible spectrophotometer. Fluorescence measurements were carried out on a Hitachi F-7000 fluorescence spectrophotometer. The slit width was set at $2.5 \mathrm{~nm}$. The emission spectrum was scanned from 300 to $700 \mathrm{~nm}$ at $1200 \mathrm{~nm} / \mathrm{min}$ and the photomultiplier voltage was set at $700 \mathrm{~V}$.

MCF7 and HeLa cells were cultured in Dulbecco's modified Eagle medium (DMEM; Gibco) containing 10\% fetal bovine serum (FBS; Gibco), $100 \mathrm{U} / \mathrm{mL}$ penicillin and $100 \mu \mathrm{g} / \mathrm{mL}$ streptomycin. HCT116 cells were cultured in McCoy's 5A media (Gibco) supplemented with $10 \%$ fetal bovine serum, $100 \mathrm{U} / \mathrm{mL}$ penicillin and $100 \mu \mathrm{g} / \mathrm{mL}$ streptomycin. Cells were maintained in a humidified $37{ }^{\circ} \mathrm{C}$ incubator with $5 \% \mathrm{CO}_{2}$. To harvest the cell lysate proteins, cells were washed twice with phosphate-buffered saline (PBS), treated with $1 \times$ trypsin, and collected by centrifugation. Cell pellets were then washed and lysed with lysis buffer $(0.1 \%$ 
SDS, 1\% Triton X-100, $150 \mathrm{mM} \mathrm{NaCl}, 0.1 \mathrm{U}$ Benzonase, Roche EDTA-free protease inhibitor cocktail, $20 \mathrm{mM}$ Tris-HCl, $\mathrm{pH}$ 8.0). Protein concentration was determined by BCA protein assay. Cell lysate samples were resolved by hand-cast SDS-PAGE. In-gel fluorescence was visualized by Typhoon FLA 9000 Gel Imaging Scanner (GE Healthcare) using $473 \mathrm{~nm}$ blue LD laser and detected by emission filter of $\geq 510 \mathrm{~nm}$. The SDS-PAGE gels were stained with Coomassie brilliant blue (CBB). For Western blot, the resolved proteins were transferred to poly(vinylidene difluoride) (PVDF) membranes. Membranes were then blocked with 3\% BSA in $0.1 \%$ Tween in Tris-buffered saline (TBST) for $1 \mathrm{~h}$ at room temperature. Membranes were incubated with the corresponding primary antibody overnight at $4^{\circ} \mathrm{C}$, washed with TBST $(3 \times$ $5 \mathrm{~min}$ ) and then incubated with an appropriate secondary antibody. Finally, blots were washed again with TBST $(3 \times 5$ min $)$ and developed with SuperSignal ${ }^{\text {TM }}$ West Pico Chemiluminescent Substrate (Thermo Scientific). The membranes were visualized by chemiluminescent mode of ThermoFischer myECL ${ }^{\mathrm{TM}}$ Imager.

For confocal imaging, cells were seeded in glass-bottom dishes at $5 \times 10^{4}$ cells $/ \mathrm{mL}$ density $24 \mathrm{~h}$ prior to the experiment. All imaging data of treated cells were collected on a Carl Zeiss LSM 780 confocal microscope system equipped with $40 \times / 1.3$ Oil and a photomultiplier tube (PMT) detector. For flow cytometry analysis, cells were seeded into a $150-\mathrm{mm}$ culture dish at $5 \times 10^{5}$ cells $/ \mathrm{mL}$ density $24 \mathrm{~h}$ prior to the experiment. Treated cells were then harvested by trypsinization and collected by centrifugation. After discarding the supernatant, cell pellets were re-suspended gently into single cells with $1 \mathrm{~mL}$ HBSS. The fluorescence intensity was measured by using BD LSR Fortessa Analyzer. The data were analyzed by FlowJo software. 


\section{Experimental Procedures}

$\underline{\text { Small scale photolysis }}$

Compound to be tested was dissolved in $3 \mathrm{~mL}$ of methanol in a quartz cuvette and was exposed to various light sources with constant stirring at room temperature. For one-photon excitation, a 7W blue LED lamp covering 430-490 nm (maxima at around $460 \mathrm{~nm}$ ) was used. For two-photon excitation, a mode-locked Ti:sapphire laser was used to project femtosecond pulses of an $800 \mathrm{~nm}$ focused light beam. At the various time intervals, the absorption and emission spectra were measured. All fluorescence measurements were carried out on a Hitachi F-7000 fluorescence spectrophotometer. The slit width was set at $2.5 \mathrm{~nm}$. The emission spectrum was scanned from 400 to $700 \mathrm{~nm}$ at $1200 \mathrm{~nm} / \mathrm{min}$ and the photomultiplier voltage was set at $700 \mathrm{~V}$. The photolysis mixture was concentrated in vacuo, re-dissolved in $0.6 \mathrm{~mL}$ $\mathrm{MeCN}$ and subjected to LC/MS analysis.

\section{Large scale photolysis of $\mathbf{1}$}

A solution of 1 (43 mg, $0.85 \mathrm{mM}$ ) in $250 \mathrm{~mL} \mathrm{MeOH}$ was irradiated with blue LED lamp for $48 \mathrm{~h}$. The reaction was monitored by HPLC to confirm complete reaction. The reaction mixture was then concentrated in vacuo and purified by preparative TLC to afford $\mathbf{1 a}(1.0 \mathrm{mg}, 2.3 \%)$, 1b (1.4 mg, 3.3\%), 1c (15 mg, 35\%), 1d (8 mg, 19\%) and 1e (17 mg, 38\%). 1a: ${ }^{1} \mathrm{H}$ NMR (400 $\left.\mathrm{MHz}_{\mathrm{CDCl}}\right) \delta 7.43(\mathrm{~d}, J=9.0 \mathrm{~Hz}, 1 \mathrm{H}), 6.58(\mathrm{dd}, J=8.8,2.5 \mathrm{~Hz}, 1 \mathrm{H}), 6.51(\mathrm{~d}, J=2.5 \mathrm{~Hz}$, $1 \mathrm{H}), 5.99(\mathrm{~s}, 1 \mathrm{H}), 3.97$ (t, $J=6.5 \mathrm{~Hz}, 2 \mathrm{H}), 3.41$ (q, $J=7.0 \mathrm{~Hz}, 4 \mathrm{H}), 2.95$ (t, $J=6.6 \mathrm{~Hz}, 2 \mathrm{H})$, $1.21(\mathrm{t}, J=7.0 \mathrm{~Hz}, 6 \mathrm{H}) .1 \mathrm{~b}:{ }^{1} \mathrm{H}$ NMR $\left(300 \mathrm{MHz}, \mathrm{CDCl}_{3}\right) \delta 7.32(\mathrm{~d}, J=9.0 \mathrm{~Hz}, 1 \mathrm{H}), 6.60-6.54$ (m, 1H), 6.54-6.50 (m, 1H), $6.25(\mathrm{~s}, 1 \mathrm{H}), 4.83(\mathrm{~s}, 1 \mathrm{H}), 3.41$ (q, $J=7.1 \mathrm{~Hz}, 4 \mathrm{H}), 1.20(\mathrm{t}, J=7.1$ $\mathrm{Hz}, 6 \mathrm{H}) . \mathbf{1 c}$ is identical to $\mathbf{S 2} . \mathbf{1 d}{ }^{1} \mathrm{H}$ NMR $\left(300 \mathrm{MHz}, \mathrm{CDCl}_{3}\right) \delta 7.36(\mathrm{~d}, J=9.0 \mathrm{~Hz}, 1 \mathrm{H}), 6.56$ $(\mathrm{dd}, J=9.0,2.6 \mathrm{~Hz}, 1 \mathrm{H}), 6.51$ (d, $J=2.6 \mathrm{~Hz}, 1 \mathrm{H}), 6.16$ (s, 1H), 4.54 (s, 2H), 3.46 (s, 3H), 3.40 $(\mathrm{q}, J=7.1 \mathrm{~Hz}, 4 \mathrm{H}), 1.20(\mathrm{t}, J=7.0 \mathrm{~Hz}, 6 \mathrm{H}) .1 \mathrm{e}:{ }^{1} \mathrm{H} \mathrm{NMR}\left(300 \mathrm{MHz}, \mathrm{CDCl}_{3}\right) \delta 7.12(\mathrm{~d}, J=8.6$ $\mathrm{Hz}, 1 \mathrm{H}), 6.91$ (dd, J = 11.2, $5.1 \mathrm{~Hz}, 1 \mathrm{H}), 6.54$ (d, $J=2.3 \mathrm{~Hz}, 1 \mathrm{H}), 6.47$ (dd, $J=8.6,2.3 \mathrm{~Hz}$, $1 \mathrm{H}), 5.86(\mathrm{~d}, J=11.2 \mathrm{~Hz}, 1 \mathrm{H}), 4.85(\mathrm{~d}, J=5.1 \mathrm{~Hz}, 1 \mathrm{H}), 3.41(\mathrm{~s}, 3 \mathrm{H}), 3.33$ (q, $J=7.0 \mathrm{~Hz}, 4 \mathrm{H})$, $1.15(\mathrm{t}, J=7.0 \mathrm{~Hz}, 6 \mathrm{H})$.

\section{$\underline{\text { Large scale photolysis of } \mathbf{2}}$}

A solution of $2(16 \mathrm{mg}, 0.05 \mathrm{mM})$ in $250 \mathrm{~mL} \mathrm{MeOH}$ was irradiated with blue LED lamp for $48 \mathrm{~h}$. The reaction was monitored by HPLC to confirm complete reaction. The reaction mixture was then concentrated in vacuo and purified by preparative TLC to afford 2a (2.4 mg, 15\%), 2b $(2.7 \mathrm{mg}, 17 \%)$, 2c (1.7 mg, 10\%) and $\mathbf{2 d}$ (7 mg, 43\%). 2a is identical to $\mathbf{S 5}$ and $\mathbf{2 b}$ is identical to $\mathbf{S 4} .2{ }^{1} \mathrm{H}$ NMR $\left(300 \mathrm{MHz}, \mathrm{CDCl}_{3}\right) \delta 7.51(\mathrm{~d}, J=9.0 \mathrm{~Hz}, 1 \mathrm{H}), 6.61-6.55(\mathrm{~m}, 1 \mathrm{H})$, $6.53(\mathrm{~d}, J=2.6 \mathrm{~Hz}, 1 \mathrm{H}), 4.77\left(\mathrm{q}, J_{\mathrm{H}, \mathrm{F}}=3.0 \mathrm{~Hz}, 1 \mathrm{H}\right), 3.50(\mathrm{~s}, 3 \mathrm{H}), 3.42$ (q, $\left.J=7.0 \mathrm{~Hz}, 4 \mathrm{H}\right), 1.22$ 
(t, $J=7.0 \mathrm{~Hz}, 6 \mathrm{H}) .2{ }^{1} \mathrm{H}$ NMR $\left(300 \mathrm{MHz}, \mathrm{CDCl}_{3}\right) \delta 12.01(\mathrm{~s}, 1 \mathrm{H}), 7.75(\mathrm{~d}, J=9.0 \mathrm{~Hz}, 1 \mathrm{H})$, $6.74-6.68(\mathrm{~m}, 1 \mathrm{H}), 6.65(\mathrm{~d}, J=2.6 \mathrm{~Hz}, 1 \mathrm{H}), 3.42(\mathrm{q}, J=7.0 \mathrm{~Hz}, 4 \mathrm{H}), 1.22$ (br t, $J=7.0 \mathrm{~Hz}$, $6 \mathrm{H})$.

Assay for the stability in the aqueous medium and towards glutathione

A solution of $2(5 \mathrm{mM})$ in $0.1 \mathrm{M}$ sodium phosphate buffer ( $\mathrm{pH}$ values 7.4) was incubated in dark for $24 \mathrm{~h}$ with or without the addition of an equivalent of reduced glutathione (GSH). The ${ }^{1} \mathrm{H}$ NMR before and after the incubation was recorded and compared.

\section{Assay for the stability of $\mathbf{2}$ in different $\mathrm{pH}$ values}

A solution of $2(10 \mu \mathrm{M})$ in $0.1 \mathrm{M}$ sodium phosphate buffer that was adjusted to various $\mathrm{pH}$ values (3-10) was incubated in dark for $1 \mathrm{~h}$. The fluorescence intensity was recorded after incubation. As a control, the fluorescence intensity of $2(10 \mu \mathrm{M})$ after irradiation in water with a blue LED lamp was measured. Emission was recorded at $510 \mathrm{~nm}$ with an excitation at 400 $\mathrm{nm}$.

$\underline{\text { In-gel fluorescence analysis of BSA labeling }}$

BSA $(15 \mu \mathrm{M})$ and 1 or $2(0.5 \mu \mathrm{L}$ DMSO stock solution) were mixed in a total volume of 50 $\mu \mathrm{L}$ solution in PBS buffer, which was then incubated under darkness for $1 \mathrm{~h}$ at room temperature. The samples were then irradiated with a blue LED lamp (430-490 nm) at a distance of $10 \mathrm{~cm}$ for $1 \mathrm{~h}$ at room temperature. The reaction was treated with $4 \times$ SDS sample buffer, then separated by $10 \%$ SDS-PAGE.

\section{Enzymatic activity assay of CA-II}

CA-II activity can be calorimetrically determined by the catalytic hydrolysis of $p$-nitrophenyl acetate into $p$-nitrophenol, which shows strong absorbance at $405 \mathrm{~nm}$. CA-II $(1 \mu \mathrm{M})$ and $p$ nitrophenyl acetate $(2.5 \mathrm{mM})$ were incubated in the presence of $\mathbf{3}$ or CBS at various concentrations in a 96-well plate in PBS buffer of $\mathrm{pH} 7.4$ (final volume of $100 \mu \mathrm{L}$ ). After incubation at $24{ }^{\circ} \mathrm{C}$ for $30 \mathrm{~min}$, the absorbance at $405 \mathrm{~nm}$ was measured using a multimode microplate detector (DTX 800, Beckman Coulter). The percentage inhibition was defined relative to the maximal activity which was measured without the inhibitor. The $\mathrm{IC}_{50}$ value was obtained from a graph of percent inhibition versus inhibitor concentration and calculated using Prism Graphpad software. 
$\underline{\text { In-gel fluorescence analysis of recombinant CA-II labeling }}$

CA-II $(1.7 \mu \mathrm{M})$ and $3(0.1 \mu \mathrm{L}$ DMSO stock solution) were mixed in a total volume of $10 \mu \mathrm{L}$ solution in PBS buffer, which was incubated under darkness for $1 \mathrm{~h}$ at room temperature. The samples were then irradiated with a blue LED lamp (430-490 nm) at a distance of $10 \mathrm{~cm}$ for 1 $\mathrm{h}$ at room temperature. The reaction was treated with $4 \times$ SDS sample buffer, then separated by 12\% SDS-PAGE. In-gel fluorescence was visualized by Typhoon FLA 9000 Gel Imaging Scanner (GE Healthcare) using $473 \mathrm{~nm}$ blue LD laser and detected by emission filter of $\geq 510$ $\mathrm{nm}$.

\section{$\underline{\mathrm{LC} / \mathrm{MS} / \mathrm{MS} \text { analysis of recombinant CA-II labeling by tryptic digestion }}$}

CA-II $(1.7 \mu \mathrm{M})$ and $3(50 \mu \mathrm{M})$ were mixed in a total volume of $100 \mu \mathrm{L}$ solution in PBS buffer, which was incubated under darkness for $1 \mathrm{~h}$ at room temperature. The samples were then irradiated with a blue LED lamp (430-490 nm) at a distance of $10 \mathrm{~cm}$ for $1 \mathrm{~h}$ at room temperature. The buffer was exchanged by size exclusion mini spin column (10 kDa) into sample buffer that contains $50 \mathrm{mM}$ Tris- $\mathrm{HCl}(\mathrm{pH} 8), 5 \mathrm{mM}$ DTT and $6 \mathrm{M}$ urea, incubated at $56^{\circ} \mathrm{C}$ for $30 \mathrm{~min}$. The sample was cooled to room temperature and alkylated with $12 \mathrm{mM}$ iodoacetamide in the dark for $30 \mathrm{~min}$ at room temperature, then quenched with $1 \mathrm{mM}$ DTT. The sample was diluted with 7 times volume of Tris- $\mathrm{HCl}$ buffer to bring the urea concentration to less than $1 \mathrm{M}$. MS grade trypsin $(1 \mu \mathrm{g}$, trypsin:protein 1:50 w/w) was added and the digestion reaction was incubated for $16 \mathrm{~h}$ at $37^{\circ} \mathrm{C}$. A final concentration of $5 \%$ acetic acid was added to terminate the reaction. The obtained peptides were desalted with a homemade spintip packed

with a $\mathrm{C} 18$ disk and dried in a speedvac. The obtained peptides were resuspended in $15 \mu \mathrm{L}$ of $0.1 \%(\mathrm{v} / \mathrm{v}) \mathrm{FA}$ and $5 \mu \mathrm{L}$ of samples were used for MS analysis. The peptides were separated by an Easy-nLC 1000 and analyzed by an Orbitrap Fusion mass spectrometer (Thermo Fisher Scientific). The full MS scans were performed with the $m / z$ range of 350-1550 and the mass resolution of 120000 . Peptides were selected in a quadrupole mass analyzer with a $1.6 \mathrm{Da}$ isolation window and fragmented by HCD. The raw data was loaded into the MaxQuant software and searched against the Uniprot Carbonic anhydrase 2 P00921 (CAH2_BOVIN).

\section{$\underline{\text { Labeling of recombinant CA-II in HeLa cell lysates }}$}

HeLa cell lysate proteins $(10 \mu \mathrm{g})$, recombinant CA-II $(1 \mu \mathrm{g}), \mathbf{3}(10 \mu \mathrm{M})$ and CBS $(100 \mu \mathrm{M})$ were mixed in a total volume of $20 \mu \mathrm{L}$ solution in PBS buffer, which was then incubated under darkness for 1 hour at room temperature. The samples were irradiated at 430-490 $\mathrm{nm}$ at a distance of $10 \mathrm{~cm}$ for $1 \mathrm{~h}$ using a blue LED lamp. The reaction was treated with SDS sample 
buffer then separated by $12 \%$ SDS-PAGE. In-gel fluorescence was visualized by Typhoon FLA 9000 Gel Imaging Scanner (GE Healthcare) using $473 \mathrm{~nm}$ blue LD laser and detected by emission filter of $\geq 510 \mathrm{~nm}$.

\section{$\underline{\text { Labeling of endogenous CA-II in living cells }}$}

MCF7 or HCT116 cells were seeded in 6-well plates at $10^{5}$ cells $/ \mathrm{mL}$ density $24 \mathrm{~h}$ prior to the experiment. Cells were then treated with $1 \mathrm{~mL}$ of the DMEM containing $3(10 \mu \mathrm{M})$, with or without CBS $(100 \mu \mathrm{M})$. After $6 \mathrm{~h}$ of incubation at $37{ }^{\circ} \mathrm{C} / 5 \% \mathrm{CO}_{2}$, the medium was aspirated, and cells were washed gently once with HBSS to remove the excessive probe, followed by the blue LED lamp irradiation for $30 \mathrm{~min}$ in HBSS. The cell lysate proteins were collected and were separated by SDS-PAGE. In-gel fluorescence was visualized by Typhoon FLA 9000 Gel Imaging Scanner (GE Healthcare) using $473 \mathrm{~nm}$ blue LD laser and detected by emission filter of $\geq 510 \mathrm{~nm}$, the resolved proteins were then transferred PVDF membranes. Western blot was performed with anti-CA-II antibody (Abcam, \#ab124687, 1:1000, Rb) and anti-Rb antibodyHRP (Cell Signaling Technology, \#7074P2, 1:2000).

\section{Labeling in CA-II knock-down MCF7 cells}

MCF7 cells were seeded in 24-well plates at $10^{4}$ cells $/ \mathrm{mL}$ density $24 \mathrm{~h}$ prior to the experiment. Knock-down of CA-II was performed by first premixing CA-II siRNA (SMARTpool siGENOME, Dharmcon, $5 \mu \mathrm{M}, 2.5 \mu \mathrm{L}$ ) and transfection reagent (DharmaFECT 1, Dharmcon, $0.25 \mu \mathrm{L}$ ) in Opti-MEM reduced serum medium at room temperature, followed by addition to $400 \mu \mathrm{L}$ DMEM to culture cells for $48 \mathrm{~h}$. Cells were then treated with medium containing $3(10 \mu \mathrm{M})$, with or without CBS $(100 \mu \mathrm{M})$. After $6 \mathrm{~h}$ of incubation at $37{ }^{\circ} \mathrm{C} / 5 \%$ $\mathrm{CO}_{2}$, the medium was aspirated, and cells were washed gently once with HBSS to remove the excessive probe, followed by the blue LED lamp irradiation for $30 \mathrm{~min}$ in HBSS. The cell lysate proteins were collected and were separated by SDS-PAGE. In-gel fluorescence was visualized by Typhoon FLA 9000 Gel Imaging Scanner (GE Healthcare) using $473 \mathrm{~nm}$ blue LD laser and detected by emission filter of $\geq 510 \mathrm{~nm}$, the resolved proteins were then transferred PVDF membranes for western blot. Western blot was performed with anti-CA-II antibody (Abcam, \#ab124687, 1:1000, Rb), anti-GAPDH antibody (Santa Cruz, \#sc-25778, 1:1000, Rb) and anti-Rb antibody-HRP (Cell Signaling Technology, \#7074P2, 1:2000).

\section{$\underline{\text { Live-cell imaging of endogenous CA-II }}$}

Cells were seeded in glass-bottom dishes at $5 \times 10^{4}$ cells $/ \mathrm{mL}$ density $24 \mathrm{~h}$ prior to the experiment. The cells were treated with $1 \mathrm{~mL}$ of DMEM with $3(5 \mu \mathrm{M})$, with or without $\mathbf{C B S}$ $(100 \mu \mathrm{M})$. After incubation for $2 \mathrm{~h}$ at $37{ }^{\circ} \mathrm{C} / 5 \% \mathrm{CO}_{2}$, the medium was removed and cells were 
gently washed once with HBSS, followed by irradiation with blue LED lamp for 30 min in HBSS. NucRed ${ }^{\mathrm{TM}}$ Live 647 ReadyProbes $^{\mathrm{TM}}$ Reagent (Thermo Scientific) was added to the incubation solution for $30 \mathrm{~min}$. All imaging data were collected on a Carl Zeiss LSM 780 confocal microscope system equipped with $40 \mathrm{x} / 1.3$ Oil and a photomultiplier tube (PMT) detector. Coumarin was excited by $405 \mathrm{~nm}$ diode laser and detected by bandpass of 420-550 $\mathrm{nm}$. NucRed was excited by $633 \mathrm{~nm}$ laser and detected by bandpass of 634-750 $\mathrm{nm}$.

$\underline{\text { Immunofluorescence staining of CA-II of fixed MCF7 cells }}$

MCF7 cells were seeded in glass-bottom dishes at $5 \times 10^{4}$ cells $/ \mathrm{mL}$ density $24 \mathrm{~h}$ prior to the experiment. The cells were treated with $1 \mathrm{~mL}$ of DMEM with $3(5 \mu \mathrm{M})$ in the presence or absence of $\mathbf{C B S}(100 \mu \mathrm{M})$. After incubation for $2 \mathrm{~h}$ at $37^{\circ} \mathrm{C} / 5 \% \mathrm{CO}_{2}$, the medium was removed and cells were gently washed once with HBSS, followed by irradiation with blue LED lamp for $30 \mathrm{~min}$ in HBSS. The cells were then fixed and permeabilized for $10 \mathrm{~min}$ at $-20^{\circ} \mathrm{C}$ with icecold methanol, then washed twice with PBS. Cells were then blocked with $2 \%$ BSA in PBS for $1 \mathrm{~h}$, and incubated with the anti-CA-II antibody (Novus, NB600-919, 1:20, Rb) for $1 \mathrm{~h}$ at room temperature, washed twice with TBST, and then incubated with Alexa Fluor 488 goat antirabbit (Thermofisher, \# A27034, 1:1000) for $1 \mathrm{~h}$, followed by washing with TBST before imaging. All imaging data were collected on a Carl Zeiss LSM 780 confocal microscope system equipped with 40x/1.3 Oil and a photomultiplier tube (PMT) detector. Coumarin was excited by $405 \mathrm{~nm}$ diode laser and detected by bandpass of 420-550 nm. NucRed was excited by 633 $\mathrm{nm}$ laser and detected by bandpass of 634-750 $\mathrm{nm}$. The Pearson's coefficient $\mathrm{r}$ was determined to be 0.92 using colocalization analysis (Coloc 2) of ImageJ software (Fiji).

\section{Flow cytometry analysis of endogenous CA-II}

Cells were seeded into a $150-\mathrm{mm}$ culture dish at $5 \times 10^{5}$ cells $/ \mathrm{mL}$ density $24 \mathrm{~h}$ prior to the experiment. The cells were treated with $1 \mathrm{~mL}$ of DMEM with $3(5 \mu \mathrm{M})$ in the presence or absence of $\mathbf{C B S}(100 \mu \mathrm{M})$. After incubation for $2 \mathrm{~h}$ at $37^{\circ} \mathrm{C} / 5 \% \mathrm{CO}_{2}$, the medium was removed and cells were gently washed with HBSS, followed by irradiation with blue LED lamp (430$490 \mathrm{~nm}$ ) for $30 \mathrm{~min}$ at room temperature. Cells were then harvested by trypsinization, and collected by centrifugation. After discarding the supernatant, cell pellets were re-suspended gently into single cells with $1 \mathrm{~mL}$ HBSS. The fluorescence intensity was measured in Pacific Blue channel (405 nm) by using BD LSR Fortessa Analyzer. The data were analyzed by FlowJo software. 
$\underline{\text { Live-cell imaging of CA-IX under hypoxia-mimetic condition }}$

HeLa cells were seeded in glass-bottom dishes at $1 \times 10^{4}$ cells $/ \mathrm{mL}$ density $24 \mathrm{~h}$ prior to the experiment. To induce CA-IX expression, cells were treatment with $1 \mathrm{~mL}$ of DMEM with DFO $(100 \mu \mathrm{M})$ and incubate for $24 \mathrm{~h}$ at $37^{\circ} \mathrm{C} / 5 \% \mathrm{CO}_{2}$. The cells were then treated with $1 \mathrm{~mL}$ of DMEM with $3(5 \mu \mathrm{M})$, with or without CBS $(100 \mu \mathrm{M})$. After incubation for $1 \mathrm{~h}$ at $37{ }^{\circ} \mathrm{C} / 5 \%$ $\mathrm{CO}_{2}$, the medium was removed, followed by irradiation with blue LED lamp for $30 \mathrm{~min}$ in HBSS. All imaging data were collected on a Carl Zeiss LSM 780 confocal microscope system equipped with 40x/1.3 Oil and a photomultiplier tube (PMT) detector. Coumarin was excited by $405 \mathrm{~nm}$ diode laser and detected by bandpass of 420-550 nm. To confirm the CA-IX expression, the cell lysate proteins were collected and were separated by SDS-PAGE. The resolved proteins were then transferred PVDF membranes for western blot. Western blot was performed with anti-CA-IX antibody (Abcam, \#ab15086, 1:1000, Rb), anti-HIF-1 $\alpha$ antibody (Santa Cruz, \#sc-10790, 1:1000, Rb), anti-GAPDH antibody (Santa Cruz, \#sc-25778, 1:1000, $\mathrm{Rb}$ ) and anti-Rb antibody-HRP (Cell Signaling Technology, \#7074P2, 1:2000).

\section{$\underline{\text { In situ two-photon labeling and imaging of CA-II in MCF7 cells }}$}

Cells were seeded in glass-bottom dishes at $5 \times 10^{4}$ cells $/ \mathrm{mL}$ density $24 \mathrm{~h}$ prior to the experiment. The cells were treated with $1 \mathrm{~mL}$ of DMEM with $3(5 \mu \mathrm{M})$ in the presence or absence of $\mathbf{C B S}(100 \mu \mathrm{M})$. After incubation for $2 \mathrm{~h}$ at $37^{\circ} \mathrm{C} / 5 \% \mathrm{CO}_{2}$, the medium was removed and cells were gently washed once with HBSS. NucRed ${ }^{\mathrm{TM}}$ Live 647 ReadyProbes $^{\mathrm{TM}}$ Reagent (Thermo Scientific) was added to the incubation solution for $30 \mathrm{~min}$. Dishes were then placed on Carl Zeiss LSM 780 confocal microscope system equipped with 40x/1.3 Oil and a photomultiplier tube (PMT) detector. Cells were first tracked with NucRed excited by $633 \mathrm{~nm}$ laser. Region of interest was selected and two-photon activation was performed with bleaching mode using $800 \mathrm{~nm}$ Coherent Chameleon Vision II laser (1\% laser power, 30 cycles). Subsequently, cells were fixed and washed with $\mathrm{MeOH}$ for $10 \mathrm{~min}$ on stage, then washed with PBS once. One-photon imaging was then performed with a $405 \mathrm{~nm}$ diode laser and detected by a bandpass of $420-550 \mathrm{~nm}$.

\section{$\underline{\text { Live-cell imaging of HeLa cells expressing mCherry-eDHFR }}$}

HeLa cells were seeded in glass-bottom dishes at $10^{4}$ cells $/ \mathrm{mL}$ density $24 \mathrm{~h}$ prior to the experiment. mCherry-eDHFR plasmid DNA (Addgene \#61500) $(2 \mu \mathrm{g}$ ) was dissolved in 100 $\mu \mathrm{L}$ Opti-MEM (Gibco) and incubated with $3 \mu \mathrm{L}$ X-treme Gene HP DNA transfection agent (Roche) for $15 \mathrm{~min}$. The cells were then treated with the transfection complex in $2 \mathrm{~mL}$ DMEM. After $48 \mathrm{~h}$, the cells were treated with $1 \mathrm{~mL}$ of DMEM with $4(5 \mu \mathrm{M})$ in the presence or absence 
of TMP $(100 \mu \mathrm{M})$. After incubation for $2 \mathrm{~h}$ at $37^{\circ} \mathrm{C} / 5 \% \mathrm{CO}_{2}$, the medium was removed and cells were gently washed once with HBSS, followed by irradiation with blue LED lamp for 30 min in HBSS. All imaging data were collected on a Carl Zeiss LSM 780 confocal microscope system equipped with 40x/1.3 Oil and a photomultiplier tube (PMT) detector. Coumarin was excited by $405 \mathrm{~nm}$ diode laser and detected by bandpass of 420-550 nm. mCherry was excited by $561 \mathrm{~nm}$ laser and detected by bandpass of $567-781 \mathrm{~nm}$. 


\section{Chemical synthesis}

Preparation of 1

Scheme S1
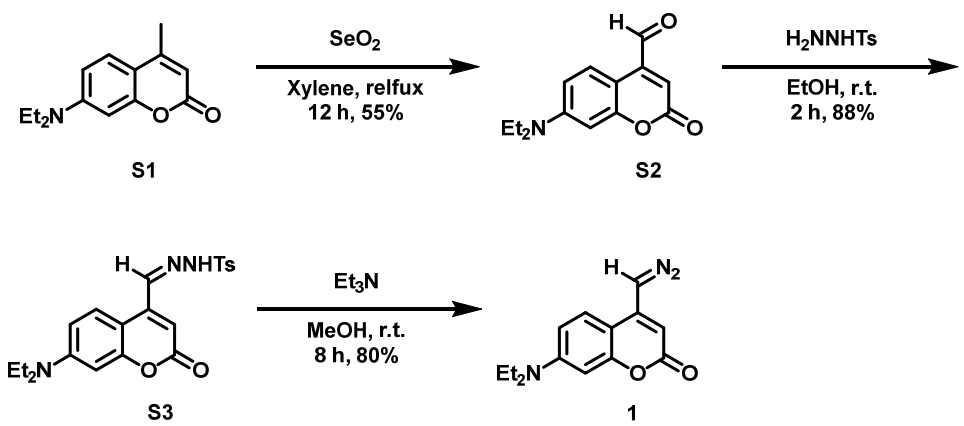

1 was synthesized according to reported procedures in literature ${ }^{[1]}$. ${ }^{1} \mathrm{H}$ NMR $(400 \mathrm{MHz}$, $\left.\mathrm{CDCl}_{3}\right) \delta 7.07(\mathrm{~d}, J=9.0 \mathrm{~Hz}, 1 \mathrm{H}), 6.47(\mathrm{dd}, J=9.0,2.2 \mathrm{~Hz}, 1 \mathrm{H}), 6.38(\mathrm{~d}, J=2.2 \mathrm{~Hz}, 1 \mathrm{H}), 5.45$ $(\mathrm{s}, 1 \mathrm{H}), 5.31(\mathrm{~s}, 1 \mathrm{H}), 3.33(\mathrm{q}, J=7.0 \mathrm{~Hz}, 4 \mathrm{H}), 1.13(\mathrm{t}, J=7.0 \mathrm{~Hz}, 6 \mathrm{H}) ;{ }^{13} \mathrm{C}$ NMR $(100 \mathrm{MHz}$, $\left.\mathrm{CDCl}_{3}\right) \delta 161.8,155.7,150.8,146.6,123.7,108.3,104.9,97.6,94.8,45.4,44.6,12.4$; HRMS (ESI): $m / z$ calcd for $\mathrm{C}_{14} \mathrm{H}_{16} \mathrm{~N}_{3} \mathrm{O}_{2}[\mathrm{M}+\mathrm{H}]^{+} 258.1243$, found 258.1239 .

\section{Preparation of 2}

\section{Scheme S2}

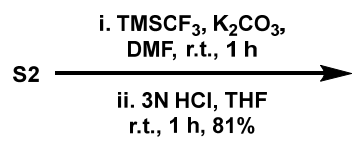

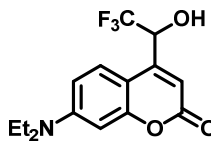

S4

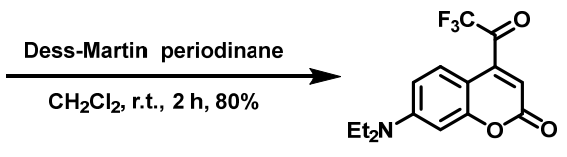

S5
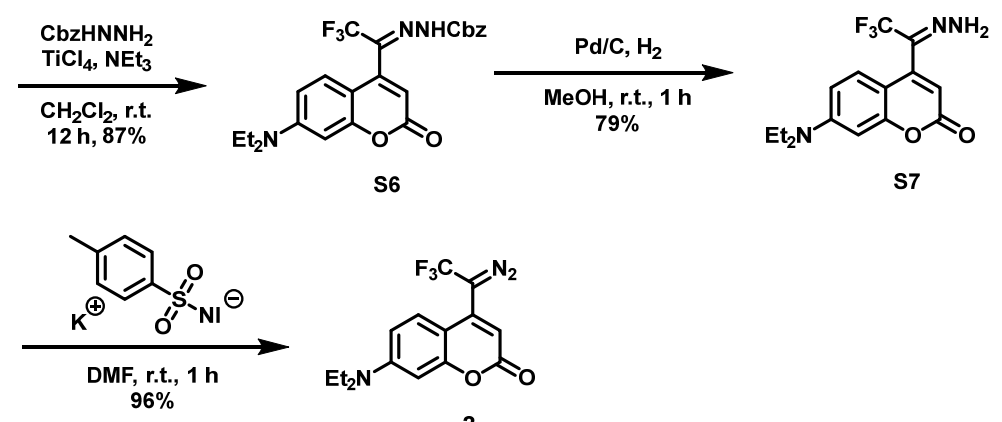

2

To a solution of $\mathbf{S} 2(56 \mathrm{mg}, 0.23 \mathrm{mmol})$ in DMF (3 mL) were added $\mathrm{TMSCF}_{3}(41 \mu \mathrm{L}, 0.28$ $\mathrm{mmol})$ and $\mathrm{K}_{2} \mathrm{CO}_{3}(3 \mathrm{mg}, 0.02 \mathrm{mmol})$. The resulting mixture was stirred at room temperature for $1 \mathrm{~h}$. The mixture was then concentrated in vacuo. The residue was dissolved in THF (10 
$\mathrm{mL})$, and $3 \mathrm{~N} \mathrm{HCl}(5 \mathrm{~mL})$ was added to the solution. The resulting mixture was stirred at room temperature for $1 \mathrm{~h}$. After that, the mixture was diluted with $\mathrm{Et}_{2} \mathrm{O}$. The organic layer was separated, and the aqueous layer was extracted three times with $\mathrm{Et}_{2} \mathrm{O}$. The combined organic layer was washed with the saturated aqueous solution of $\mathrm{NaHCO}_{3}$ and brine subsequently, dried over anhydrous magnesium sulfate and concentrated in vacuo. The residue was purified by silica gel column chromatography (20\% EA/Hexane) to afford $\mathbf{S 4}(62 \mathrm{mg}, 81 \%)$ as a yellow oil. ${ }^{1} \mathrm{H}$ NMR $\left(400 \mathrm{MHz}, \mathrm{CDCl}_{3}\right) \delta 7.70-7.43(\mathrm{~m}, 1 \mathrm{H}), 6.57(\mathrm{dd}, J=9.1,2.4 \mathrm{~Hz}, 1 \mathrm{H}), 6.42(\mathrm{~d}$, $J=2.4 \mathrm{~Hz}, 1 \mathrm{H}), 6.36(\mathrm{~s}, 1 \mathrm{H}), 5.39\left(\mathrm{q}, J_{\mathrm{H}, \mathrm{F}}=6.1 \mathrm{~Hz}, 1 \mathrm{H}\right), 5.17-4.81(\mathrm{~m}, 1 \mathrm{H}), 3.38(\mathrm{q}, J=7.0$ $\mathrm{Hz}, 4 \mathrm{H}), 1.18(\mathrm{t}, J=7.0 \mathrm{~Hz}, 6 \mathrm{H}) ;{ }^{13} \mathrm{C} \mathrm{NMR}\left(100 \mathrm{MHz}, \mathrm{CDCl}_{3}\right) \delta 163.0,156.4,150.9,149.6$, 126.0, 109.4 (q, $\left.{ }^{1} J_{\mathrm{C}, \mathrm{F}}=288.1 \mathrm{~Hz}\right), 109.2,108.5,97.6,78.2,68.4\left(\mathrm{q},{ }^{2} J_{\mathrm{C}, \mathrm{F}}=33.5 \mathrm{~Hz}\right), 44.8,12.5$; ${ }^{19} \mathrm{~F}$ NMR (376.5 MHz, $\left.\mathrm{CDCl}_{3}\right) \delta-76.1(\mathrm{~d}, J=6.0 \mathrm{~Hz}$ ); HRMS (ESI): $m / z$ calcd for $\mathrm{C}_{15} \mathrm{H}_{17} \mathrm{~F}_{3} \mathrm{NO}_{3}[\mathrm{M}+\mathrm{H}]^{+}$316.1161, found 316.1139.

To a solution of $\mathbf{S 4}(62 \mathrm{mg}, 0.2 \mathrm{mmol})$ in $\mathrm{CH}_{2} \mathrm{Cl}_{2}(2 \mathrm{~mL})$ was added freshly prepared DessMartin periodinane $(170 \mathrm{mg}, 0.4 \mathrm{mmol})$. The resulting suspension was stirred at room temperature for $2 \mathrm{~h}$. The reaction was quenched by aqueous solution of sodium thiosulfate. The organic layer was separated, and the aqueous layer was extracted three times with $\mathrm{CH}_{2} \mathrm{Cl}_{2}$. The combined organic layer was washed with saturated aqueous solution of $\mathrm{NaHCO}_{3}$ and brine subsequently, dried over anhydrous magnesium sulfate and concentrated in vacuo. The residue was purified by silica gel column chromatography (40\% EA/Hexane) to give S5 (50 mg, 80\%) as a red oil. ${ }^{1} \mathrm{H}$ NMR $\left(400 \mathrm{MHz}, \mathrm{CD}_{3} \mathrm{OD}\right) \delta$ (hydrate form) 8.29-8.09 (m, 1H), 6.69-6.64 (m, $1 \mathrm{H}), 6.51-6.48(\mathrm{~m}, 1 \mathrm{H}), 6.47-6.40(\mathrm{~m}, 1 \mathrm{H}), 3.45-3.39(\mathrm{~m}, 4 \mathrm{H}), 1.24-1.13(\mathrm{~m}, 6 \mathrm{H}) ;{ }^{13} \mathrm{C} \mathrm{NMR}$ $\left(100 \mathrm{MHz}, \mathrm{CD}_{3} \mathrm{OD}\right) \delta$ (hydrate form) $164.2,158.3,152.2,150.7,130.11,124.0$ (q, ${ }^{1} J_{\mathrm{C}, \mathrm{F}}=288.1$ $\mathrm{Hz}), 112.3,110.4,107.1,98.29$ (q, $\left.{ }^{2} J_{\mathrm{C}, \mathrm{F}}=33.5 \mathrm{~Hz}\right), 98.25,45.7,12.9 ;{ }^{19} \mathrm{~F}$ NMR $(376.5 \mathrm{MHz}$, $\left.\mathrm{CD}_{3} \mathrm{OD}\right) \delta-83.6(\mathrm{~s})$; HRMS (ESI): $m / z$ calcd for $\mathrm{C}_{15} \mathrm{H}_{15} \mathrm{~F}_{3} \mathrm{NO}_{3}[\mathrm{M}+\mathrm{H}]^{+} 314.1004$, found 314.0982.

To a solution of $\mathbf{S 5}(75 \mathrm{mg}, 0.24 \mathrm{mmol})$ in freshly distilled $\mathrm{CH}_{2} \mathrm{Cl}_{2}(3 \mathrm{~mL})$ were added $\mathrm{NEt}_{3}$ $(0.10 \mathrm{~mL}, 0.73 \mathrm{mmol}), \mathrm{CbzHNNH}_{2}(73 \mathrm{mg}, 0.29 \mathrm{mmol})$ and $\mathrm{TiCl}_{4}(13 \mu \mathrm{L}, 0.12 \mathrm{mmol})$ at $0{ }^{\circ} \mathrm{C}$ under argon atmosphere. The reaction was allowed to warm to room temperature and react for $12 \mathrm{~h}$. The reaction was quenched by the saturated aqueous $\mathrm{NH}_{4} \mathrm{Cl}$. The organic layer was separated, and the aqueous layer then extracted three times with EA. The combined organic layer was washed with brine, dried over anhydrous magnesium sulfate and concentrated in vacuo. The residue was purified by silica gel column chromatography ( $20 \% \mathrm{EA} / \mathrm{Hexane})$ to give S6 (114 mg, 87\%) as a yellow solid. ${ }^{1} \mathrm{H}$ NMR (500 MHz, DMSO-d6) mixture of two isomers in 2.3:1 ratio $\delta 11.70(\mathrm{br} \mathrm{s}, 0.3 \mathrm{H}), 11.16(\mathrm{br} \mathrm{s}, 0.7 \mathrm{H}), 7.63(\mathrm{~d}, J=7.2 \mathrm{~Hz}, 0.3 \mathrm{H}), 7.47-$ $7.28(\mathrm{~m}, 5 \mathrm{H}), 6.91(\mathrm{~d}, J=8.9 \mathrm{~Hz}, 0.7 \mathrm{H}), 6.69$ (d, $J=9.0 \mathrm{~Hz}, 1 \mathrm{H}), 6.60(\mathrm{~d}, J=10.8 \mathrm{~Hz}, 1 \mathrm{H})$, $6.16(\mathrm{~s}, 0.7 \mathrm{H}), 6.11(\mathrm{~s}, 0.3 \mathrm{H}), 5.23-5.15(\mathrm{~m}, 2 \mathrm{H}), 3.42(\mathrm{q}, J=7.0 \mathrm{~Hz}, 4 \mathrm{H}), 1.11(\mathrm{t}, J=7.0 \mathrm{~Hz}$, $6 \mathrm{H}) ;{ }^{13} \mathrm{C}$ NMR (125 MHz, DMSO-d6) $\delta 160.1$ (160.0), 156.6 (156.2), 153.0 (153.2), 150.94 
(150.86), 141.3, $135.6(135.7), 132.4\left(\mathrm{q},{ }^{2} J_{\mathrm{C}, \mathrm{F}}=33.5 \mathrm{~Hz}\right), 128.7,128.4,128.0,126.6,120.2$ (117.4) (q, $\left.{ }^{1} J_{\mathrm{C}, \mathrm{F}}=288.1 \mathrm{~Hz}\right), 110.8,109.2$ (109.3), 104.8, 97.3 (97.1), 67.1 (67.2), 44.1, 12.3; ${ }^{19} \mathrm{~F}$ NMR (470.5 MHz, DMSO- $\left.d_{6}\right) \delta-66.3$ (s); HRMS (ESI): $m / z$ calcd for $\mathrm{C}_{23} \mathrm{H}_{23} \mathrm{~F}_{3} \mathrm{~N}_{3} \mathrm{O}_{4}$ $[\mathrm{M}+\mathrm{H}]^{+}$462.1641, found 462.1609 .

To a solution of $\mathbf{S 6}(38 \mathrm{mg}, 0.05 \mathrm{mmol})$ in methanol $(10 \mathrm{~mL})$ was added $\mathrm{Pd} / \mathrm{C}(4 \mathrm{mg})$. The reaction was stirred at room temperature for $1 \mathrm{~h}$ under $\mathrm{H}_{2}$ atmosphere. After that, the mixture was filtered through celite and concentrated in vacuo. The residue was purified by silica gel column chromatography (20\% EA/Hexane) to give $\mathbf{S 7}(13 \mathrm{mg}, 79 \%)$ as a yellow oil. ${ }^{1} \mathrm{H}$ NMR $\left(400 \mathrm{MHz} \mathrm{CDCl}_{3}\right) \delta 7.06(\mathrm{~d}, J=9.0 \mathrm{~Hz}, 1 \mathrm{H}), 6.58(\mathrm{dd}, J=9.0,2.5 \mathrm{~Hz}, 1 \mathrm{H}), 6.53(\mathrm{~d}, J=2.5$ $\mathrm{Hz}, 1 \mathrm{H}), 6.03-6.05(\mathrm{~m}, 3 \mathrm{H}), 3.42(\mathrm{q}, J=7.0 \mathrm{~Hz}, 4 \mathrm{H}), 1.21(\mathrm{t}, J=7.14,6 \mathrm{H}) ;{ }^{13} \mathrm{C}$ NMR $(100$ $\mathrm{MHz}_{\mathrm{CDCl}} \mathrm{CD} \delta 161.2,156.9,151.7,150.9,142.5,129.3\left(\mathrm{q},{ }^{2} J_{\mathrm{C}, \mathrm{F}}=33.5 \mathrm{~Hz}\right), 126.9,120.9(\mathrm{q}$, $\left.{ }^{1} J_{\mathrm{C}, \mathrm{F}}=272.8 \mathrm{~Hz}\right), 110.2,109.5,97.9,45.0,12.5 ;{ }^{19} \mathrm{~F} \mathrm{NMR}\left(376.5 \mathrm{MHz}, \mathrm{CDCl}_{3}\right) \delta-66.9(\mathrm{~s})$; HRMS (ESI): $m / z$ calcd for $\mathrm{C}_{15} \mathrm{H}_{17} \mathrm{~F}_{3} \mathrm{~N}_{3} \mathrm{O}_{2}[\mathrm{M}+\mathrm{H}]^{+} 328.1273$, found 328.1250 .

To a stirring solution of $\mathbf{S} 7(48 \mathrm{mg}, 0.13 \mathrm{mmol})$ in DMF $(1 \mathrm{~mL})$ was added TsNIK ${ }^{[2]}(42 \mathrm{mg}$, $0.14 \mathrm{mmol}$ ). The reaction was stirred at room temperature for $1 \mathrm{~h}$. Then the mixture was concentrated in vacuo, purified by silica gel column chromatography (10\% EA/Hexane) to afford $2(41 \mathrm{mg}, 96 \%)$ as a yellow solid. ${ }^{1} \mathrm{H} \mathrm{NMR}\left(500 \mathrm{MHz}, \mathrm{CDCl}_{3}\right) \delta 7.30(\mathrm{~d}, J=9.1 \mathrm{~Hz}$, $1 \mathrm{H}), 6.58(\mathrm{dd}, J=9.1,2.6 \mathrm{~Hz}, 1 \mathrm{H}), 6.53(\mathrm{~d}, J=2.6 \mathrm{~Hz}, 1 \mathrm{H}), 6.05(\mathrm{~s}, 1 \mathrm{H}), 3.42(\mathrm{q}, J=7.1 \mathrm{~Hz}$, $4 \mathrm{H}), 1.22(\mathrm{t}, J=7.1 \mathrm{~Hz}, 6 \mathrm{H}) ;{ }^{13} \mathrm{C} \mathrm{NMR}\left(125 \mathrm{MHz}, \mathrm{CDCl}_{3}\right) \delta 161.5,157.4,151.94,139.1,126.9$, $125.8\left(\mathrm{q},{ }^{1} J_{\mathrm{C}, \mathrm{F}}=270.9 \mathrm{~Hz}\right), 109.7,105.8,102.6\left(\mathrm{q},{ }^{2} J_{\mathrm{C}, \mathrm{F}}=38.1 \mathrm{~Hz}\right), 99.3,45.8,30.7,13.4 ;{ }^{19} \mathrm{~F}$ NMR (470.5 MHz, $\mathrm{CDCl}_{3}$ ) $\delta-56.2(\mathrm{~s})$; HRMS (ESI): $m / z$ calcd for $\mathrm{C}_{15} \mathrm{H}_{15} \mathrm{~F}_{3} \mathrm{~N}_{3} \mathrm{O}_{2}[\mathrm{M}+\mathrm{H}]^{+}$ 326.1116, found 326.1094 . 


\section{Preparation of $\mathbf{3}$ and $\mathbf{4}$}

\section{Scheme S3}
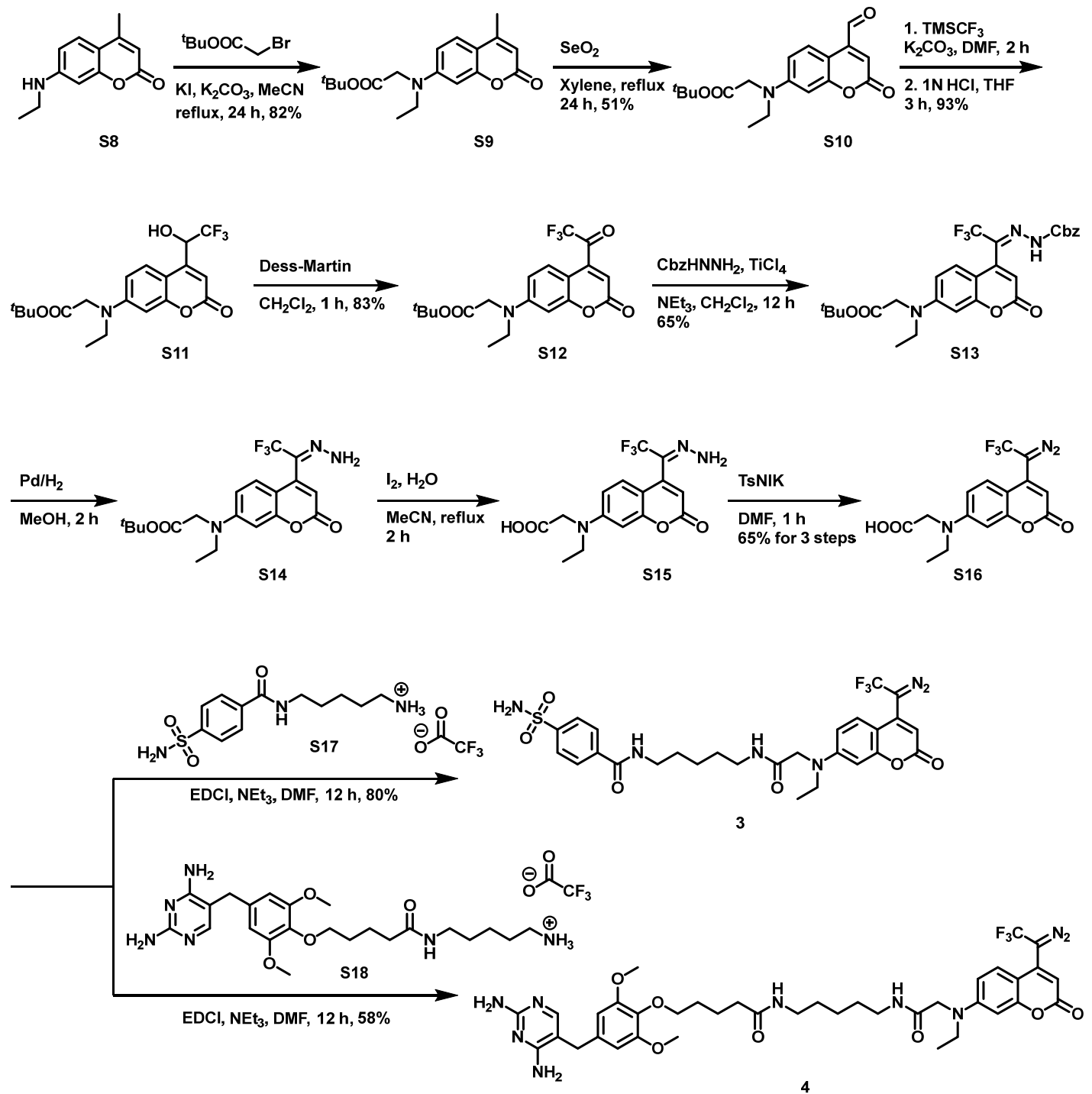

S8 was prepared according to procedures reported in literature ${ }^{[3]} .{ }^{1} \mathrm{H} \mathrm{NMR}\left(300 \mathrm{MHz}, \mathrm{CDCl}_{3}\right)$ $\delta 7.32(\mathrm{~d}, J=8.6 \mathrm{~Hz}, 1 \mathrm{H}), 6.51(\mathrm{dd}, J=8.6,2.4 \mathrm{~Hz}, 1 \mathrm{H}), 6.43(\mathrm{~d}, J=2.4 \mathrm{~Hz}, 1 \mathrm{H}), 5.94(\mathrm{~d}, J=$ $0.9 \mathrm{~Hz}, 1 \mathrm{H}), 4.48(\mathrm{~s}, 1 \mathrm{H}), 3.31-3.08(\mathrm{~m}, 2 \mathrm{H}), 2.32(\mathrm{~d}, J=1.1 \mathrm{~Hz}, 3 \mathrm{H}), 1.28(\mathrm{t}, J=7.2 \mathrm{~Hz}, 3 \mathrm{H})$. ${ }^{13} \mathrm{C} \mathrm{NMR}\left(75 \mathrm{MHz}, \mathrm{CDCl}_{3}\right) \delta 162.2,156.0,153.3,151.8,125.5,110.3,110.2,108.9,97.8,38.0$, 18.6, 14.4 .

To a solution of $\mathbf{S 8}(7.0 \mathrm{~g}, 34.4 \mathrm{mmol})$ in $\mathrm{MeCN}(150 \mathrm{~mL})$ were added tert-butyl bromoacetate (25 g, $170 \mathrm{mmol}), \mathrm{K}_{2} \mathrm{CO}_{3}(6.18 \mathrm{~g}, 44.7 \mathrm{mmol})$ and $\mathrm{KI}(5.7 \mathrm{~g}, 34.4 \mathrm{mmol})$. The reaction was stirred under reflux for $24 \mathrm{~h}$ and was filtered after cooling down. The solvent was 
evaporated, and the residue was then dissolved with EA. The organic layer was washed with water and brine subsequently, dried over anhydrous magnesium sulfate and concentrated in vacuo. The residue was purified by silica gel column chromatography ( $20 \% \mathrm{EA} / \mathrm{Hexane})$ to give S9 (8.89 g, 82\%) as a yellow crystal. ${ }^{1} \mathrm{H}$ NMR (500 MHz, $\left.\mathrm{CDCl}_{3}\right) \delta 7.37(\mathrm{~d}, J=8.9 \mathrm{~Hz}$, $1 \mathrm{H}), 6.53$ (dd, $J=8.9,2.6 \mathrm{~Hz}, 1 \mathrm{H}), 6.43$ (d, $J=2.6 \mathrm{~Hz}, 1 \mathrm{H}), 5.94$ (d, $J=1.1 \mathrm{~Hz}, 1 \mathrm{H}), 3.95$ (s, $2 \mathrm{H}), 3.48$ (q, $J=7.1 \mathrm{~Hz}, 2 \mathrm{H}), 2.31(\mathrm{~d}, J=0.9 \mathrm{~Hz}, 3 \mathrm{H}), 1.44(\mathrm{~s}, 9 \mathrm{H}), 1.27-1.17(\mathrm{~m}, 3 \mathrm{H}) ;{ }^{13} \mathrm{C}$ $\operatorname{NMR}\left(125 \mathrm{MHz}, \mathrm{CDCl}_{3}\right) \delta 169.3,162.0,155.7,152.9,150.9,125.6,110.2,109.5,108.7,98.3$, 82.2, 53.1, 46.7, 28.1, 18.5, 12.4; HRMS (ESI): $m / z$ calcd for $\mathrm{C}_{18} \mathrm{H}_{24} \mathrm{NO}_{4}[\mathrm{M}+\mathrm{H}]^{+} 318.1705$, found 318.1679 .

To a suspension of $\mathbf{S 9}(8.89 \mathrm{~g}, 28.0 \mathrm{mmol})$ in xylene $(280 \mathrm{~mL})$ was added $\mathrm{SeO}_{2}(4.67 \mathrm{~g}, 42$ mmol). The mixture was heated under reflux for $24 \mathrm{~h}$. While hot, the solution was filtered through celite and washed thoroughly with EA. The filtrate was then concentrated in vacuo. The residue was purified by silica gel column chromatography ( $40 \% \mathrm{EA} / \mathrm{Hexane}$ ) to give $\mathbf{S 1 0}$ $(4.78 \mathrm{~g}, 51 \%)$ as a red solid. ${ }^{1} \mathrm{H}$ NMR $\left(500 \mathrm{MHz}, \mathrm{CDCl}_{3}\right) \delta 9.97(\mathrm{~s}, 1 \mathrm{H}), 8.26(\mathrm{dd}, J=9.1,1.6$ $\mathrm{Hz}, 1 \mathrm{H}), 6.54$ (d, $J=9.2 \mathrm{~Hz}, 1 \mathrm{H}), 6.47-6.42(\mathrm{~m}, 2 \mathrm{H}), 3.95$ (s, 2H), 3.48 (q, $J=7.2 \mathrm{~Hz}, 2 \mathrm{H})$, $1.43(\mathrm{~s}, 9 \mathrm{H}), 1.22(\mathrm{t}, J=7.2 \mathrm{~Hz}, 3 \mathrm{H}) ;{ }^{13} \mathrm{C} \mathrm{NMR}\left(125 \mathrm{MHz}, \mathrm{CDCl}_{3}\right) \delta 192.4,168.9,161.6,157.0$, 151.4, 143.8, 127.1, 118.5, 109.7, 104.7, 98.3, 82.4, 53.0, 46.8, 28.1, 12.3; HRMS (ESI): $m / z$ calcd for $\mathrm{C}_{18} \mathrm{H}_{22} \mathrm{NO}_{5}[\mathrm{M}+\mathrm{H}]^{+} 331.1414$, found 331.1415 .

To a solution of $\mathbf{S 1 0}(4.78 \mathrm{mg}, 14.4 \mathrm{mmol})$ in DMF (100 mL) were added TMSCF $3(2.77 \mathrm{~mL}$, $18.8 \mathrm{mmol})$ and $\mathrm{K}_{2} \mathrm{CO}_{3}(20 \mathrm{mg}, 0.14 \mathrm{mmol})$. The resulting mixture was stirred at room temperature for $2 \mathrm{~h}$ and then concentrated in vacuo. The residue was dissolved in THF $(60 \mathrm{~mL})$ and $1 \mathrm{~N} \mathrm{HCl}(30 \mathrm{~mL})$ was added to the solution. The resulting mixture was stirred at room temperature for $3 \mathrm{~h}$. The mixture was then diluted with $\mathrm{Et}_{2} \mathrm{O}$. The organic layer was separated, and the aqueous layer was extracted three times with $\mathrm{Et}_{2} \mathrm{O}$. The combined organic layer was washed with saturated aqueous solution of $\mathrm{NaHCO}_{3}$ and brine subsequently, dried over anhydrous magnesium sulfate and concentrated in vacuo. The residue was purified by silica gel column chromatography (30\% EA/Hexane) to afford $\mathbf{S 1 1}(5.38 \mathrm{~g}, 93 \%)$ as a yellow oil. ${ }^{1} \mathrm{H}$ NMR (400 MHz, DMSO-d $)) \delta .80(\mathrm{~d}, J=9.0 \mathrm{~Hz}, 1 \mathrm{H}), 7.23$ (d, $J=5.3 \mathrm{~Hz}, 1 \mathrm{H}), 6.64$ (dd, $J=$ 9.0, $2.3 \mathrm{~Hz}, 1 \mathrm{H}), 6.51(\mathrm{~d}, J=2.3 \mathrm{~Hz}, 1 \mathrm{H}), 6.27(\mathrm{~s}, 1 \mathrm{H}), 5.74-5.61(\mathrm{~m}, 1 \mathrm{H}), 4.18(\mathrm{~s}, 2 \mathrm{H}), 3.48$ (q, $J=7.4 \mathrm{~Hz}, 2 \mathrm{H}), 1.41(\mathrm{~s}, 9 \mathrm{H}), 1.12(\mathrm{t}, J=7.4 \mathrm{~Hz}, 3 \mathrm{H}) ;{ }^{13} \mathrm{C}$ NMR (100 MHz, DMSO- $\left.d 6\right) \delta$ 169.3, 160.4, 155.7, 151.1, 150.2, 126.8, 124.4 (q, $\left.{ }^{1} J_{\mathrm{C}, \mathrm{F}}=283.4 \mathrm{~Hz}\right), 109.0,106.5,97.5,81.1$, $66.8\left(\mathrm{q},{ }^{2} J_{\mathrm{C}, \mathrm{F}}=31.0 \mathrm{~Hz}\right), 52.3,45.9,27.7,12.2 ;{ }^{19} \mathrm{~F}$ NMR $\left(376.5 \mathrm{MHz}, \mathrm{DMSO}-d_{6}\right) \delta-75.1(\mathrm{~d}$, $J=6.6 \mathrm{~Hz}$ ); HRMS (ESI): $m / z$ calcd for $\mathrm{C}_{19} \mathrm{H}_{23} \mathrm{~F}_{3} \mathrm{NO}_{5}[\mathrm{M}+\mathrm{H}]^{+} 402.1528$, found 402.1504 .

To a solution of $\mathbf{S 1 1}(5.38 \mathrm{mg}, 13.4 \mathrm{mmol})$ in $\mathrm{CH}_{2} \mathrm{Cl}_{2}(100 \mathrm{~mL})$ was added freshly prepared Dess-Martin periodinane $(6.2 \mathrm{~g}, 14.6 \mathrm{mmol})$. The resulting suspension was stirred at room temperature for $1 \mathrm{~h}$. The reaction was quenched by aqueous solution of sodium thiosulfate. The 
organic layer was separated, and the aqueous layer was extracted three times with $\mathrm{CH}_{2} \mathrm{Cl}_{2}$. The combined organic layer was washed with saturated aqueous solution of $\mathrm{NaHCO}_{3}$ and brine subsequently, dried over anhydrous magnesium sulfate and concentrated in vacuo. The residue was purified by silica gel column chromatography (40\% EA/Hexane) to give S12 (4.46 g, 83\%) as a red oil. ${ }^{1} \mathrm{H}$ NMR $\left(500 \mathrm{MHz}, \mathrm{DMSO}-d_{6}\right) \delta$ (hydrate form) $8.22(\mathrm{~s}, 2 \mathrm{H}), 8.12(\mathrm{~d}, J=9.3 \mathrm{~Hz}$, $1 \mathrm{H}), 6.70-6.56(\mathrm{~m}, 1 \mathrm{H}), 6.47(\mathrm{~d}, J=2.4 \mathrm{~Hz}, 1 \mathrm{H}), 6.34(\mathrm{~s}, 1 \mathrm{H}), 4.16(\mathrm{~s}, 2 \mathrm{H}), 3.56-3.42(\mathrm{~m}, 2 \mathrm{H})$, $1.41(\mathrm{~s}, 9 \mathrm{H}), 1.12$ (t, $J=7.0 \mathrm{~Hz}, 3 \mathrm{H}) ;{ }^{13} \mathrm{C}$ NMR (125 MHz, DMSO- $\left.d_{6}\right) \delta$ (hydrate form) 169.2, $160.5,156.0,151.6,150.6,129.4,123.3\left(\mathrm{q},{ }^{1} J_{\mathrm{C}, \mathrm{F}}=290.3 \mathrm{~Hz}\right), 110.3,108.7,106.1,97.3,93.1$ $\left(\mathrm{q},{ }^{2} J_{\mathrm{C}, \mathrm{F}}=33.2 \mathrm{~Hz}\right), 81.0,52.2,45.7,27.7,12.2 ;{ }^{19} \mathrm{~F}$ NMR $\left(470.5 \mathrm{MHz}, \mathrm{DMSO}-d_{6}\right) \delta-81.6(\mathrm{~s})$; HRMS (ESI): $m / z$ calcd for $\mathrm{C}_{19} \mathrm{H}_{20} \mathrm{~F}_{3} \mathrm{NNaO}_{5}[\mathrm{M}+\mathrm{Na}]^{+} 422.1191$, found 422.2913 .

To a stirring solution of $\mathbf{S 1 2}(4.46 \mathrm{~g}, 11.1 \mathrm{mmol})$ in freshly distilled $\mathrm{CH}_{2} \mathrm{Cl}_{2}(110 \mathrm{~mL})$ were added $\mathrm{NEt}_{3}(7.74 \mathrm{~mL}, 55.5 \mathrm{mmol}), \mathrm{CbzHNNH}_{2}(2.41 \mathrm{~g}, 14.5 \mathrm{mmol})$ and $\mathrm{TiCl}_{4}(1.46 \mathrm{~mL}, 13.3$ $\mathrm{mmol}$ ) at $0{ }^{\circ} \mathrm{C}$ under argon atmosphere. The reaction was allowed to warm to room temperature and react for $12 \mathrm{~h}$. The reaction was quenched by saturated aqueous $\mathrm{NH}_{4} \mathrm{Cl}$. The organic layer was separated, and the aqueous layer then extracted three times with EA. The combined organic layer was washed with brine, dried over anhydrous magnesium sulfate and concentrated in vacuo. The residue was purified by silica gel column chromatography (20\% EA/Hexane) to give $\mathbf{S 1 3 ~ ( 3 . 9 6 ~ g , ~ 6 5 \% ) ~ a s ~ a n ~ o r a n g e ~ s o l i d . ~}{ }^{1} \mathrm{H} \mathrm{NMR}\left(500 \mathrm{MHz}, \mathrm{CDCl}_{3}\right) \delta 8.04$ (br s, $\left.1 \mathrm{H}\right), 7.38-$ $7.29(\mathrm{~m}, 5 \mathrm{H}), 7.00(\mathrm{~d}, J=9.0 \mathrm{~Hz}, 1 \mathrm{H}), 6.59-6.45(\mathrm{~m}, 2 \mathrm{H}), 6.05(\mathrm{~s}, 1 \mathrm{H}), 5.33-5.12(\mathrm{~m}, 2 \mathrm{H})$, $3.97(\mathrm{~s}, 2 \mathrm{H}), 3.51$ (q, $J=7.2 \mathrm{~Hz}, 2 \mathrm{H}), 1.46(\mathrm{~s}, 9 \mathrm{H}), 1.25(\mathrm{t}, J=7.2 \mathrm{~Hz}, 3 \mathrm{H}) ;{ }^{13} \mathrm{C} \mathrm{NMR}(125$ $\left.\mathrm{MHz}, \mathrm{CDCl}_{3}\right) \delta 168.7,160.0,156.8,152.5,140.8,134.8,129.1,129.0,128.92,128.86,128.85$ $\left(\mathrm{q},{ }^{1} J_{\mathrm{C}, \mathrm{F}}=275.6 \mathrm{~Hz}\right), 126.4,119.9\left(\mathrm{q},{ }^{2} J_{\mathrm{C}, \mathrm{F}}=32.4 \mathrm{~Hz}\right), 111.3,110.1,104.7,99.0,82.9,68.9$, 53.1, 47.1, 28.2, 12.4; ${ }^{19} \mathrm{~F}$ NMR (470.5 MHz, $\left.\mathrm{CDCl}_{3}\right) \delta-67.6$ (s); HRMS (ESI): $\mathrm{m} / z$ calcd for $\mathrm{C}_{27} \mathrm{H}_{29} \mathrm{~F}_{3} \mathrm{~N}_{3} \mathrm{O}_{6}[\mathrm{M}+\mathrm{H}]^{+}$548.2008, found 548.1963.

To a flask containing $\mathbf{S 1 3}$ (3.96 g, $7.23 \mathrm{mmol})$ under argon atmosphere were added Pd/C (400 $\mathrm{mg})$ and $\mathrm{MeOH}(50 \mathrm{~mL})$ sequentially. The reaction atmosphere was then purged with hydrogen gas via a balloon, allowed to stir for $2 \mathrm{~h}$ at room temperature. The reaction mixture was then filtered through celite and concentrated in vacuo to afford $\mathbf{S 1 4}$ as a yellow oil. Subsequently, to the solution of $\mathbf{S 1 4}$ in MeCN (30 mL) and water $(0.6 \mathrm{~mL})$ was added iodine (549 $\mathrm{mg}, 2.16$ mmol). The reaction was warmed to gentle reflux for $2 \mathrm{~h}$ and concentrated in vacuo to afford S15, which was used for next step without further purification. To a stirring solution of S15 in DMF $(20 \mathrm{~mL})$ was added TsNIK $(1.90 \mathrm{~g}, 5.54 \mathrm{mmol})$. The reaction was stirred at room temperature for $1 \mathrm{~h}$. Then the mixture was concentrated in vacuo. The residue was dissolved in water, washed with EA three times. The aqueous layer was acidified to $\mathrm{pH} 3$ with $1 \mathrm{~N} \mathrm{HCl}$ and extracted with EA three times. The combined organic layer was concentrated in vacuo to afford S16 (1.68 g, 65\% for 3 steps) as a yellow solid. ${ }^{1} \mathrm{H}$ NMR $\left(400 \mathrm{MHz}, \mathrm{CDCl}_{3}\right) \delta(\mathrm{ppm}) 9.11$ (br s, 1H), 7.28 (d, $J=9.0 \mathrm{~Hz}, 1 \mathrm{H}), 6.56(\mathrm{dd}, J=9.0,2.7 \mathrm{~Hz}, 1 \mathrm{H}), 6.44(\mathrm{~d}, J=2.2 \mathrm{~Hz}, 1 \mathrm{H}), 6.02$ 
(s, 1H), $4.08(\mathrm{~s}, 2 \mathrm{H}), 3.47(\mathrm{q}, J=7.0 \mathrm{~Hz}, 2 \mathrm{H}), 1.20(\mathrm{t}, J=7.1 \mathrm{~Hz}, 3 \mathrm{H}) ;{ }^{13} \mathrm{C}$ NMR $(100 \mathrm{MHz}$, $\left.\mathrm{CDCl}_{3}\right) \delta 174.7,160.9,156.0,151.4,138.6,124.8\left(\mathrm{q},{ }^{1} J_{\mathrm{C}, \mathrm{F}}=271.3 \mathrm{~Hz}\right), 124.7,109.3,105.7$, $105.1,99.2,58.4\left(\mathrm{q},{ }^{2} J_{\mathrm{C}, \mathrm{F}}=44.0 \mathrm{~Hz}\right), 52.0,46.7,12.2 ;{ }^{19} \mathrm{~F} \mathrm{NMR}\left(376.5 \mathrm{MHz}, \mathrm{CDCl}_{3}\right) \delta-72.3$ (s); HRMS (ESI): $m / z$ calcd for $\mathrm{C}_{15} \mathrm{H}_{13} \mathrm{~F}_{3} \mathrm{~N}_{3} \mathrm{O}_{4}\left[\mathrm{M}-\mathrm{N}_{2}+\mathrm{H}\right]^{+} 328.0797$, found 328.0891.

S17 was synthesized from CBS according to procedures reported in literature ${ }^{[4]}$. To a solution of $\mathbf{S 1 6}$ (40 mg, $0.1 \mathrm{mmol})$ in DMF (10 mL) were added EDCI (38 mg, $0.2 \mathrm{mmol})$ and NEt 3 (40 $\mu \mathrm{L}, 0.2 \mathrm{mmol}$ ) under argon atmosphere. The mixture was stirred for $15 \mathrm{~min}$, and $\mathbf{S 1 8}(60 \mathrm{mg}$, $0.2 \mathrm{mmol}$ ) was added. The resulting mixture was stirred for further $12 \mathrm{~h}$ at room temperature. The reaction was then concentrated in vacuo and was purified by silica gel column chromatography $\left(2 \% \mathrm{MeOH} / \mathrm{CH}_{2} \mathrm{Cl}_{2}\right)$ to afford $3(60 \mathrm{mg}, 80 \%)$ as a yellow oil. ${ }^{1} \mathrm{H}$ NMR (400 $\left.\mathrm{MHz}, \mathrm{CD}_{3} \mathrm{OD}\right) \delta 7.32-7.11(\mathrm{~m}, 4 \mathrm{H}), 6.78(\mathrm{~d}, J=9.2 \mathrm{~Hz}, 1 \mathrm{H}), 6.00(\mathrm{dd}, J=9.2,2.5 \mathrm{~Hz}, 1 \mathrm{H})$, $5.81(\mathrm{~d}, J=2.5 \mathrm{~Hz}, 1 \mathrm{H}), 5.24(\mathrm{~d}, J=1.0 \mathrm{~Hz}, 1 \mathrm{H}), 2.84$ (q, $J=7.0 \mathrm{~Hz}, 2 \mathrm{H}), 2.68-2.47(\mathrm{~m}, 6 \mathrm{H})$, 2.47-2.38 (m, 2H), 1.14-1.10 (m, 2H), 0.98-0.74 (m, 4H), 0.73-0.56 (m, 2H), 0.56-0.42 (m, $3 \mathrm{H}) ;{ }^{13} \mathrm{C}$ NMR (100 MHz, CD $\left.3 \mathrm{OD}\right) \delta 172.0,169.0,162.8,157.5,153.6,147.9,141.2,139.4$, $129.2,127.6,126.8\left(\mathrm{q},{ }^{1} J_{\mathrm{C}, \mathrm{F}}=270.3 \mathrm{~Hz}\right), 126.5,111.3,107.0,105.3,100.3,59.9\left(\mathrm{q},{ }^{2} J_{\mathrm{C}, \mathrm{F}}=44.8\right.$ $\mathrm{Hz}), 54.9,47.7,41.3,40.5,30.4,27.6,25.6,12.4 ;{ }^{19} \mathrm{~F}$ NMR (376.5 MHz, $\left.\mathrm{CD}_{3} \mathrm{OD}\right) \delta-57.2(\mathrm{~s})$; HRMS (ESI): $m / z$ calcd for $\mathrm{C}_{27} \mathrm{H}_{30} \mathrm{~F}_{3} \mathrm{~N}_{6} \mathrm{O}_{6} \mathrm{~S}[\mathrm{M}+\mathrm{H}]^{+} 623.1900$, found 623.1857 .

S18 was synthesized from TMP according to procedures reported in literature ${ }^{[5]}$. To a solution of $\mathbf{S 1 6}$ (14 mg, $0.04 \mathrm{mmol}$ ) in DMF (4 mL) were added EDCI (15 mg, $0.08 \mathrm{mmol}$ ) and $\mathrm{NEt}_{3}(16 \mu \mathrm{L}, 0.08 \mathrm{mmol})$ under argon atmosphere. The mixture was stirred for $15 \mathrm{~min}$, and $\mathbf{S 1 7}$ (46 mg, $0.08 \mathrm{mmol}$ ) was added. The resulting mixture was stirred for further $12 \mathrm{~h}$ at room temperature. The reaction was then concentrated in vacuo and was purified by silica gel column chromatography $\left(10 \% \mathrm{MeOH} / \mathrm{CH}_{2} \mathrm{Cl}_{2}\right)$ to afford $4(19 \mathrm{mg}, 58 \%)$ as a yellow oil. ${ }^{1} \mathrm{H} \mathrm{NMR}(500$ $\left.\mathrm{MHz}, \mathrm{CD}_{3} \mathrm{OD}\right) \delta 7.53(\mathrm{~d}, J=9.2 \mathrm{~Hz}, 1 \mathrm{H}), 7.21(\mathrm{~d}, J=5.1 \mathrm{~Hz}, 1 \mathrm{H}), 6.75(\mathrm{dd}, J=9.2,2.4 \mathrm{~Hz}$, $1 \mathrm{H}), 6.58-6.52(\mathrm{~m}, 3 \mathrm{H}), 5.99(\mathrm{~s}, 1 \mathrm{H}), 4.05(\mathrm{~s}, 2 \mathrm{H}), 3.91(\mathrm{t}, J=6.1 \mathrm{~Hz}, 2 \mathrm{H}), 3.79(\mathrm{~s}, 6 \mathrm{H}), 3.64$ (s, 2H), $3.58(\mathrm{q}, J=7.4 \mathrm{~Hz}, 2 \mathrm{H}), 3.21(\mathrm{t}, J=6.9 \mathrm{~Hz}, 2 \mathrm{H}), 3.14(\mathrm{t}, J=6.9 \mathrm{~Hz}, 2 \mathrm{H}), 2.24(\mathrm{t}, J=$ $7.3 \mathrm{~Hz}, 2 \mathrm{H}), 1.83-1.75(\mathrm{~m}, 2 \mathrm{H}), 1.66-1.73(\mathrm{~m}, 2 \mathrm{H}), 1.55-1.44(\mathrm{~m}, 4 \mathrm{H}), 1.36-1.26(\mathrm{~m}, 2 \mathrm{H})$, $1.22(\mathrm{t}, J=7.4 \mathrm{~Hz}, 3 \mathrm{H}) ;{ }^{13} \mathrm{C} \mathrm{NMR}\left(125 \mathrm{MHz}, \mathrm{CD}_{3} \mathrm{OD}\right) \delta 176.0,171.7,166.3,162.4,157.3$, $156.1,155.1,153.3,140.9,140.3,137.2,133.7,133.6,127.6,126.9,126.2$ (q, $\left.{ }^{1} J_{\mathrm{C}, \mathrm{F}}=270.3 \mathrm{~Hz}\right)$, 111.1, 111.0, 107.3, 106.7, 105.0, 100.0, 99.5, 74.0, 56.6, 54.7 (q, $\left.{ }^{2} J_{\mathrm{C}, \mathrm{F}}=44.8 \mathrm{~Hz}\right), 54.6,47.5$, $40.3,40.2,36.8,33.9,30.6,30.08,30.06,25.2,23.7,12.1 ;{ }^{19} \mathrm{~F} \mathrm{NMR}\left(470.6 \mathrm{MHz}, \mathrm{CD}_{3} \mathrm{OD}\right) \delta$ -55.2 (s); HRMS (ESI): $m / z$ calcd for $\mathrm{C}_{38} \mathrm{H}_{47} \mathrm{~F}_{3} \mathrm{~N}_{9} \mathrm{O}_{7}[\mathrm{M}+\mathrm{H}]^{+}$798.3551, found 798.3546. 


\section{Appendix}

MS/MS spectra of BSA modification by 1

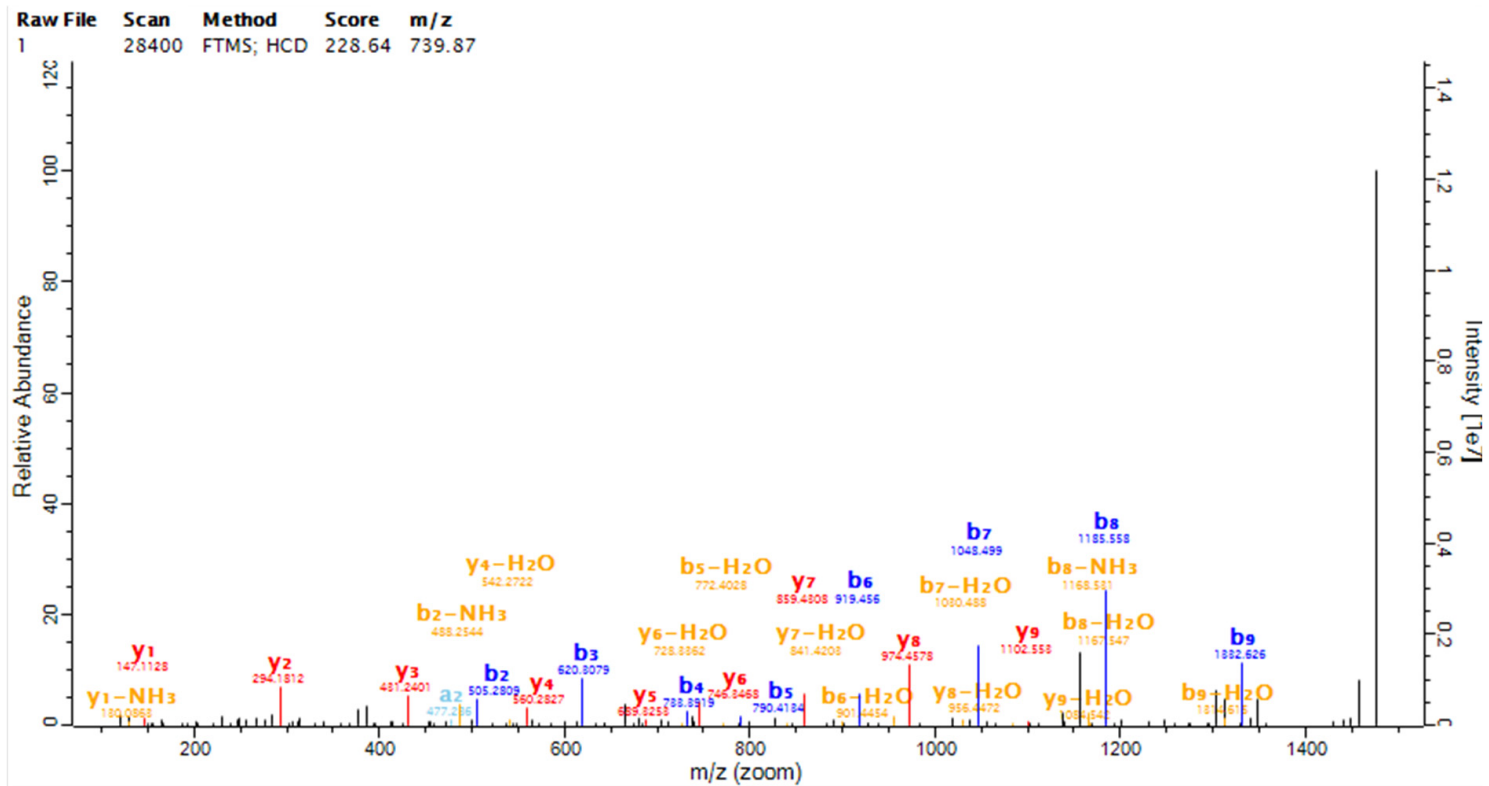

Sequence PSMs Fragments Properties

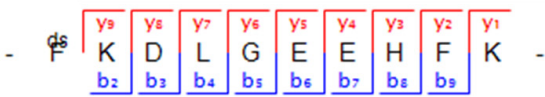

Raw File Scan Method Score $\mathrm{m} / \mathbf{z}$

$\begin{array}{llllll}1 & 27948 & \text { FTMS; HCD } & 201.84 & 739.87\end{array}$

(1)

?-1

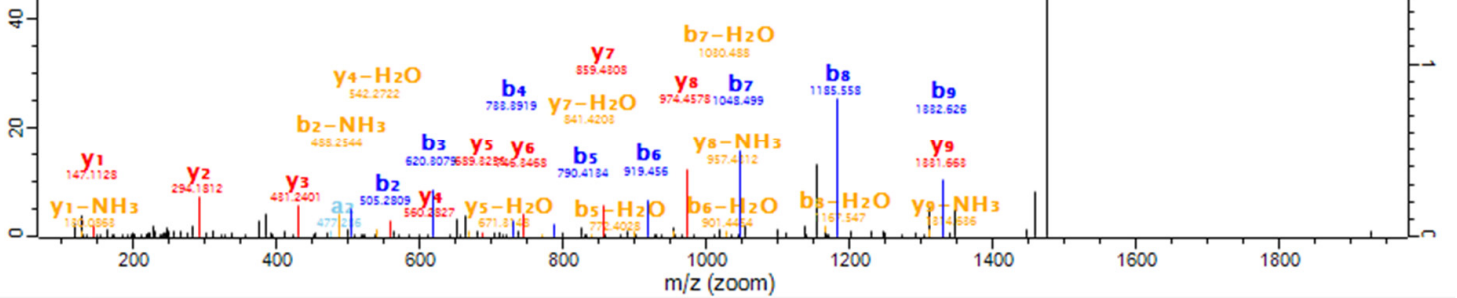

200

Sequence PSMs Fragments Properties

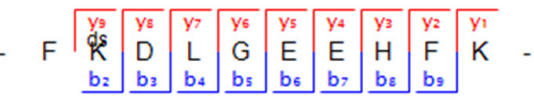




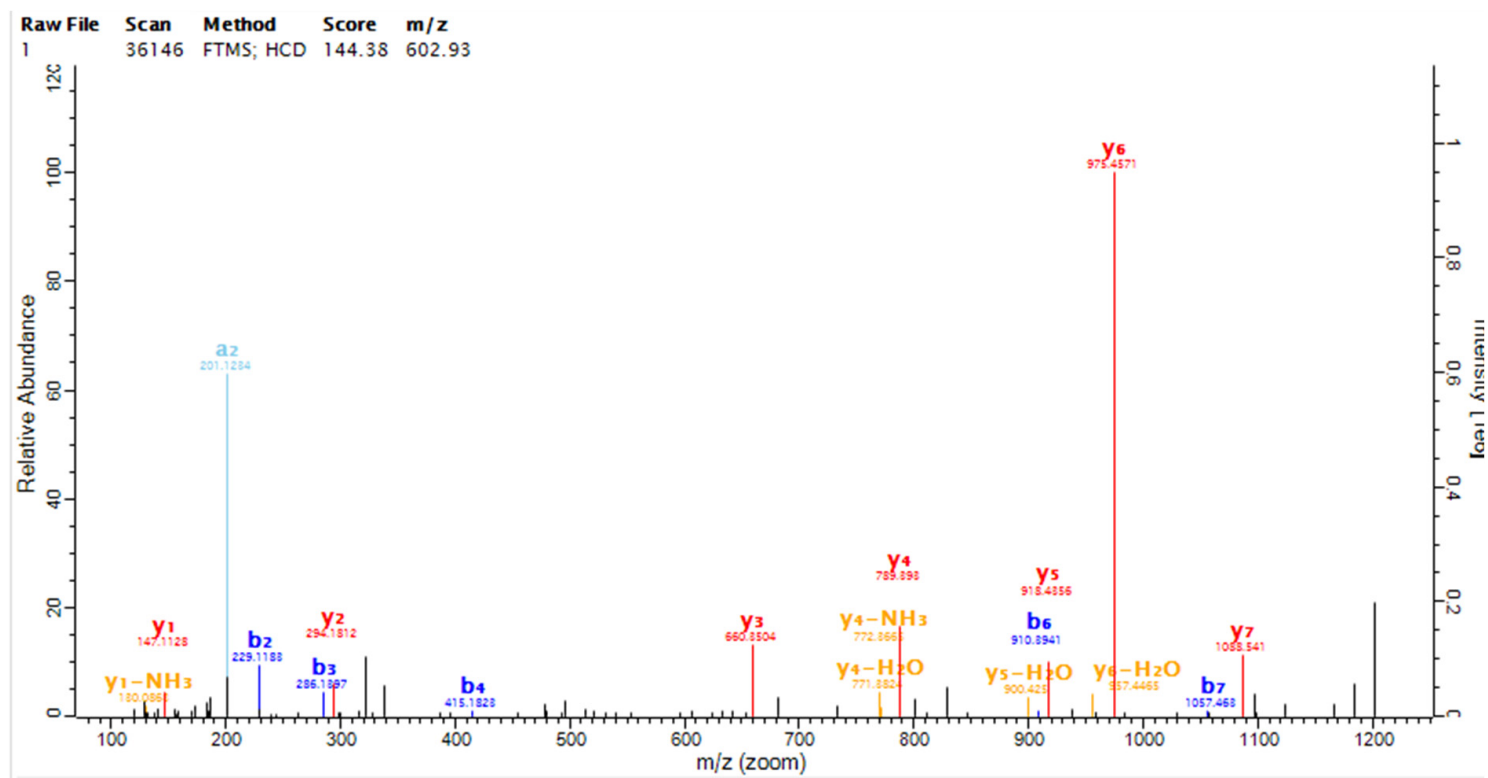

Sequence PSMs Fragments Properties

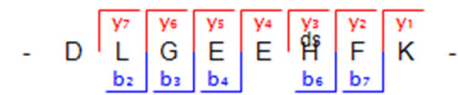

Raw File Scan Method Score $\mathrm{m} / \mathbf{z}$

$\begin{array}{lllll}1 & 42181 & \text { FTMS; HCD } & 169.41 & 696.88\end{array}$

$\stackrel{\check{I}}{\leftrightarrows}$
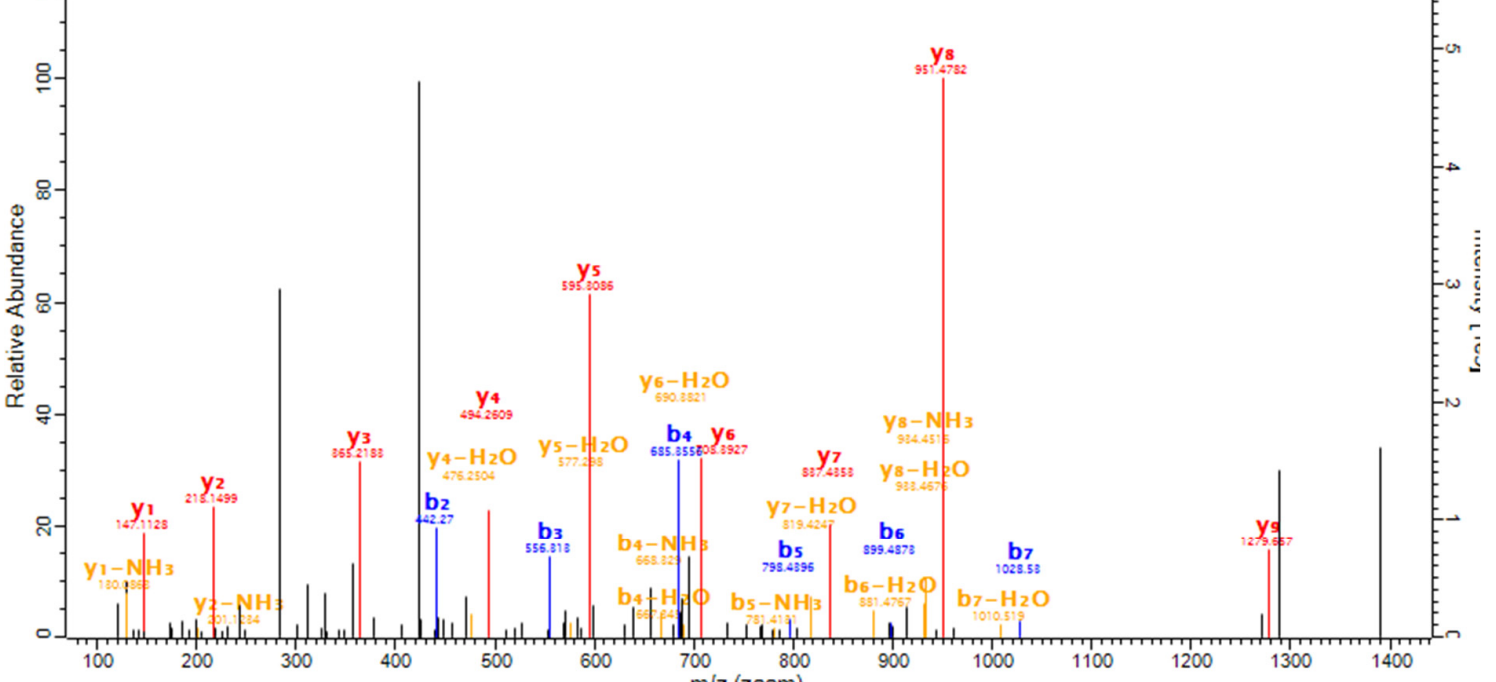

Sequence PSMs Fragments Properties

- L \begin{tabular}{ll|l|l|l|l|l|l|l|ll}
$\mathrm{y}_{9}$ & $\mathrm{y}_{5}$ & $\mathrm{y}_{7}$ & $\mathrm{y}_{6}$ & $\mathrm{y}_{5}$ & $\mathrm{y}_{4}$ & $\mathrm{y}_{3}$ & $\mathrm{y}_{2}$ & $\mathrm{y}_{1}$ & \\
$\mathrm{~V}$ & $\mathrm{E}$ & $\mathrm{L}$ & $\mathrm{T}$ & $\mathrm{E}$ & $\mathrm{F}$ & $\mathrm{A}$ & $\mathrm{K}$ & - \\
$\mathrm{b}_{2}$ & $\mathrm{~b}_{3}$ & $\mathrm{~b}_{4}$ & $\mathrm{~b}_{5}$ & $\mathrm{~b}_{6}$ & $\mathrm{~b}_{7}$ & & &
\end{tabular} 


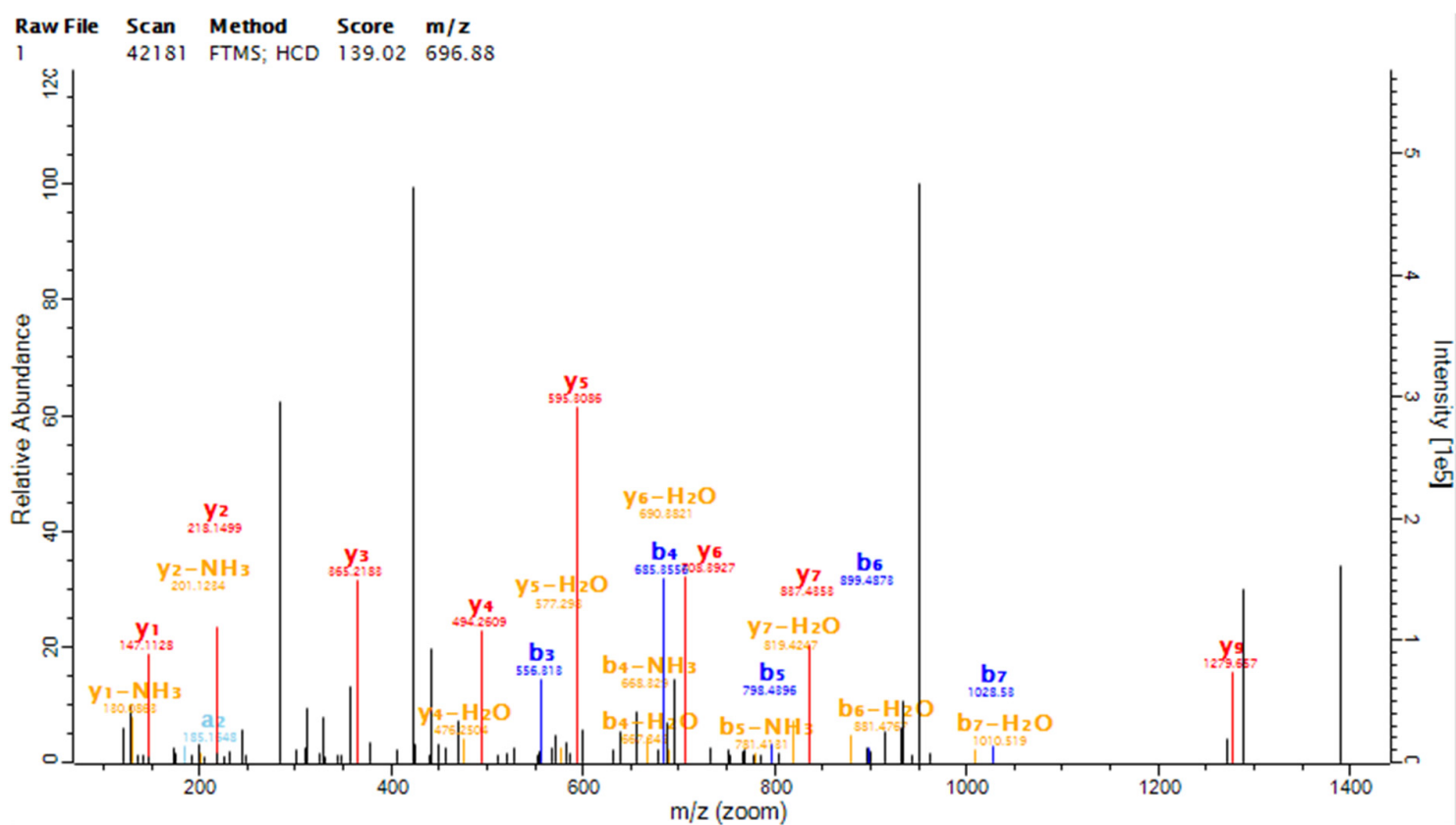

Sequence PSMs Fragments Properties

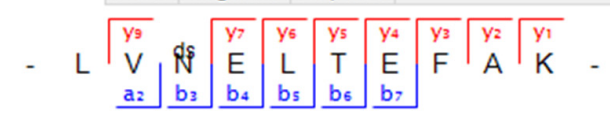

Raw File Scan Method Score $\mathrm{m} / \mathbf{z}$

40688 FTMS; HCD $261.65 \quad 825.41$

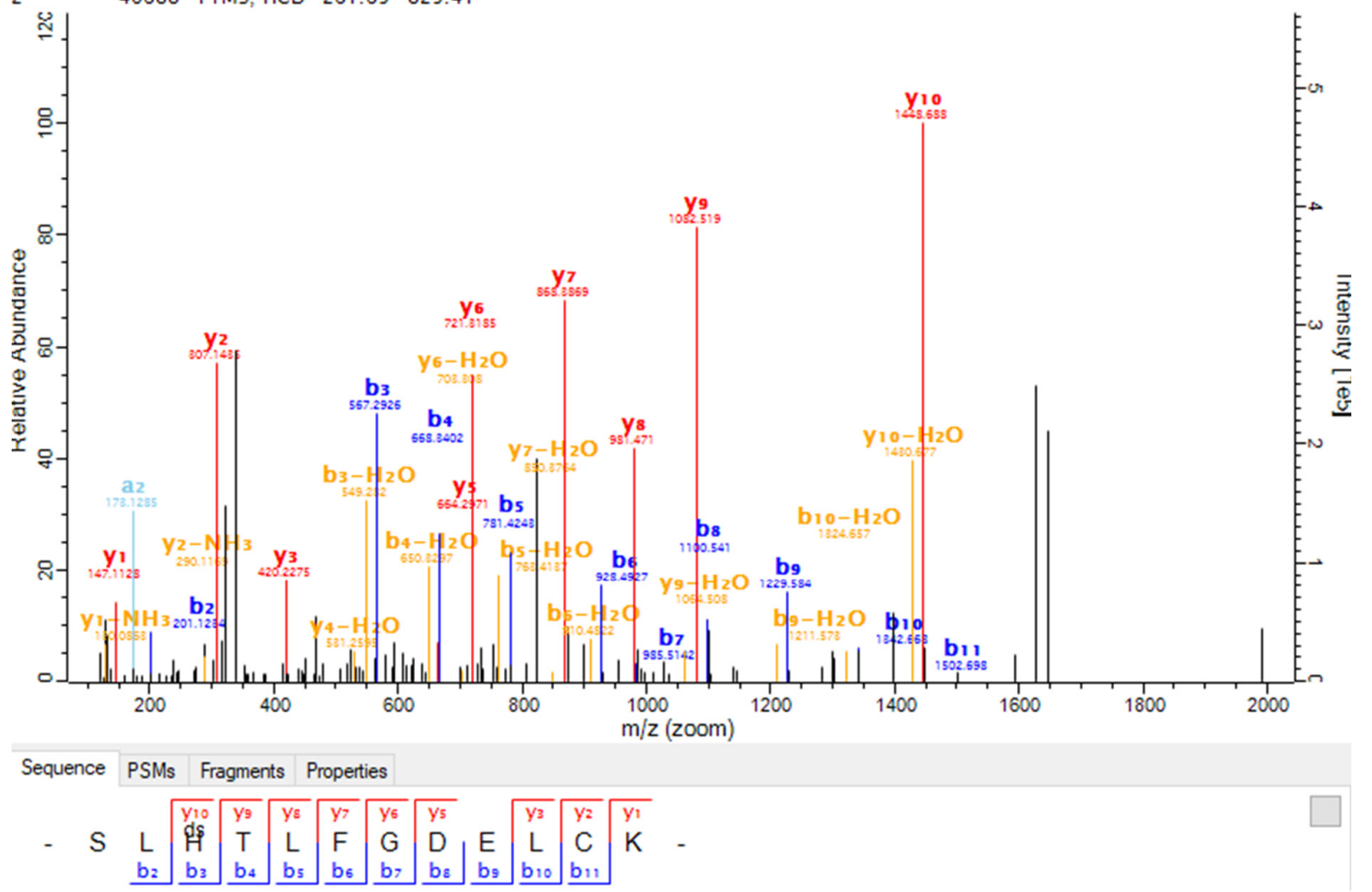




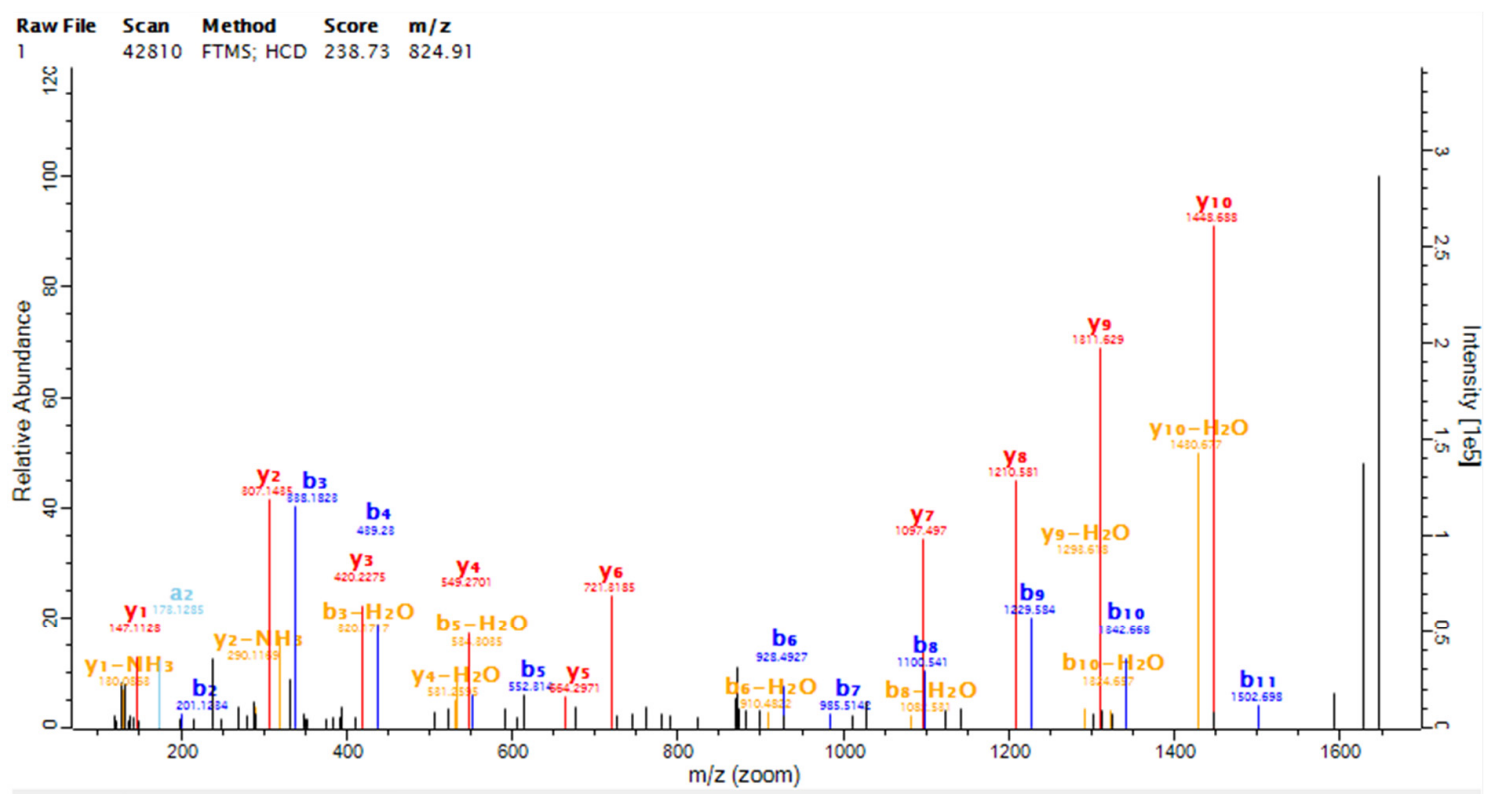

Sequence PSMs Fragments Properties

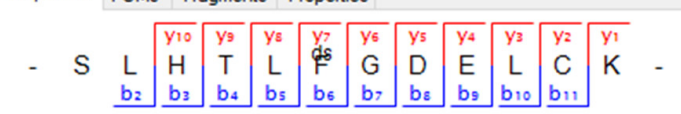

Raw File Scan Method Score $\mathbf{m} / \mathbf{z}$

134923 FTMS; HCD $97.58 \quad 533.75$

$\stackrel{\check{2}}{\check{2}}$
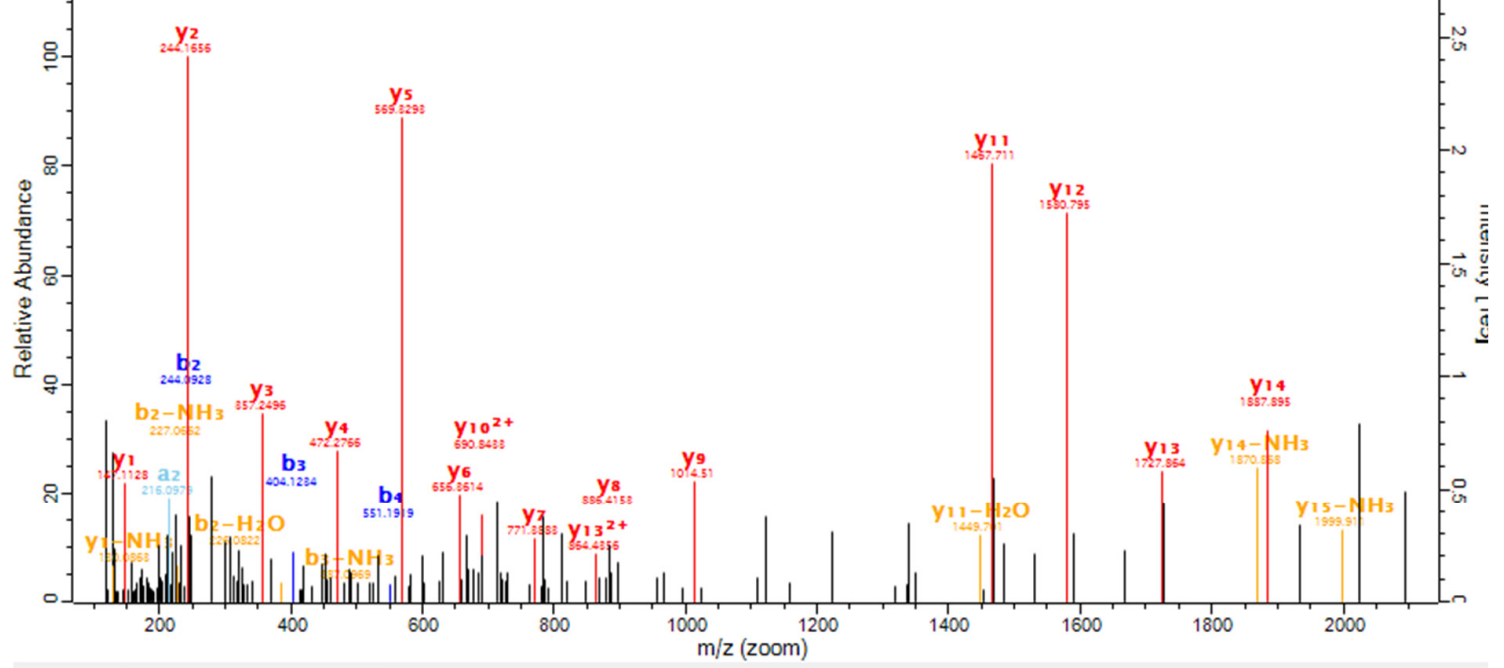

Sequence PSMs Fragments Properties

- N $\begin{array}{lll}E \\ \mathrm{~b}_{2}\end{array}$ 


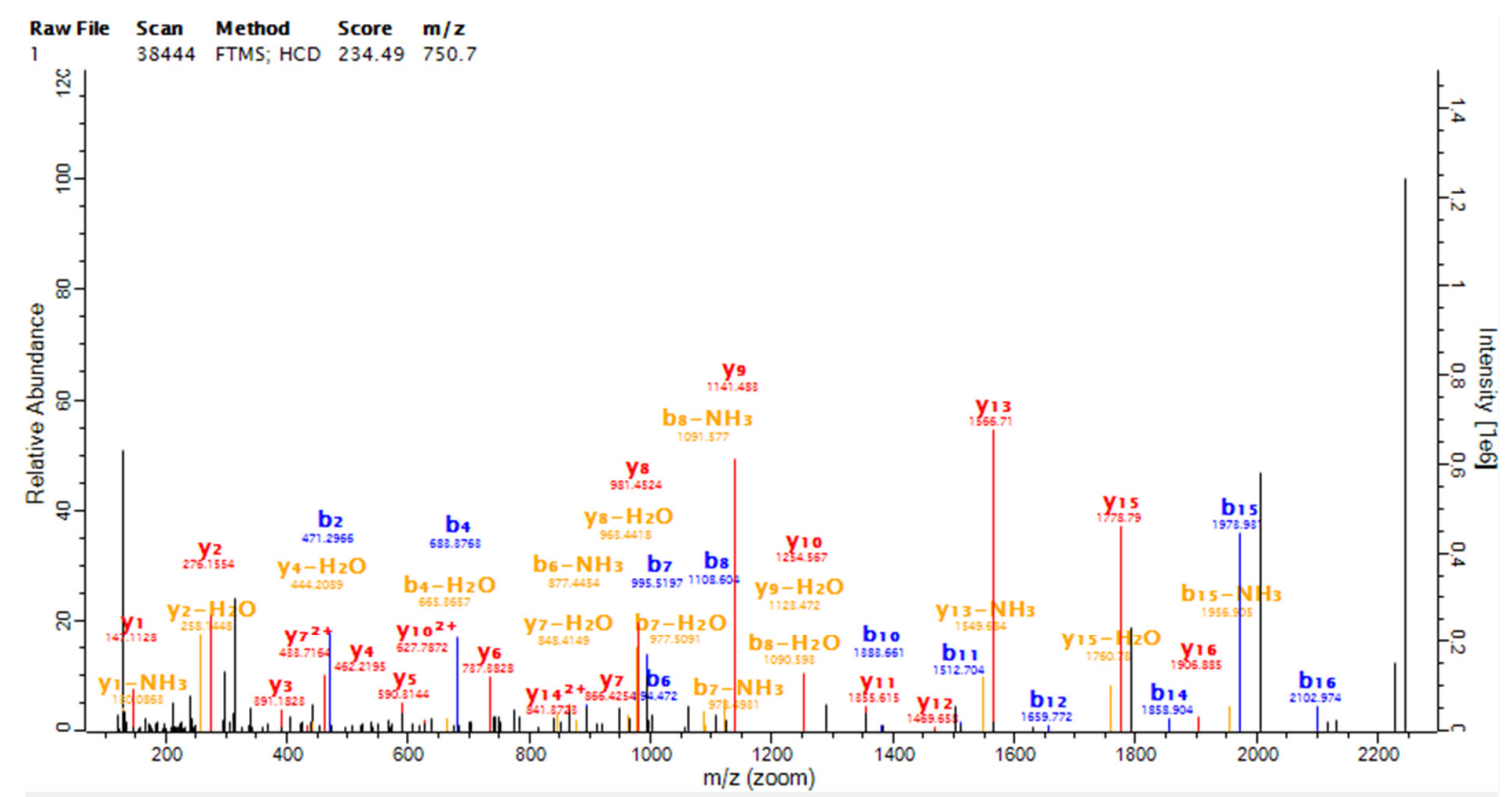

Sequence PSMs Fragments Properties

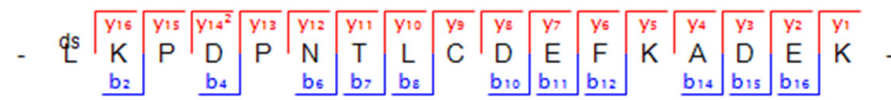

Raw File Scan Method Score $\mathbf{m} / \mathbf{z}$

$14 \quad 40083$ FTMS; HCD $182.33 \quad 602.63$

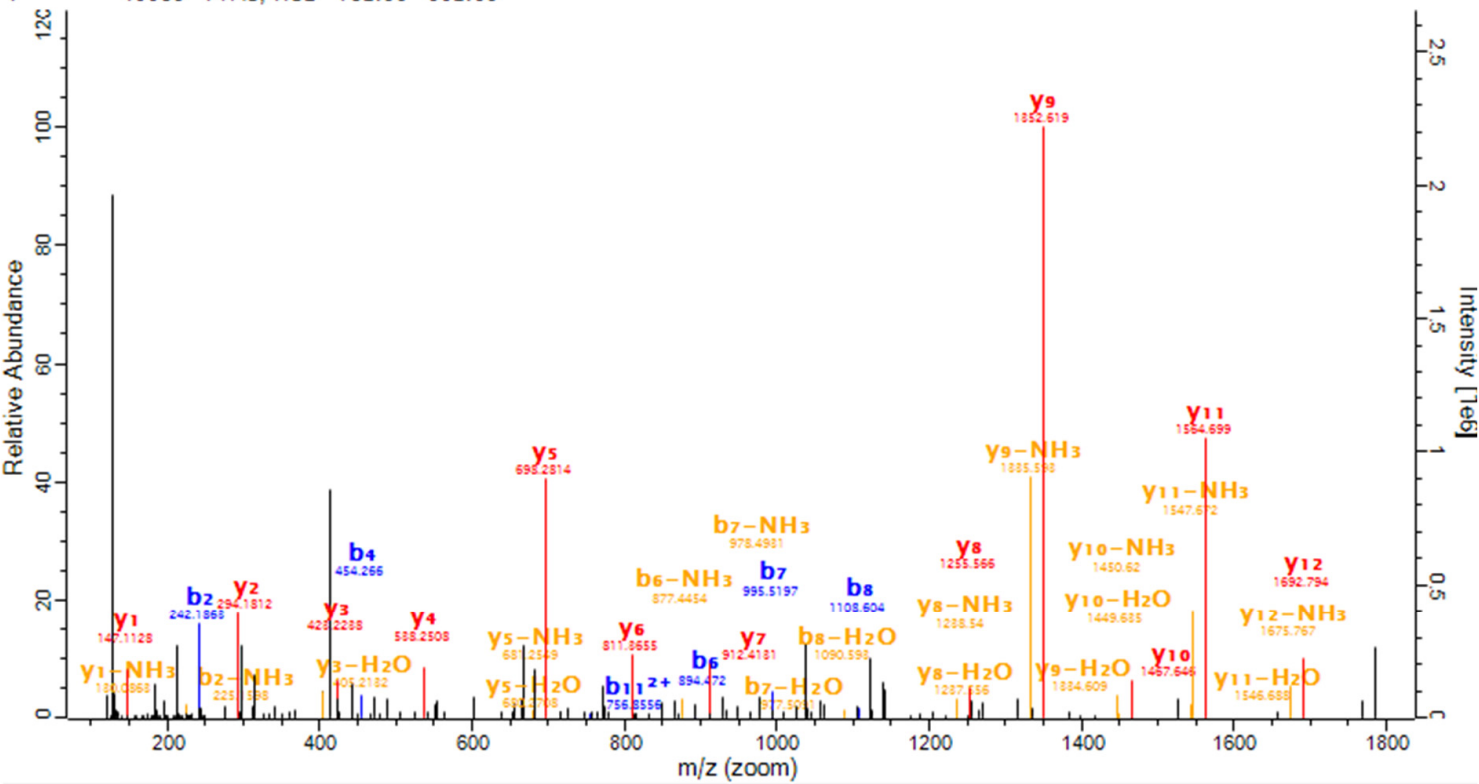

Sequence PSMs Fragments Properties

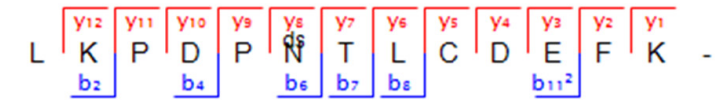



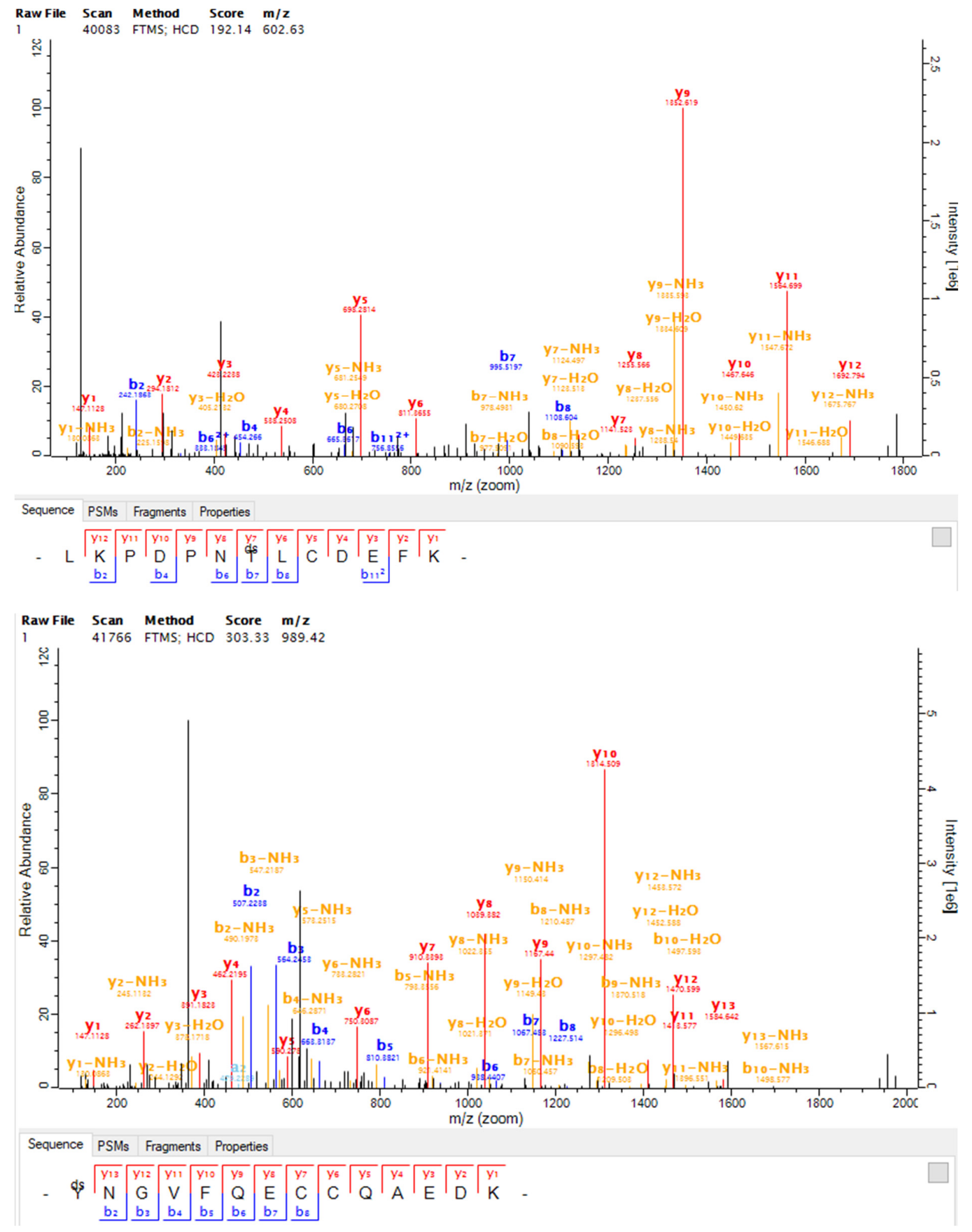


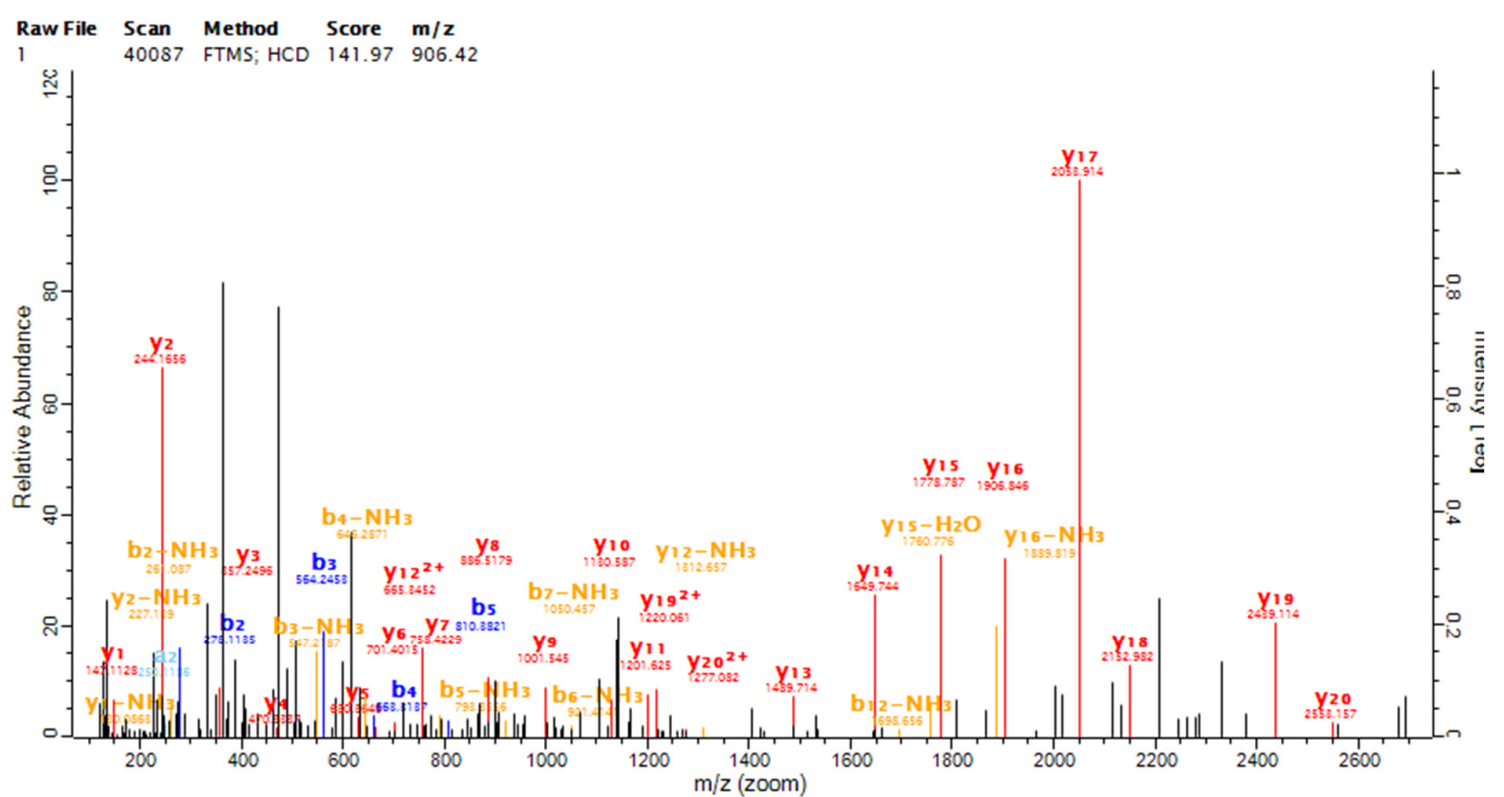

Sequence PSMs Fragments Properties

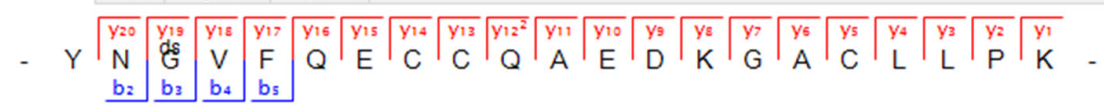

Raw File Scan Method Score $\mathbf{m} / \mathbf{z}$

$139941 \quad$ FTMS; HCD $234.65 \quad 989.49$

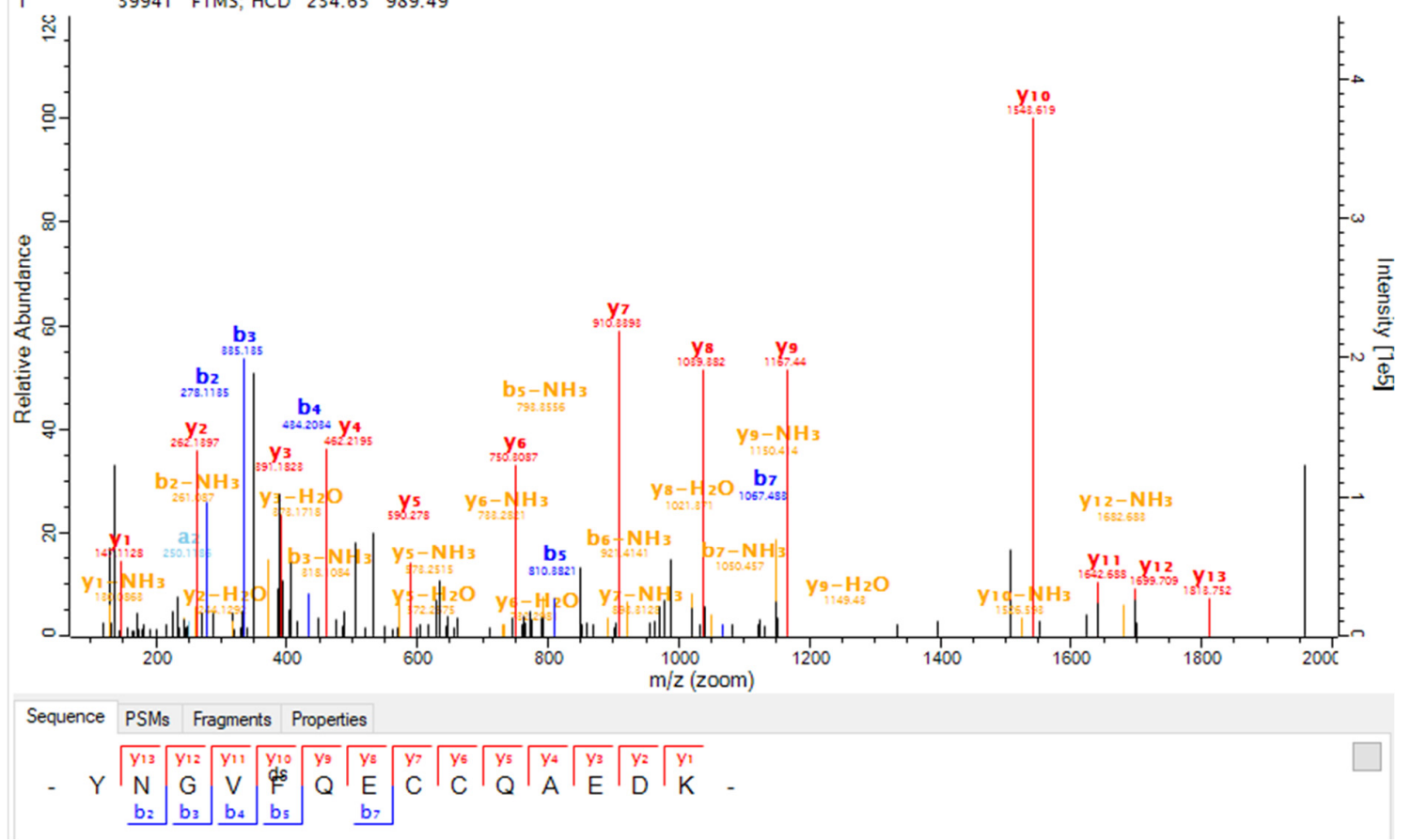




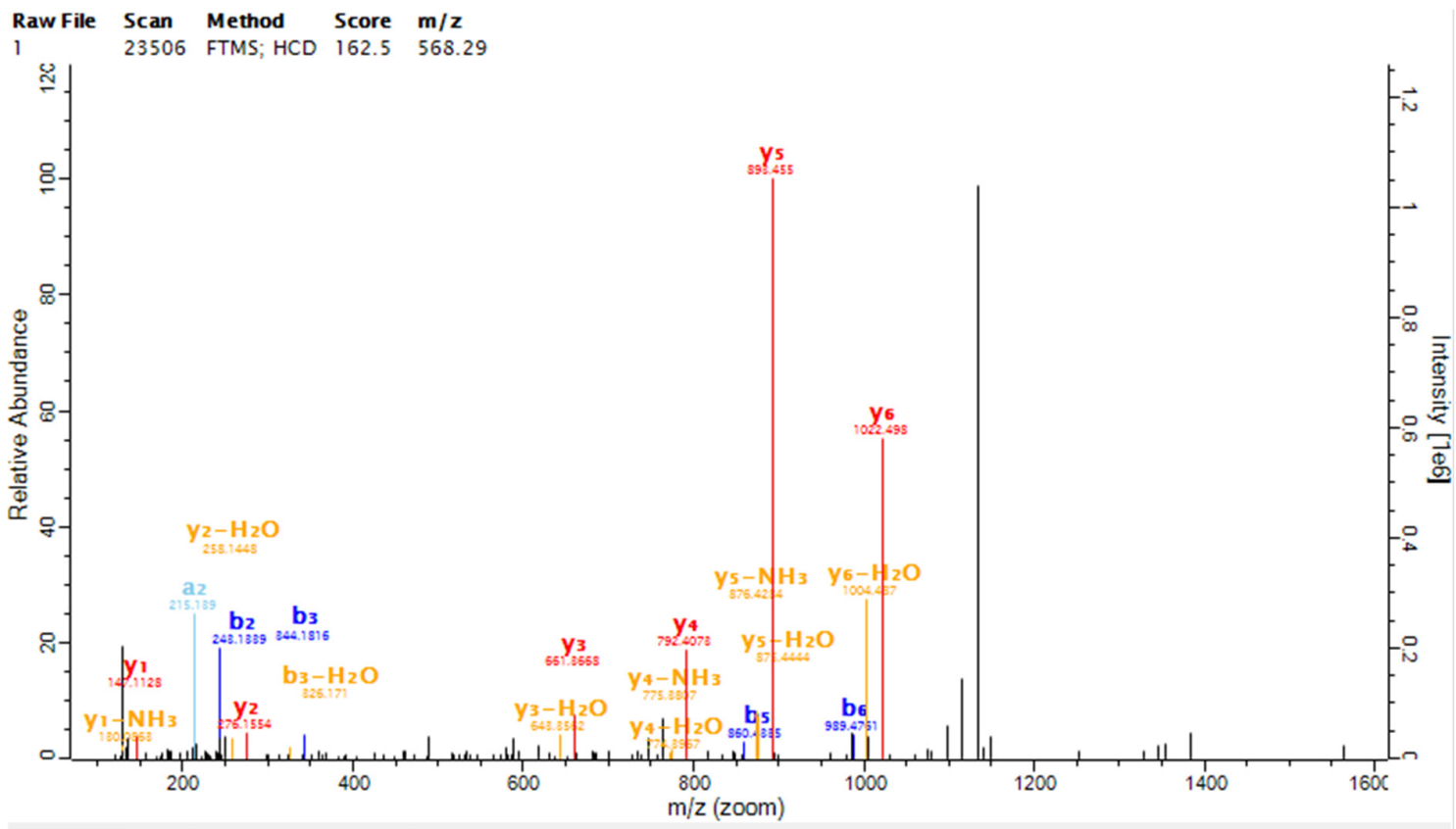

Sequence PSMs Fragments Properties

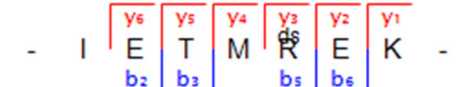

Raw File Scan Method Score $\mathrm{m} / \mathbf{z}$

$\begin{array}{lllll}1 & 23155 & \text { FTMS; HCD } & 163.72 & 602.83\end{array}$

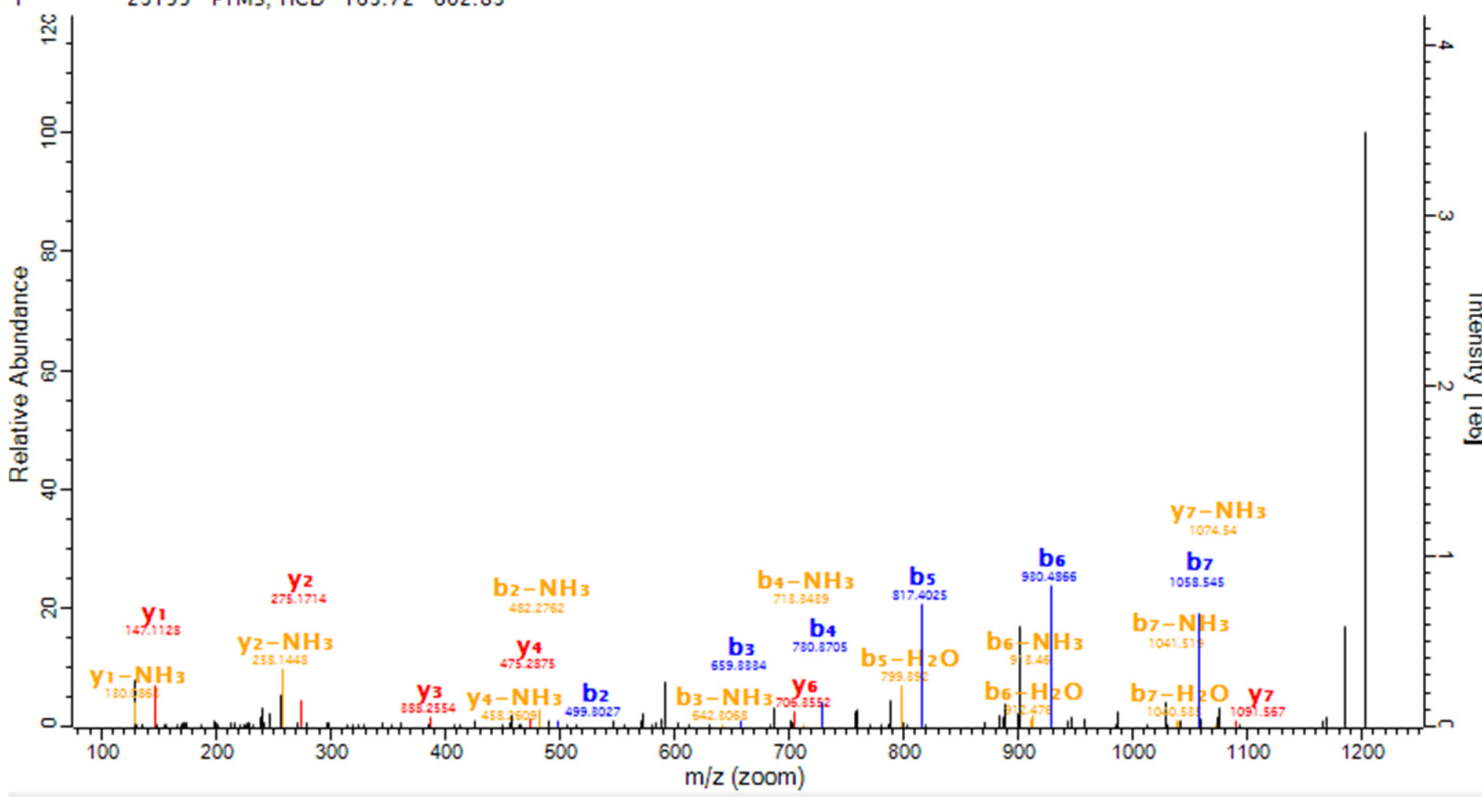

Sequence PSMs Fragments Properties

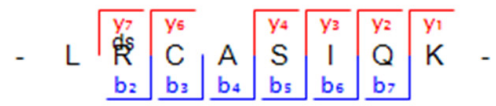




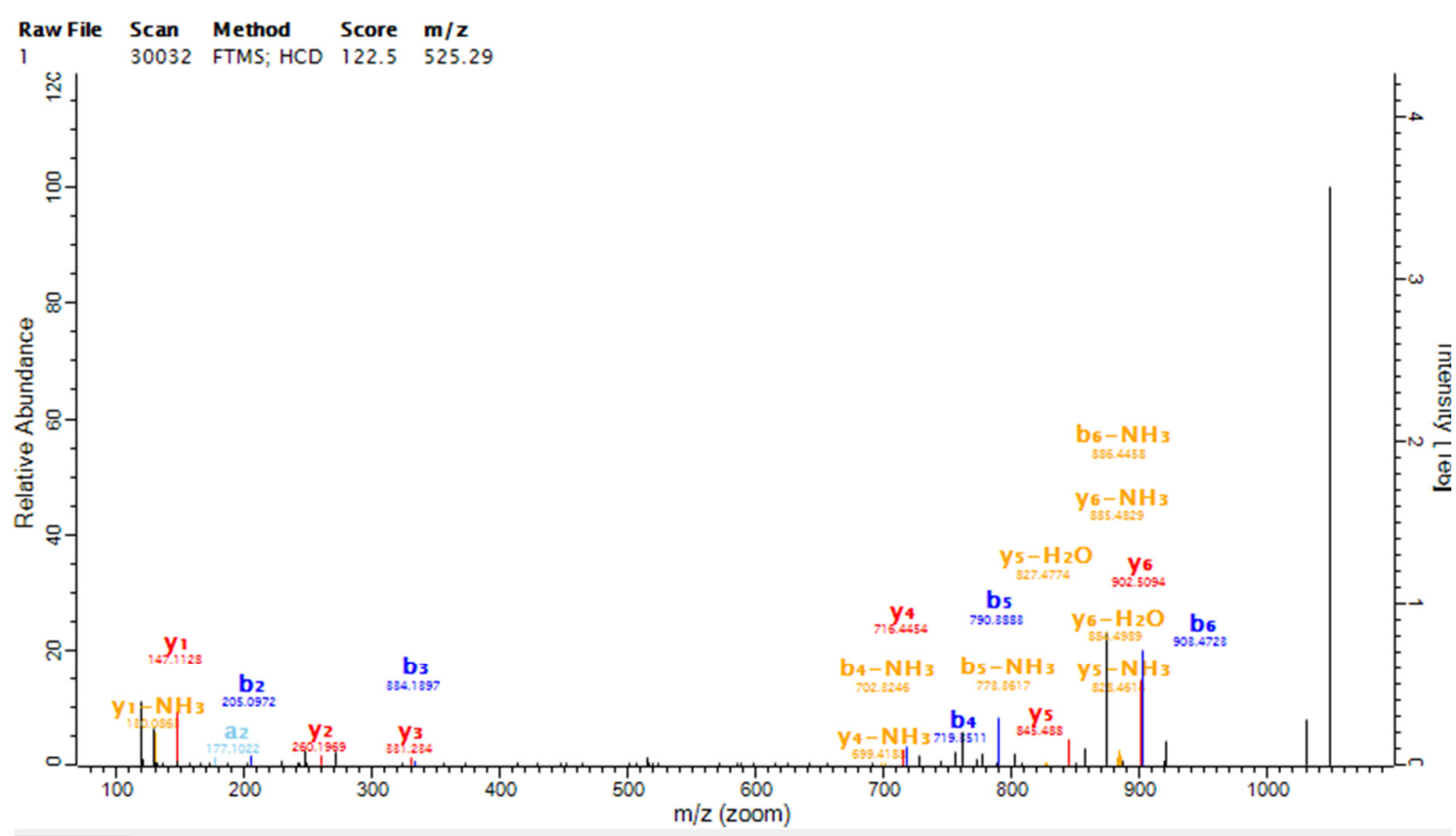

Sequence PSMs Fragments Properties

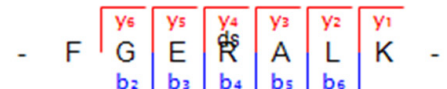

Raw File Scan Method Score $\mathrm{m} / \mathbf{z}$

139926 FTMS; HCD $195.05 \quad 615.85$

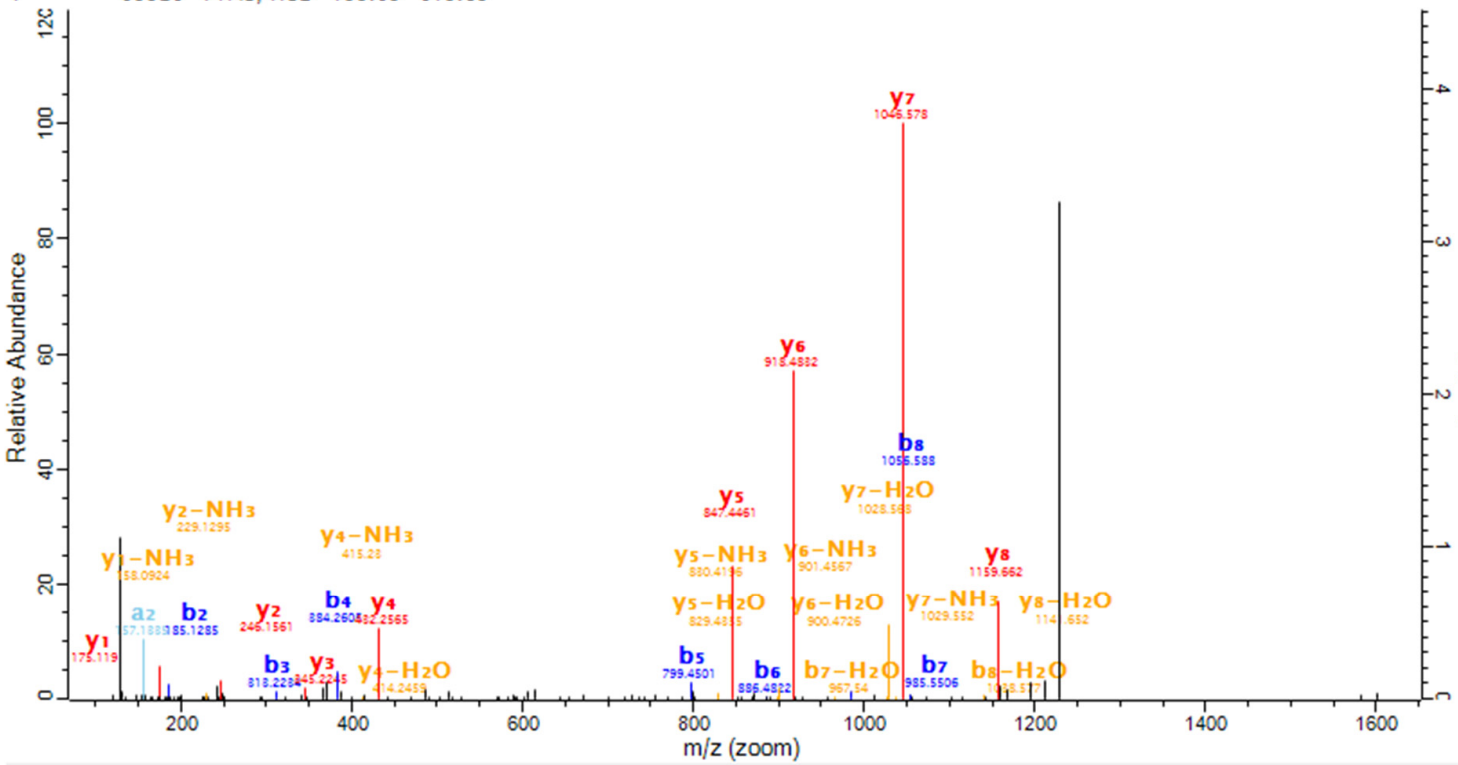

Sequence PSMs Fragments Properties

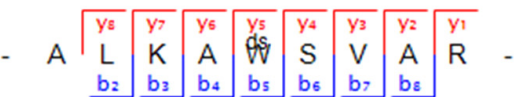




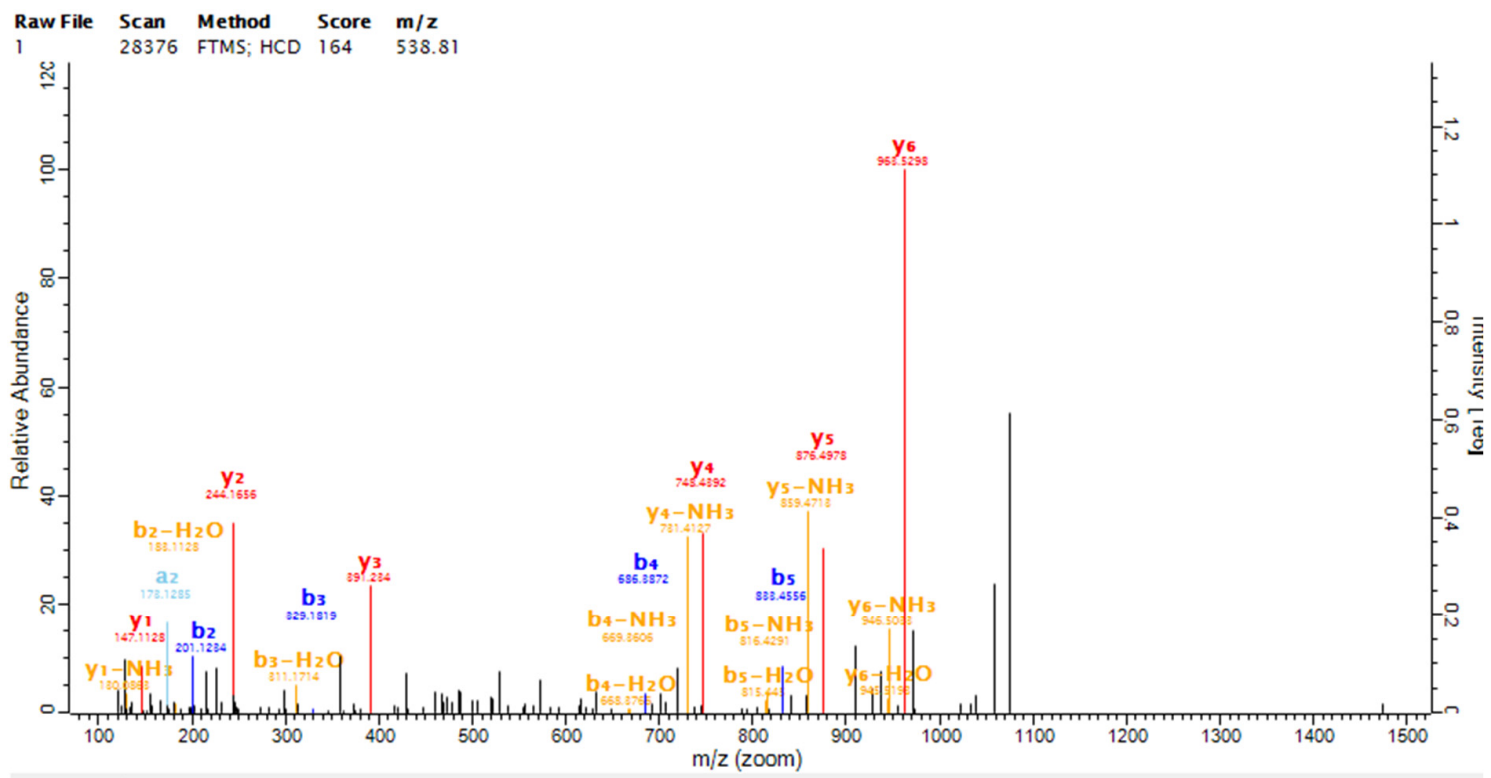

Sequence PSMs Fragments Properties

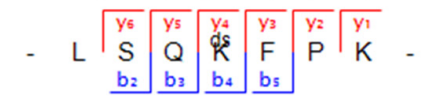
$\begin{array}{lllll}\text { Raw File } & \text { Scan } & \text { Method } & \text { Score } & \mathbf{m} / \mathbf{z} \\ 1 & 22350 & \text { FTMS; HCD } & 204.78 & 782.01\end{array}$

$\stackrel{\mathscr{J}}{\dddot{1}}$

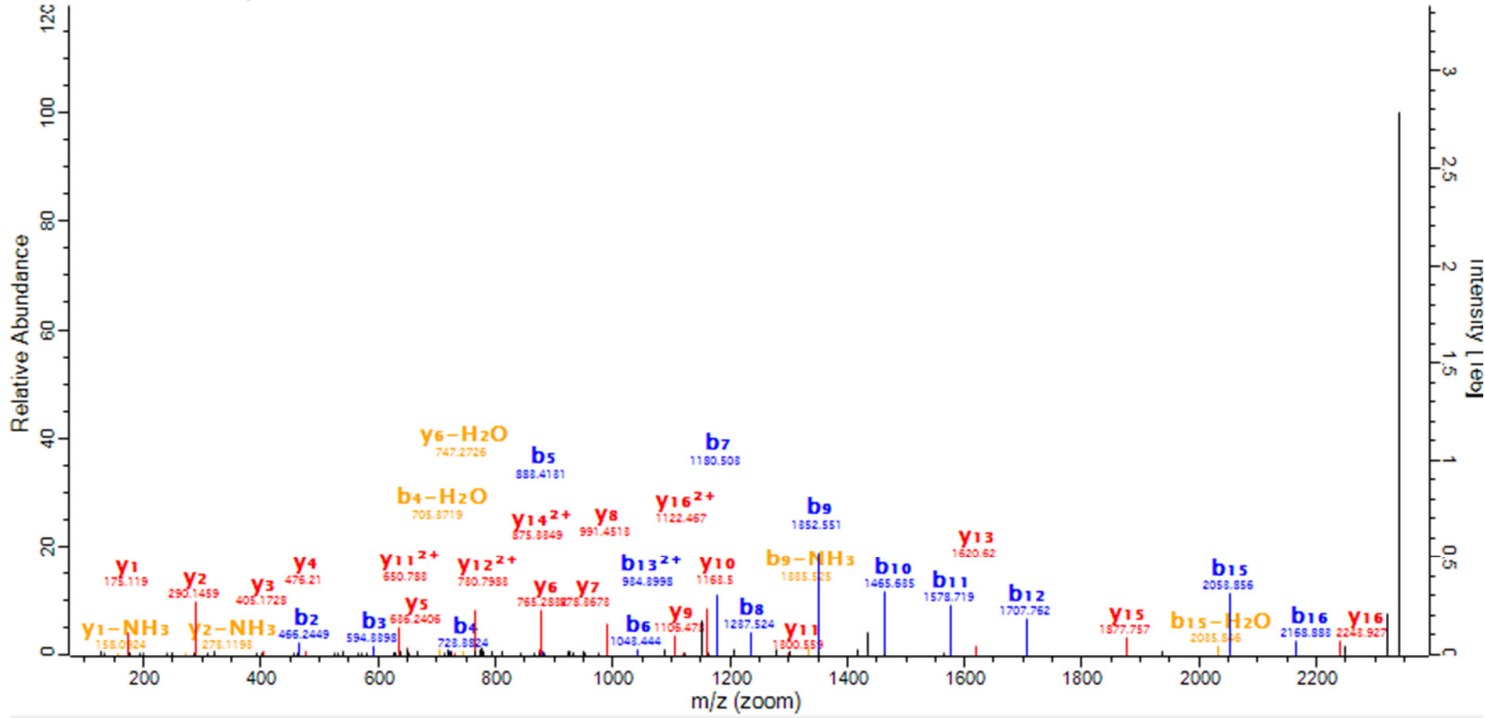

Sequence PSMs Fragments Properties

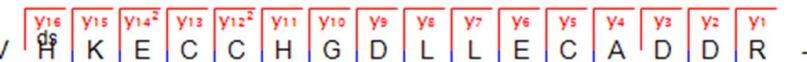

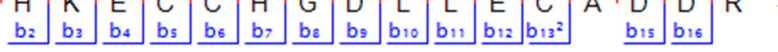




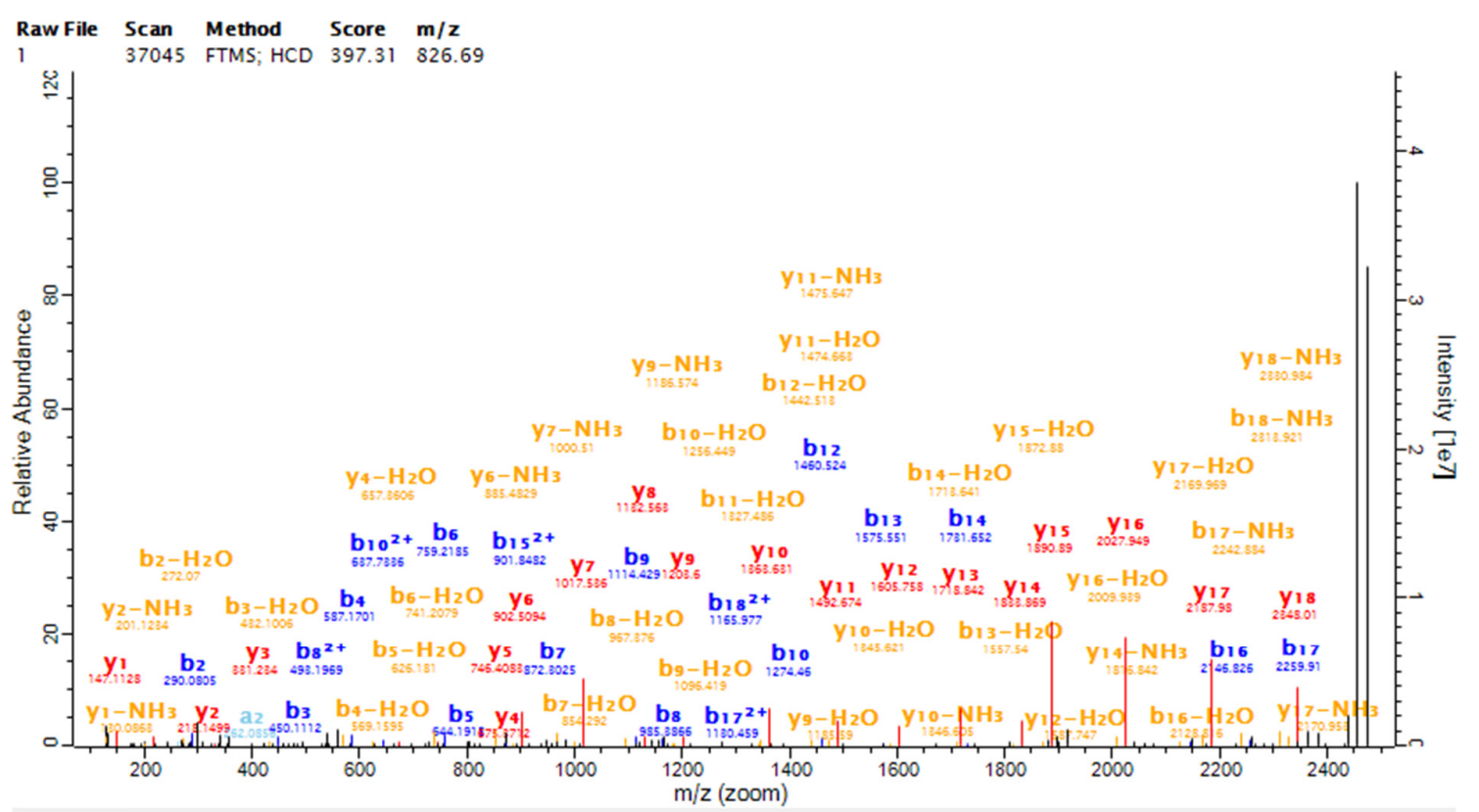

Sequence PSMs Fragments Properties

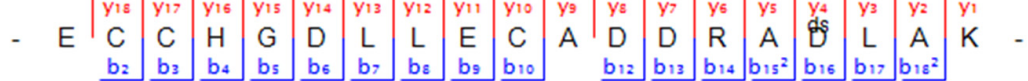

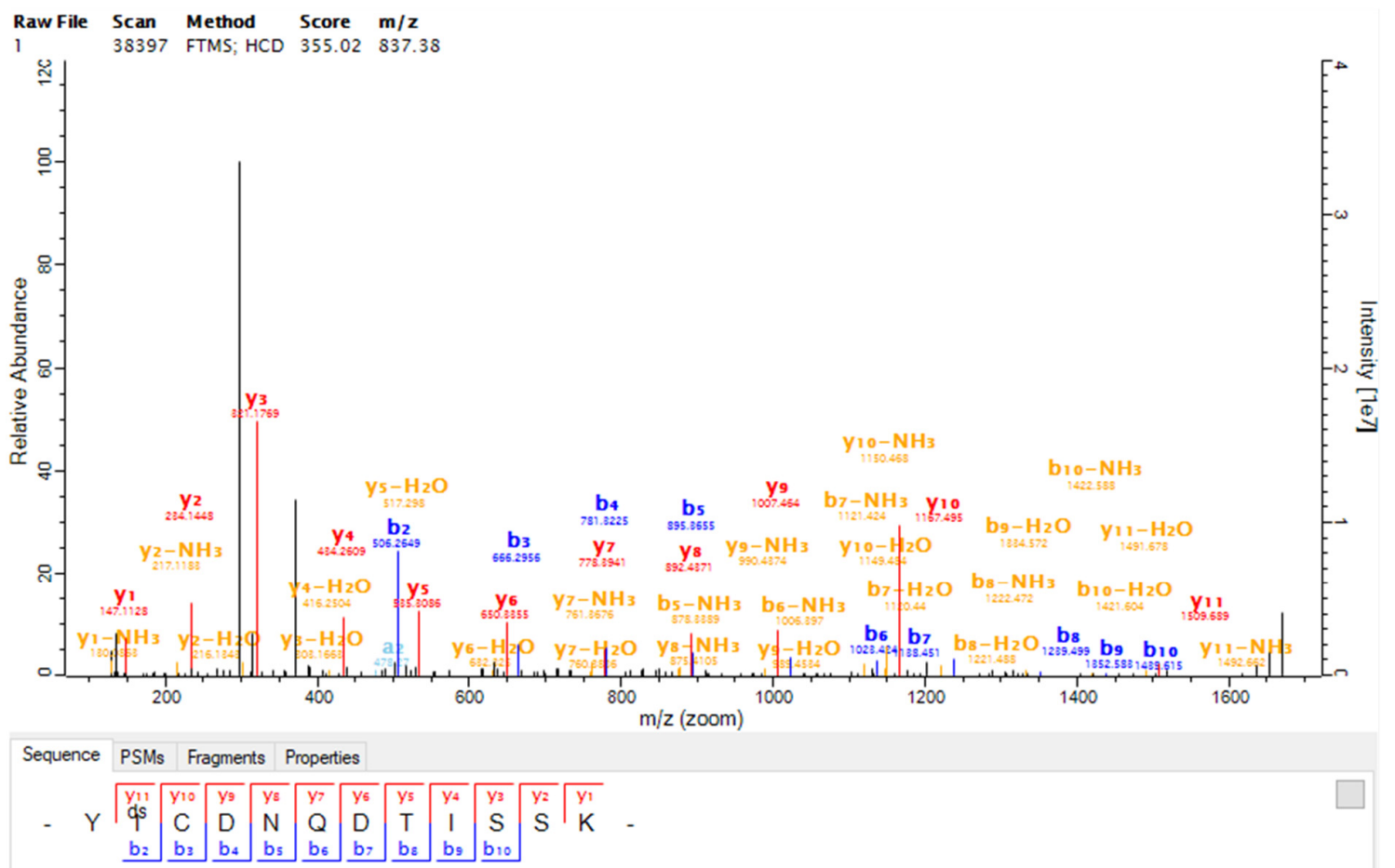




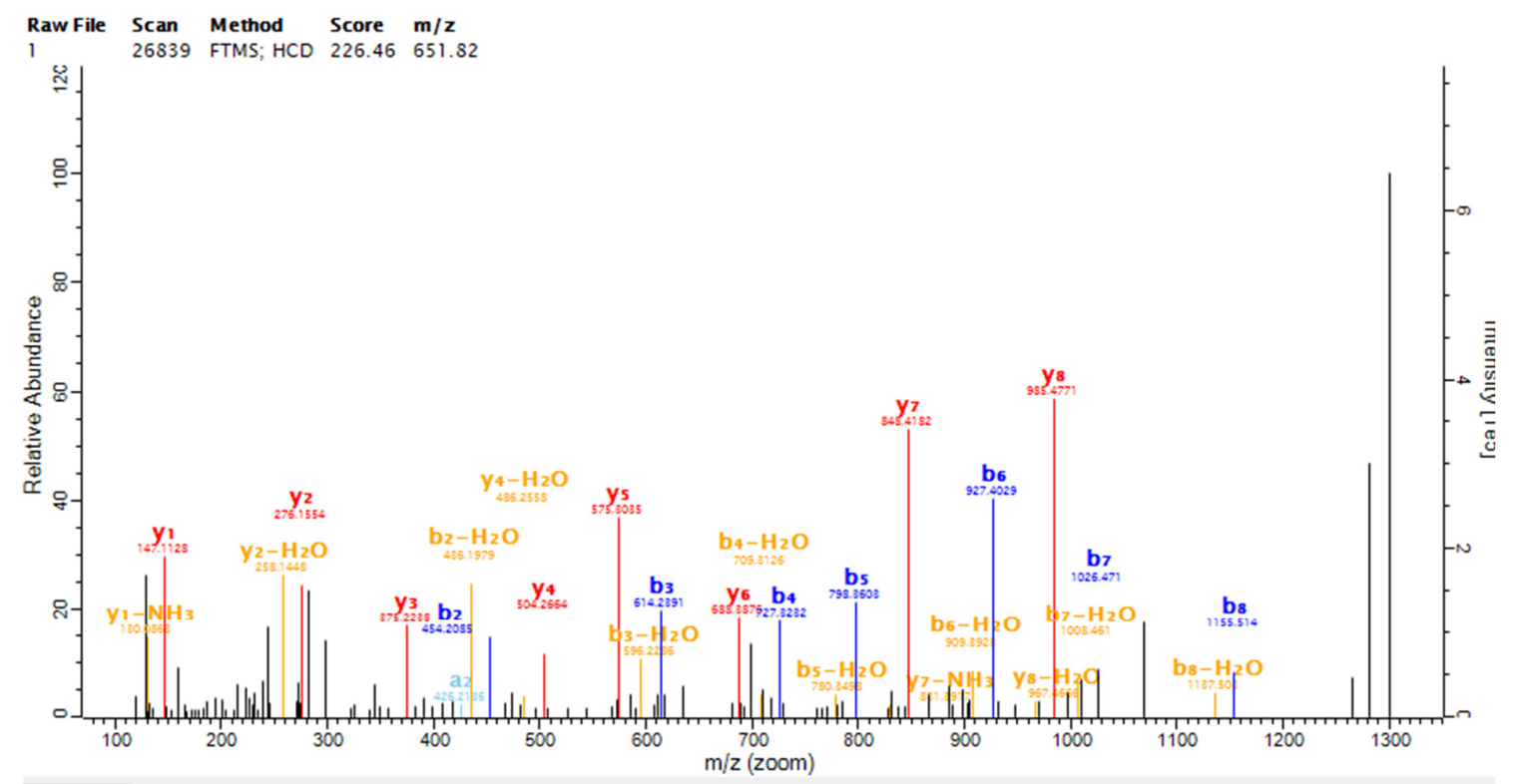

Sequence PSMs Fragments Properties

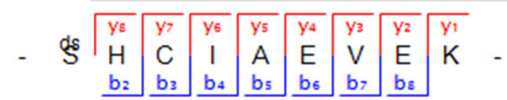

Raw File Scan Method Score $\mathrm{m} / \mathbf{z}$

$\begin{array}{lllll}1 & 32066 & \text { FTMS; HCD } & 223.88 & 651.31\end{array}$
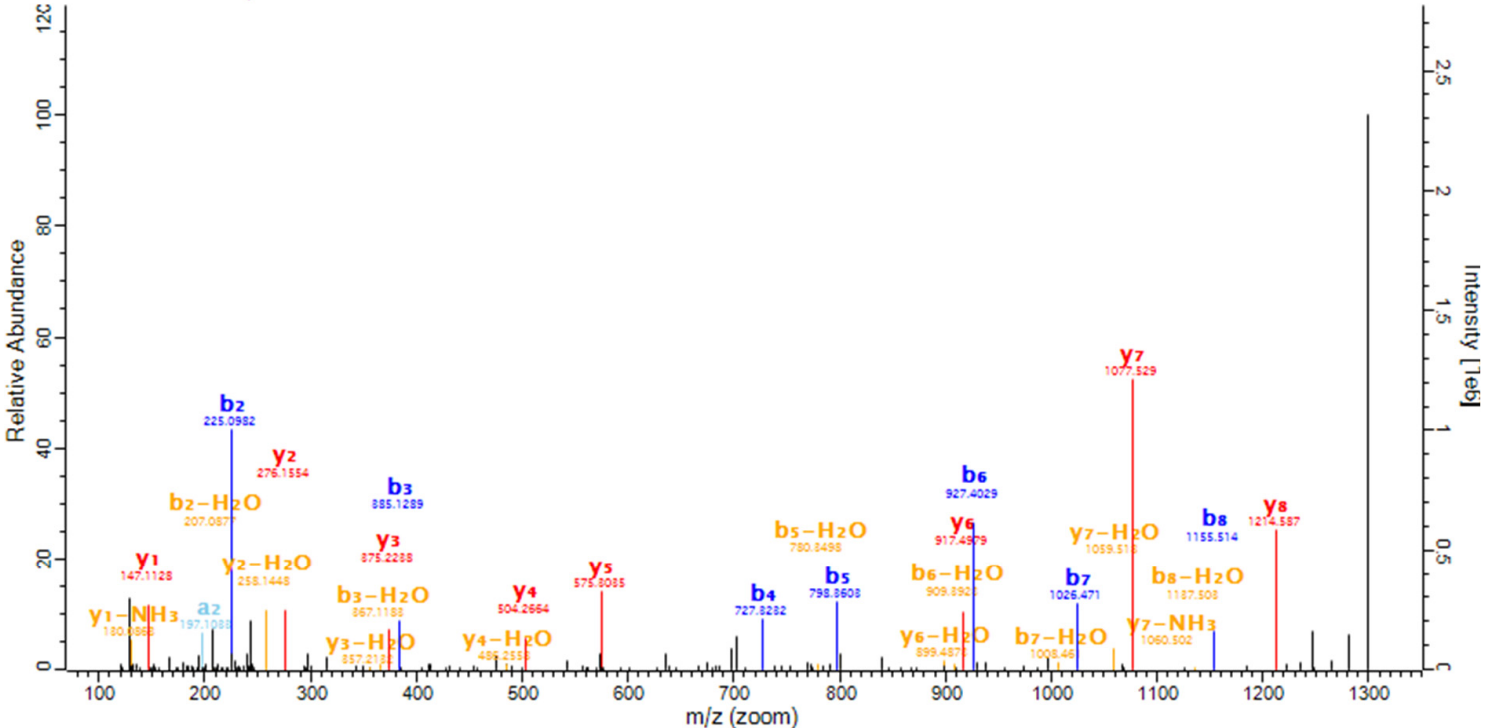

Sequence PSMs Fragments Properties

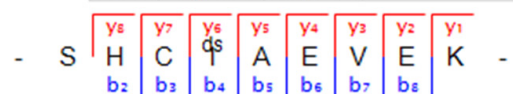



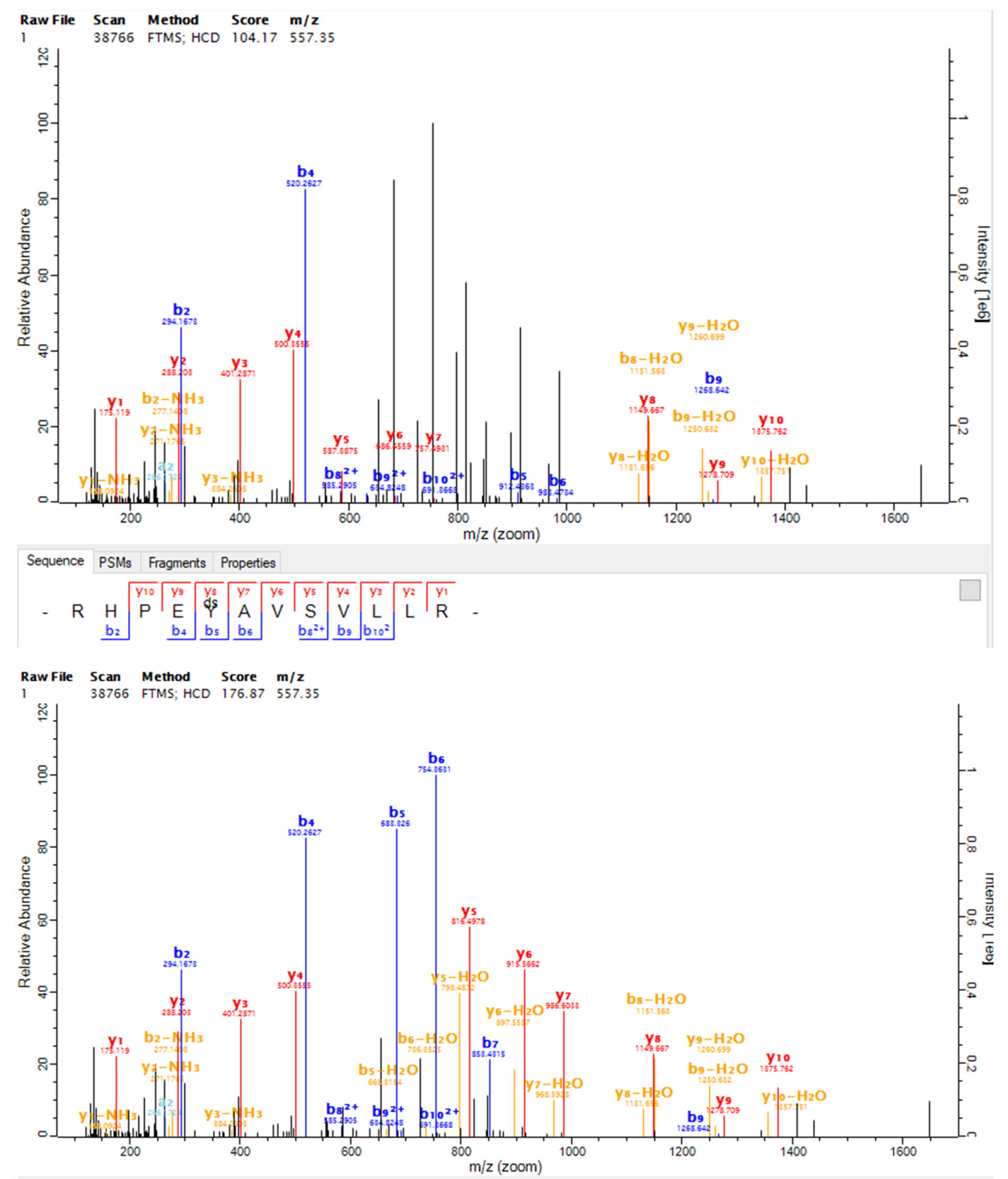

Sequence PSMs Fragments Properties

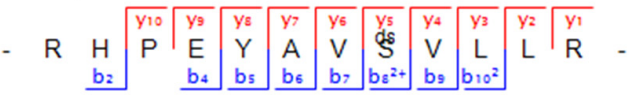




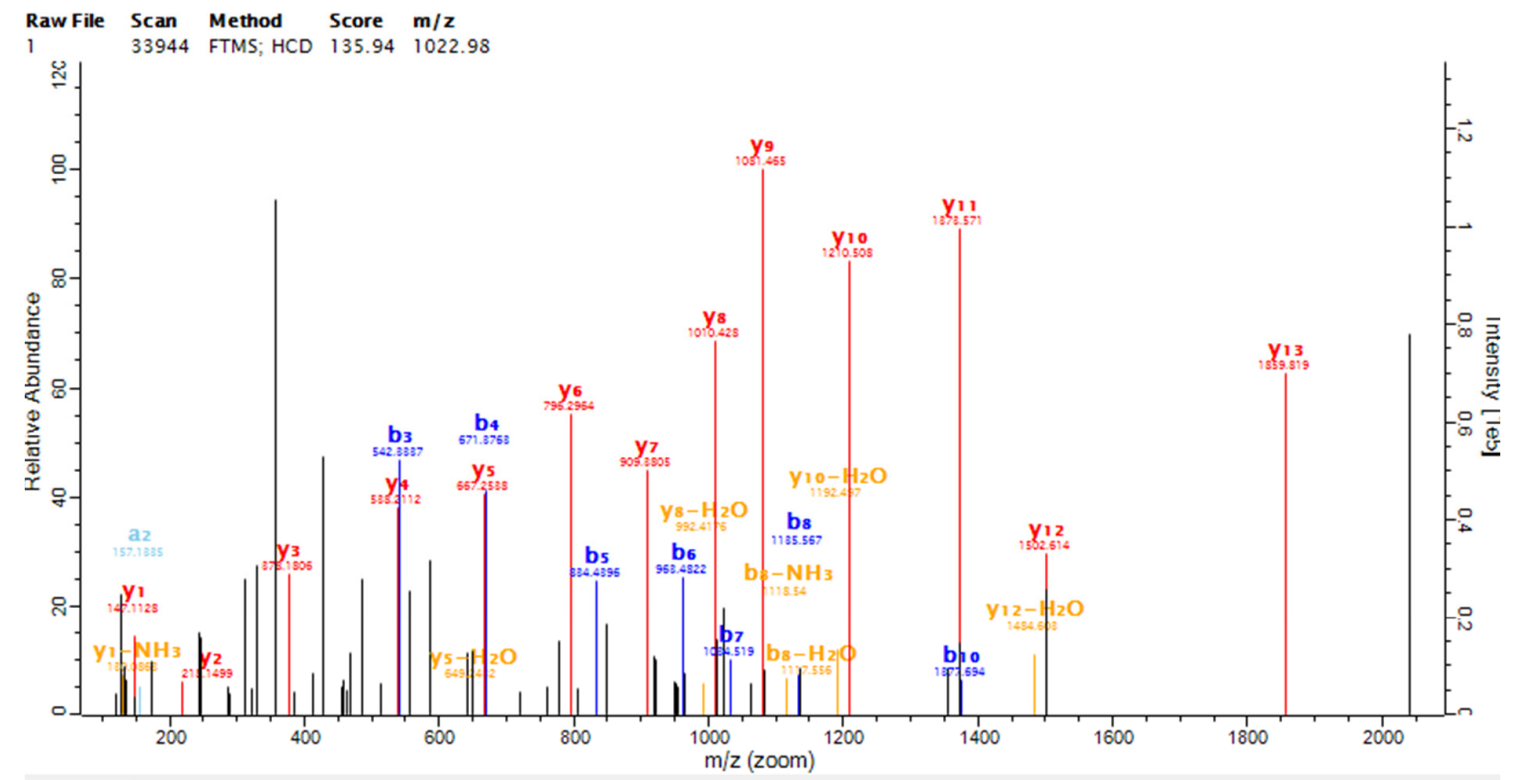

Sequence PSMs Fragments Properties

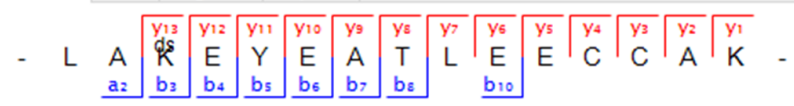

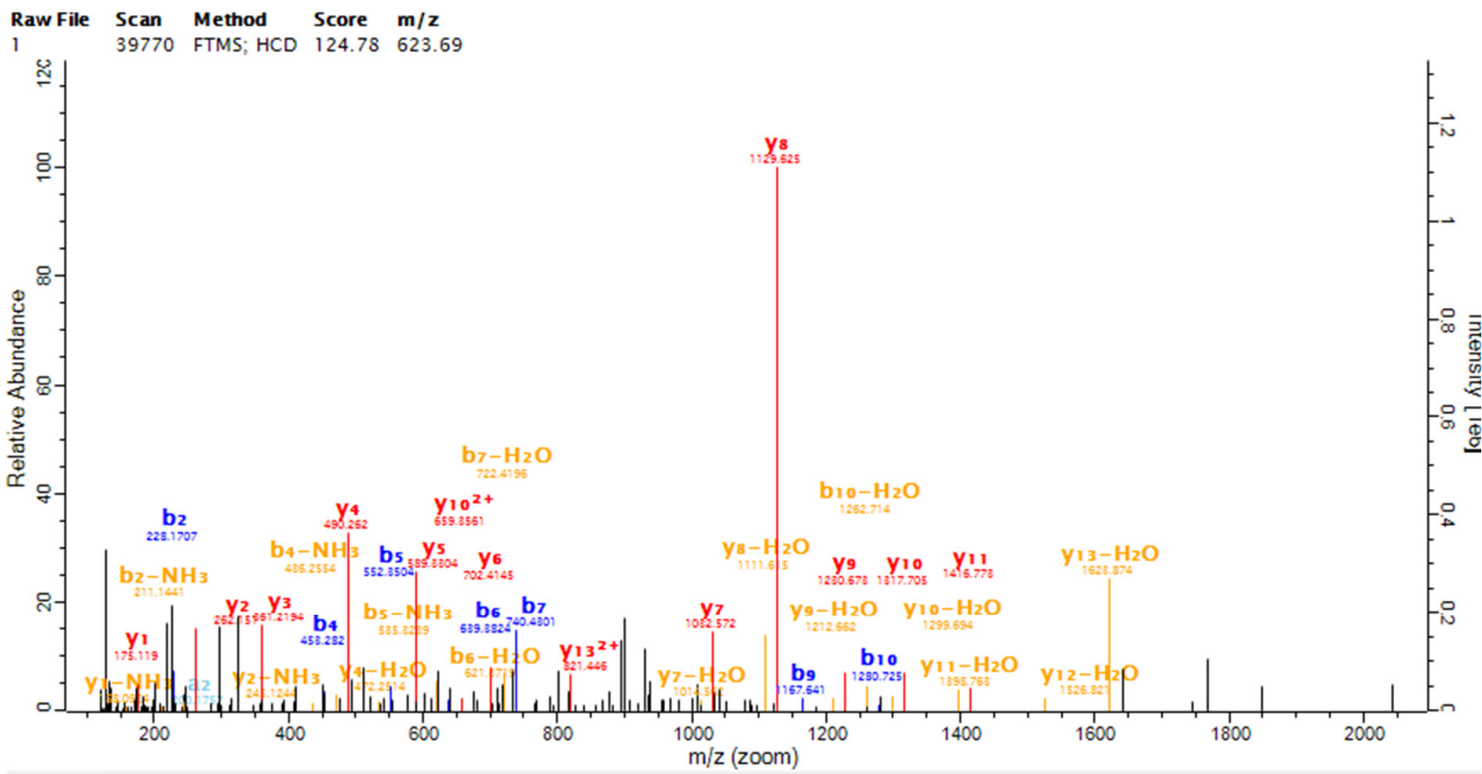

Sequence PSMs Fragments Properties

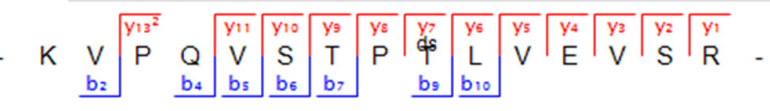




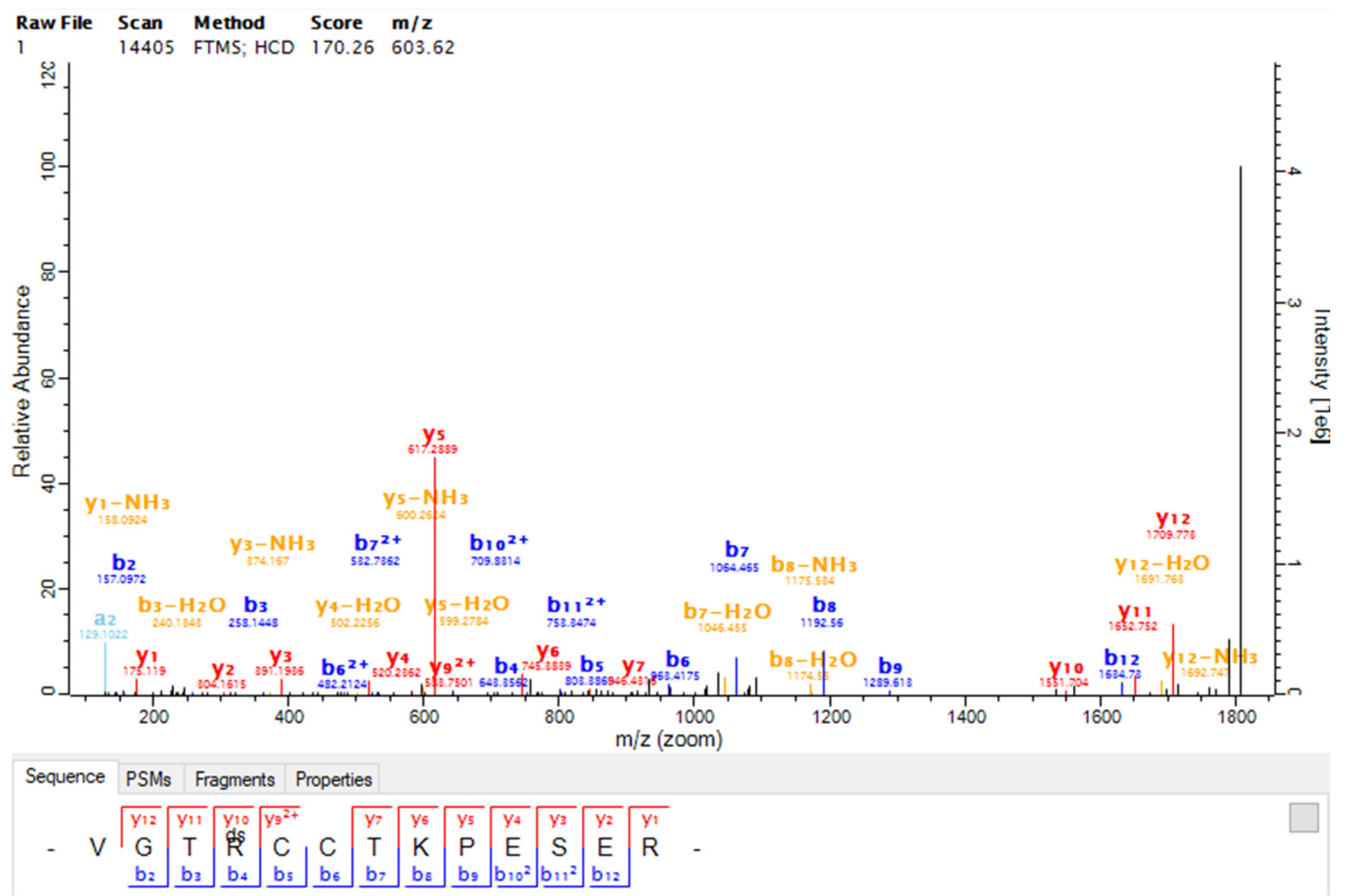

$\begin{array}{lllll}\text { Raw File } & \text { Scan } & \text { Method } & \text { Score } & \mathbf{m} / \mathbf{z} \\ 1 & 34160 & \text { FTMS; HCD } & 97.47 & 564.3\end{array}$

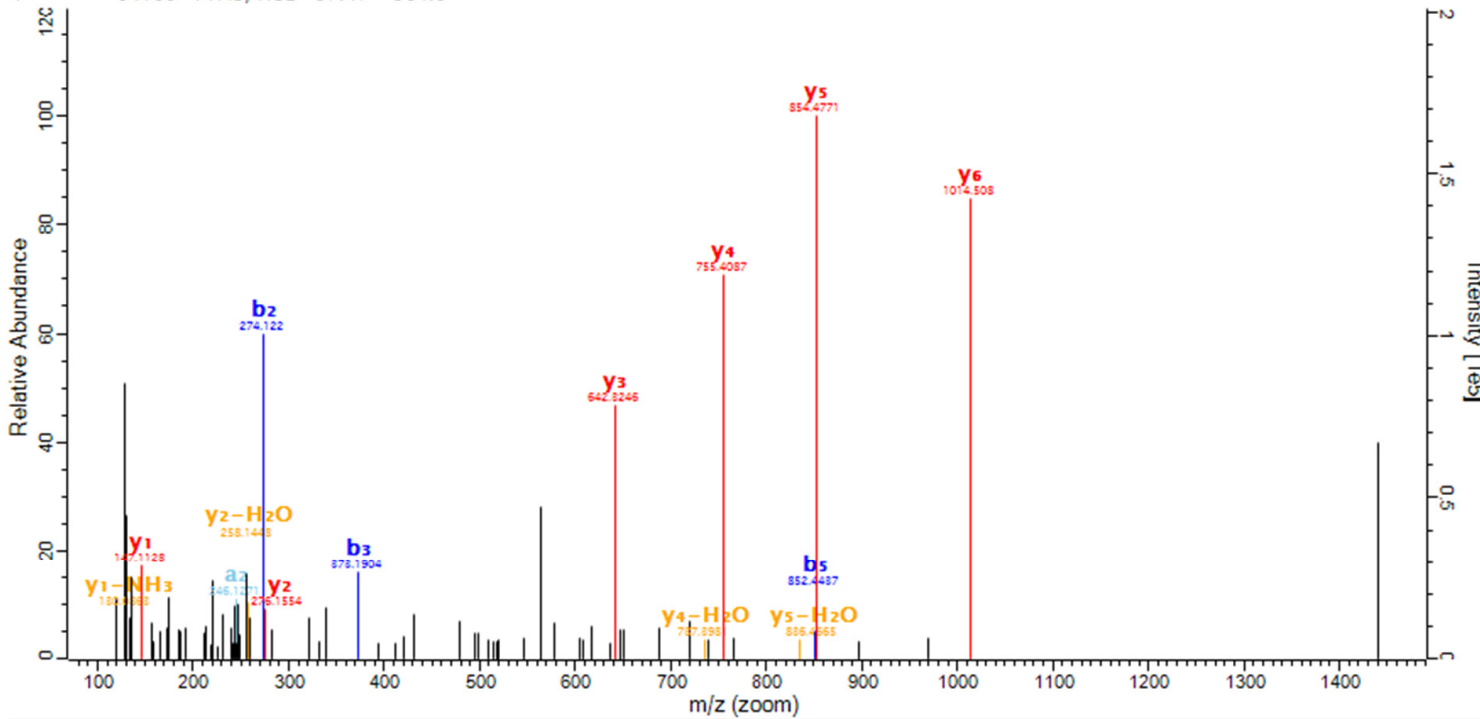

Sequence PSMs Fragments Properties

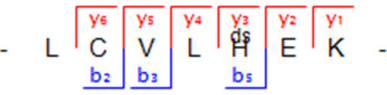



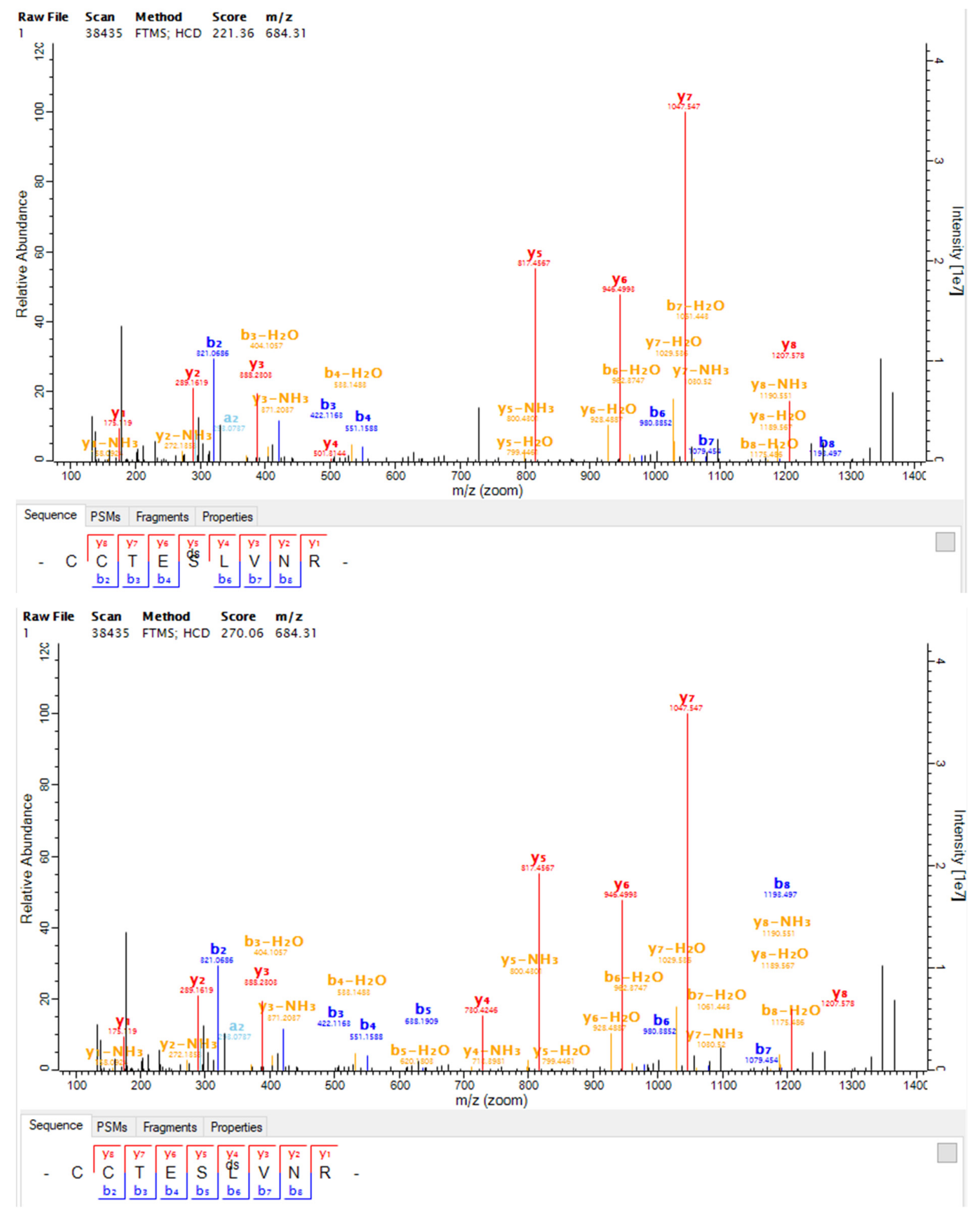


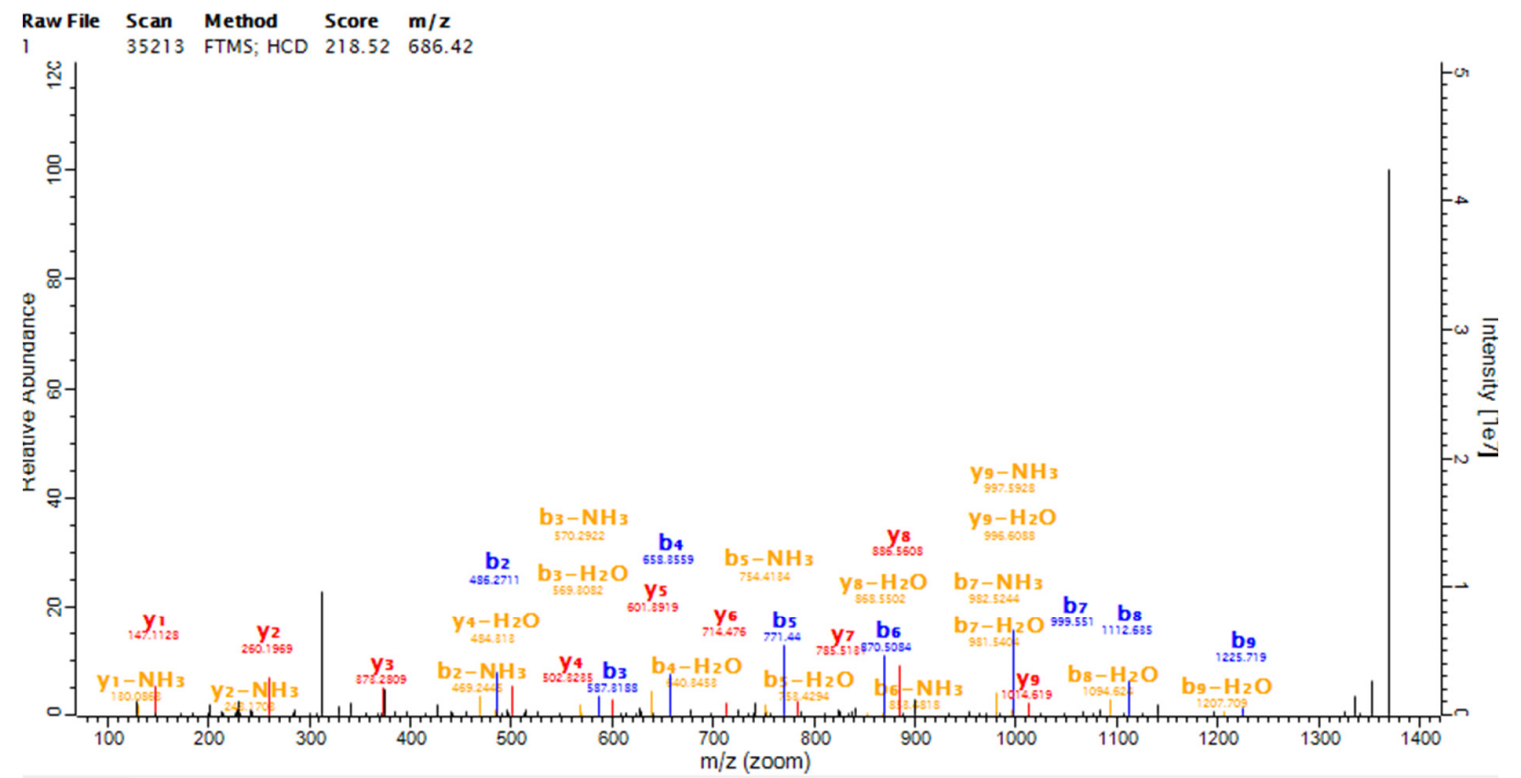

Sequence PSMs Fragments Properties

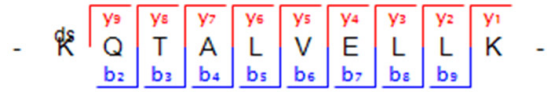

$\begin{array}{lllll}\text { Raw File } & \text { Scan } & \text { Method } & \text { Score } & \mathbf{m} / \mathbf{z} \\ 1 & 38665 & \text { FTMS; HCD } & 209.44 & 524.27\end{array}$

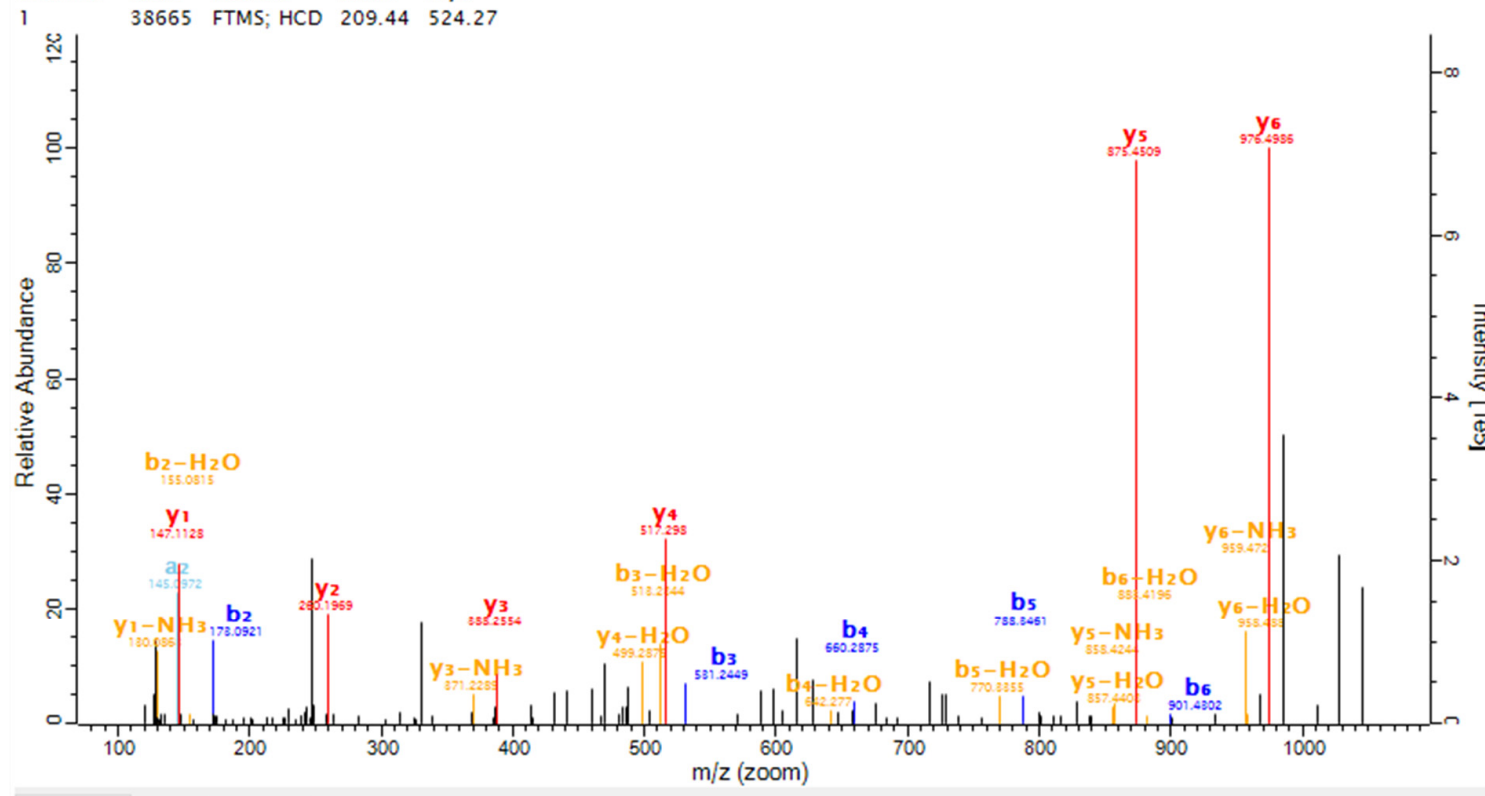

Sequence PSMs Fragments Properties

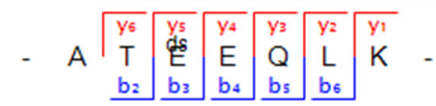


MS/MS spectra of BSA modification by $\mathbf{2}$
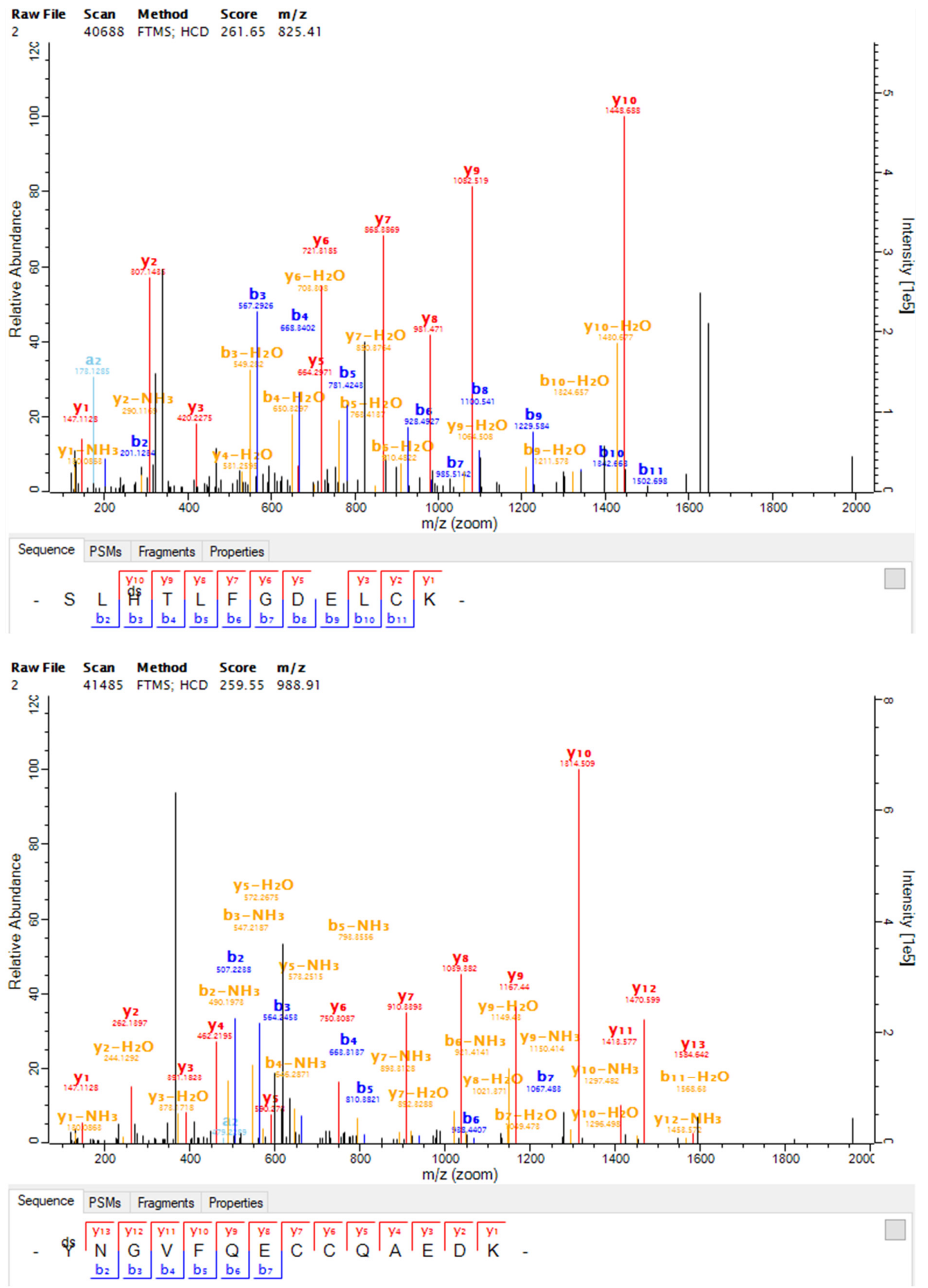


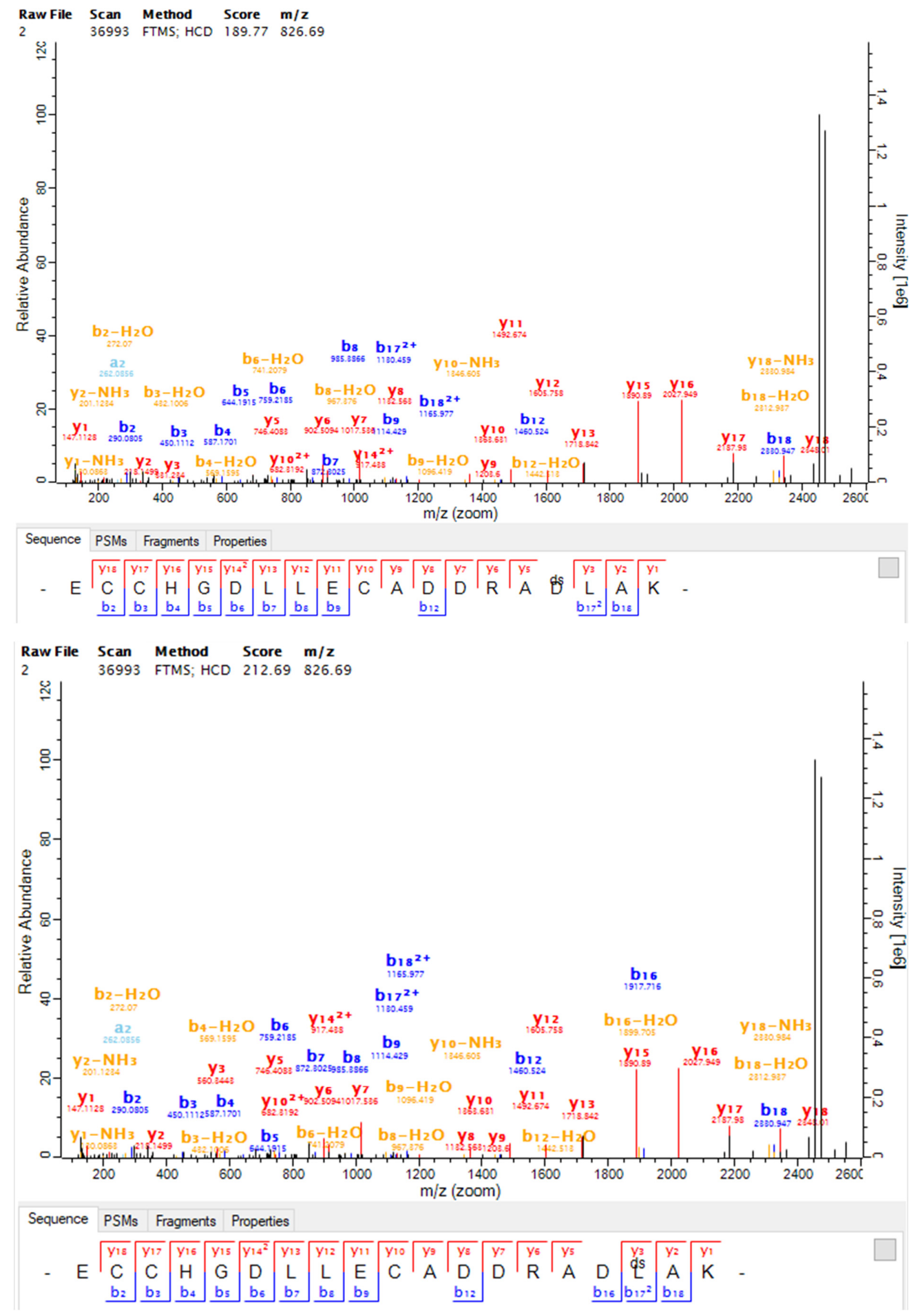



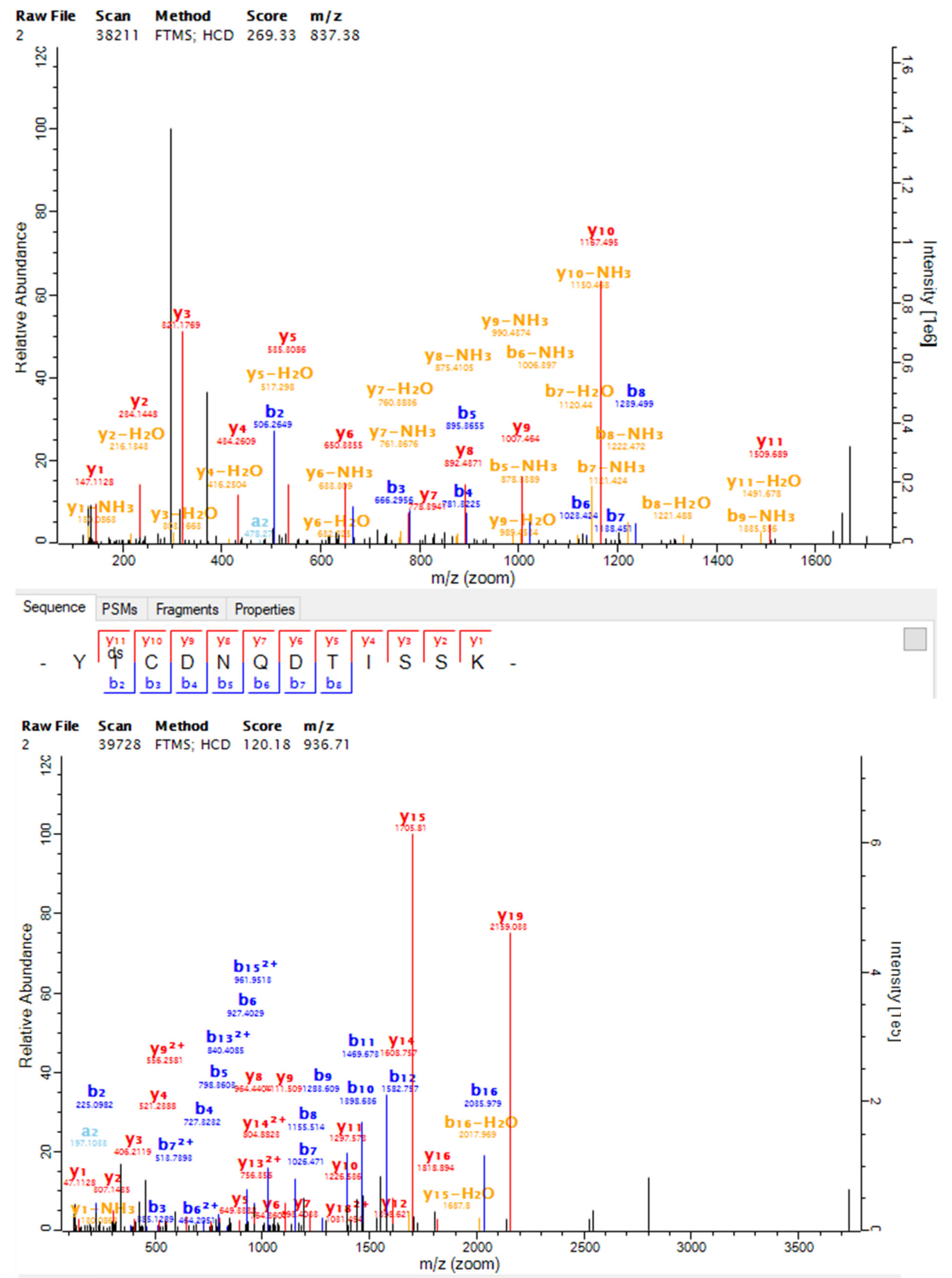

Sequence PSMs Fragments Properties

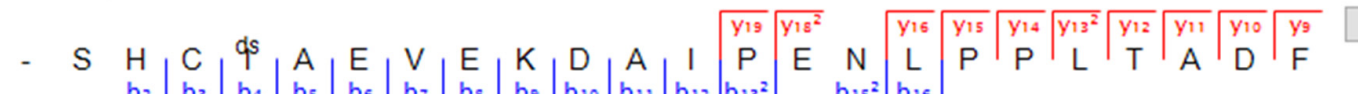

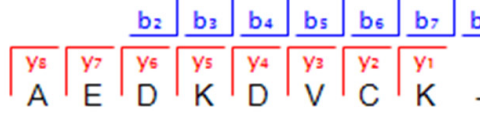




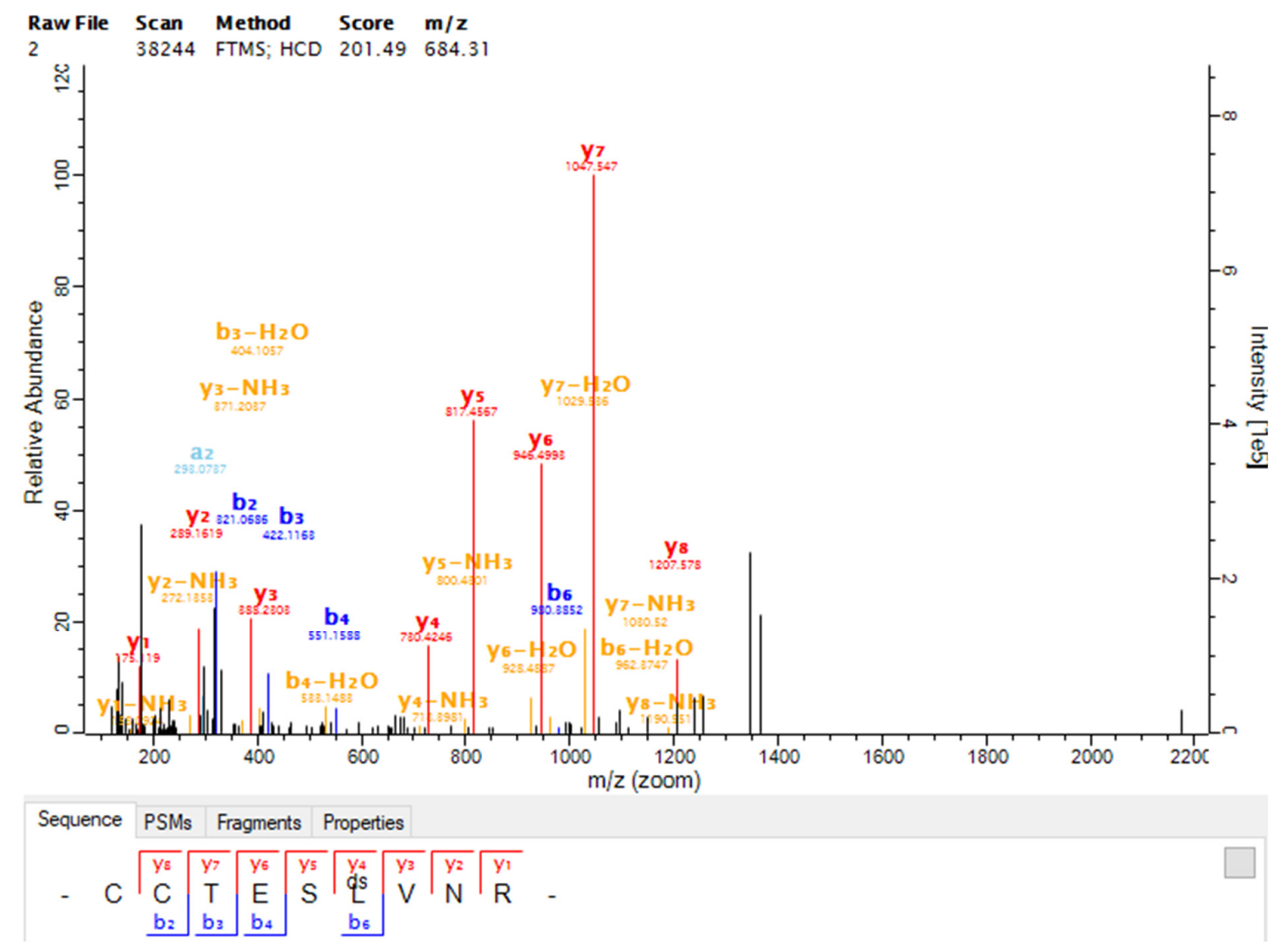


$\underline{\text { NMR spectra of compounds }}$

\section{Compound S2}
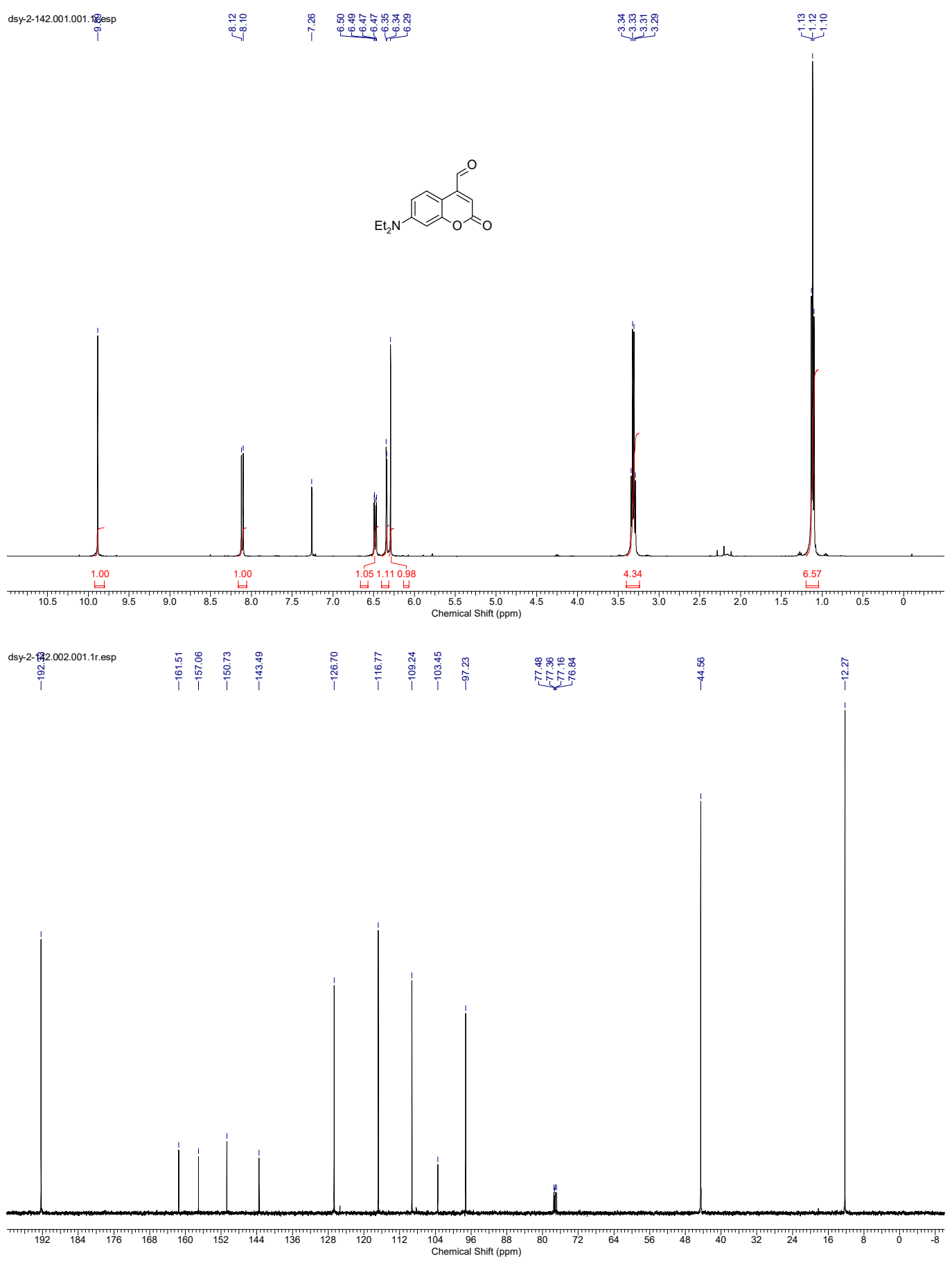


\section{Compound S3}
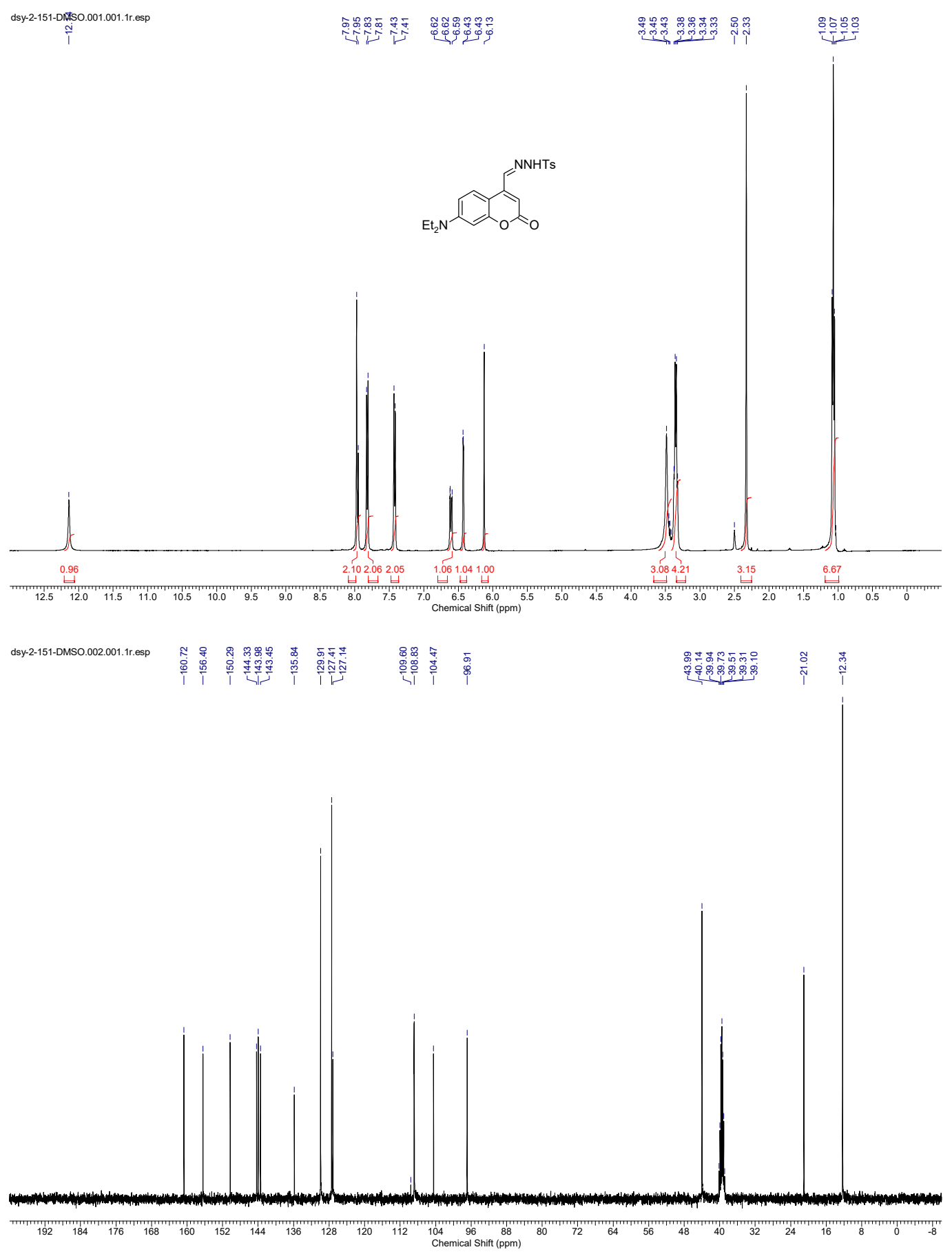
Compound 1
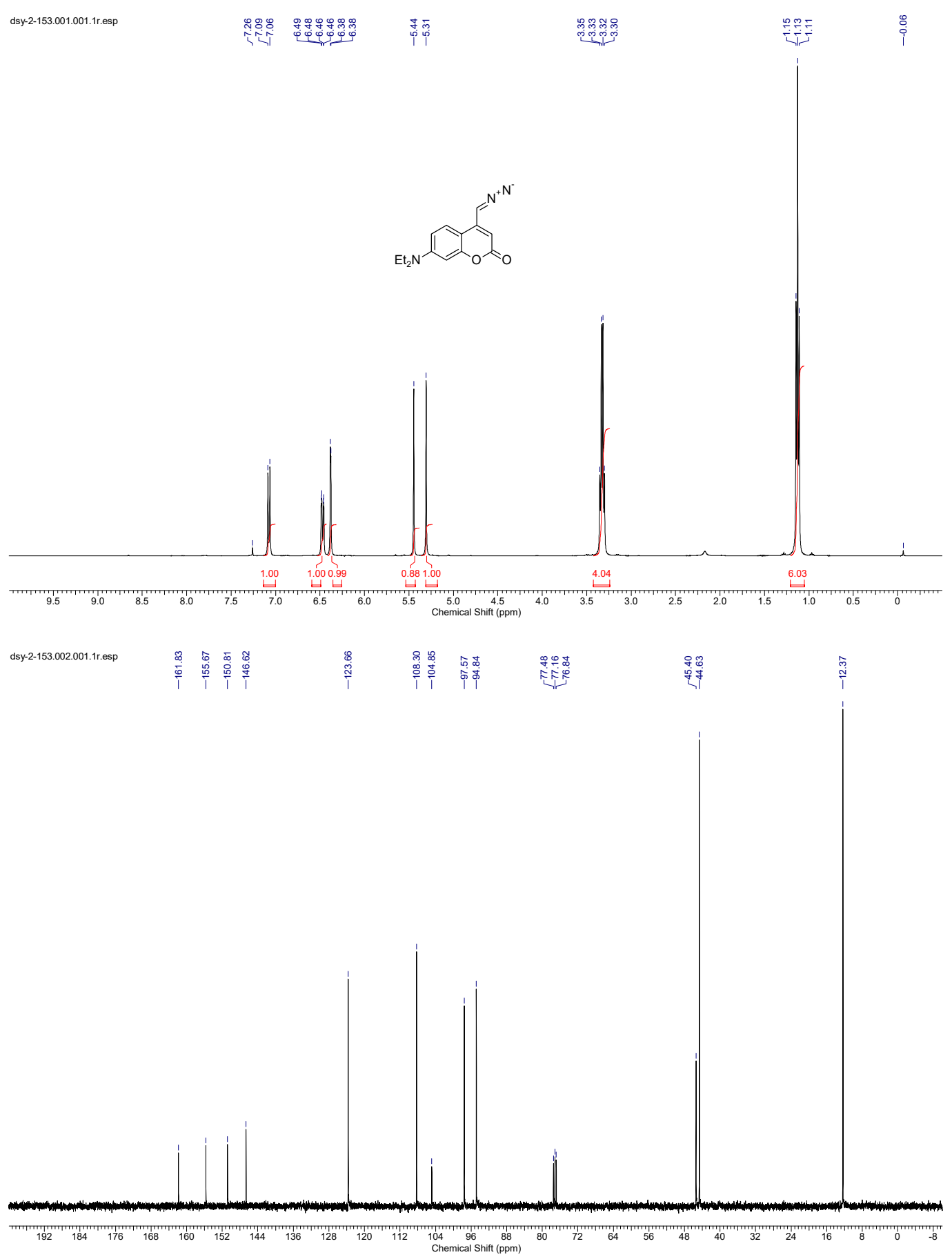


\section{Compound S4}

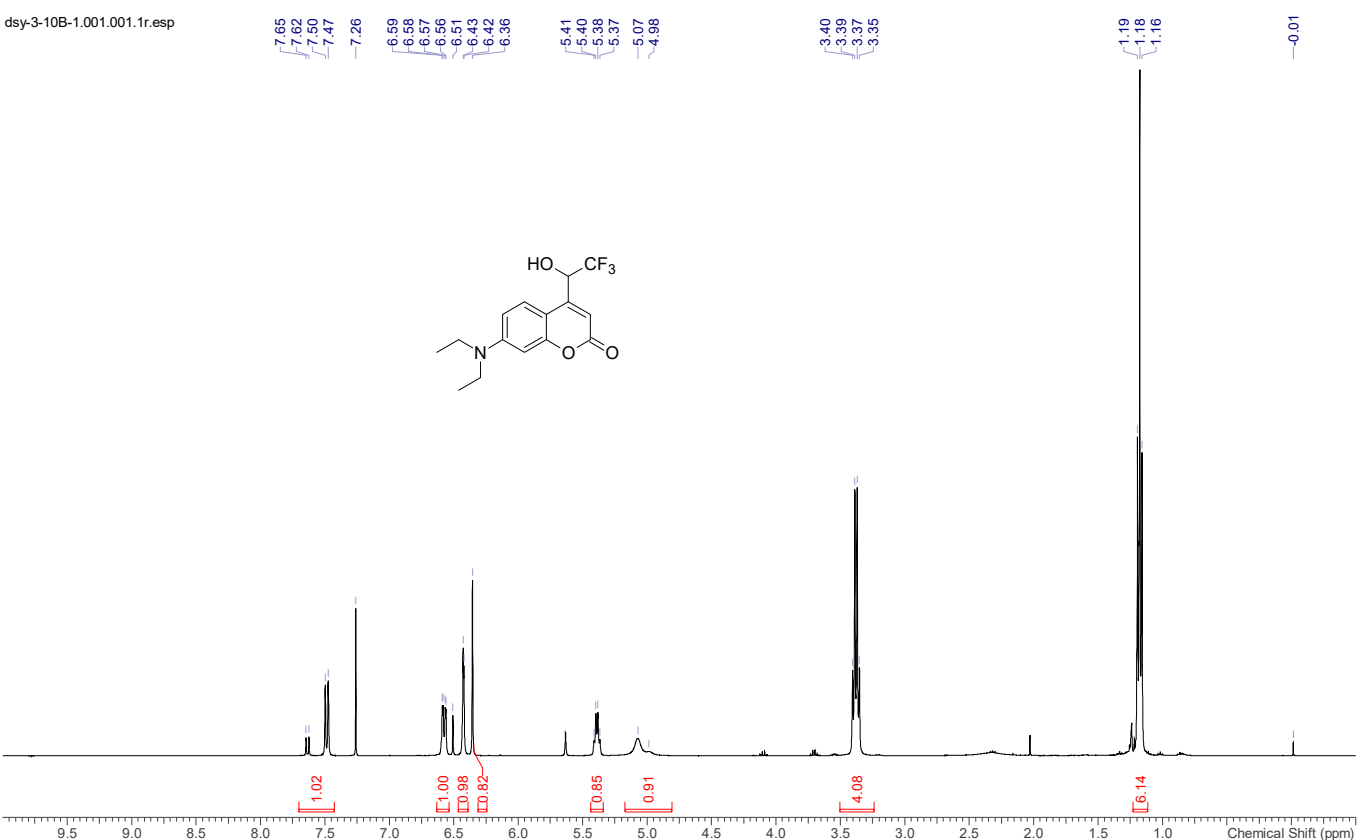

dsy-3-10B-1.002001.1res

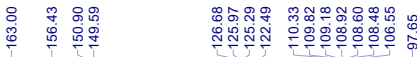

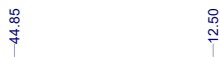

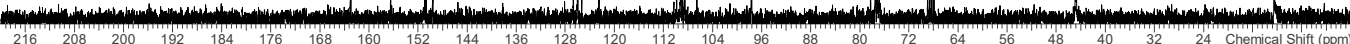




\section{Compound S5}
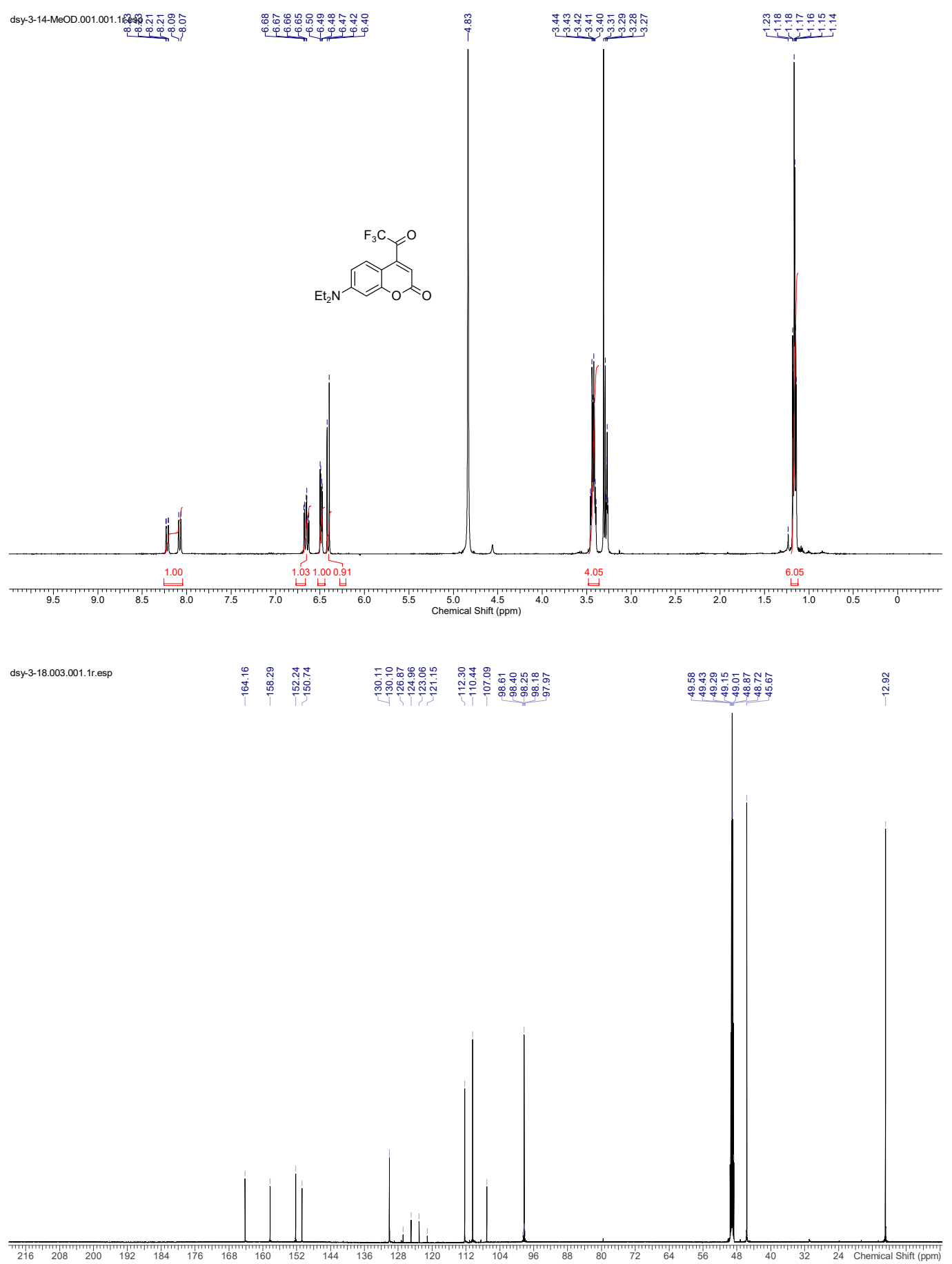


\section{Compound S6}

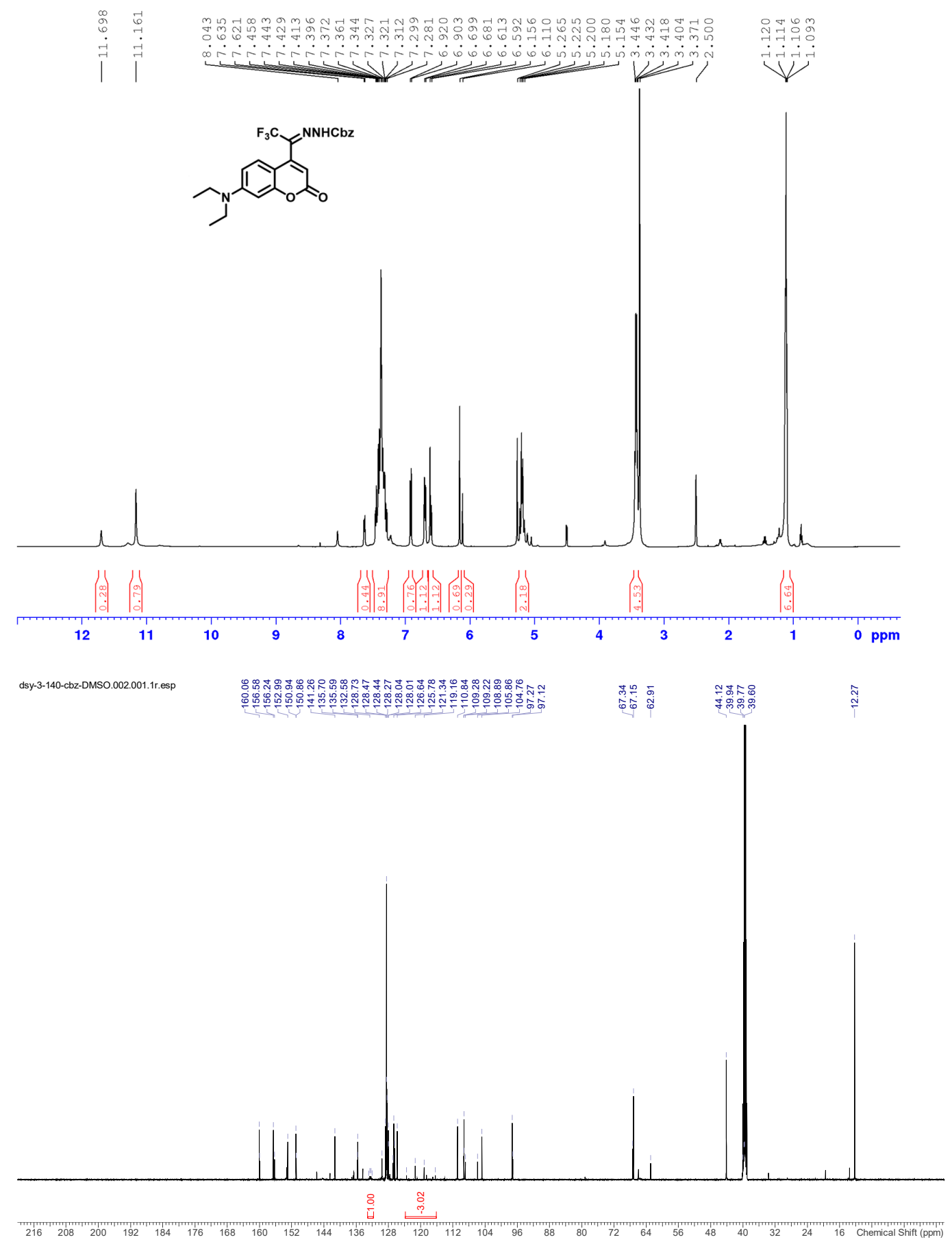




\section{Compound S7}

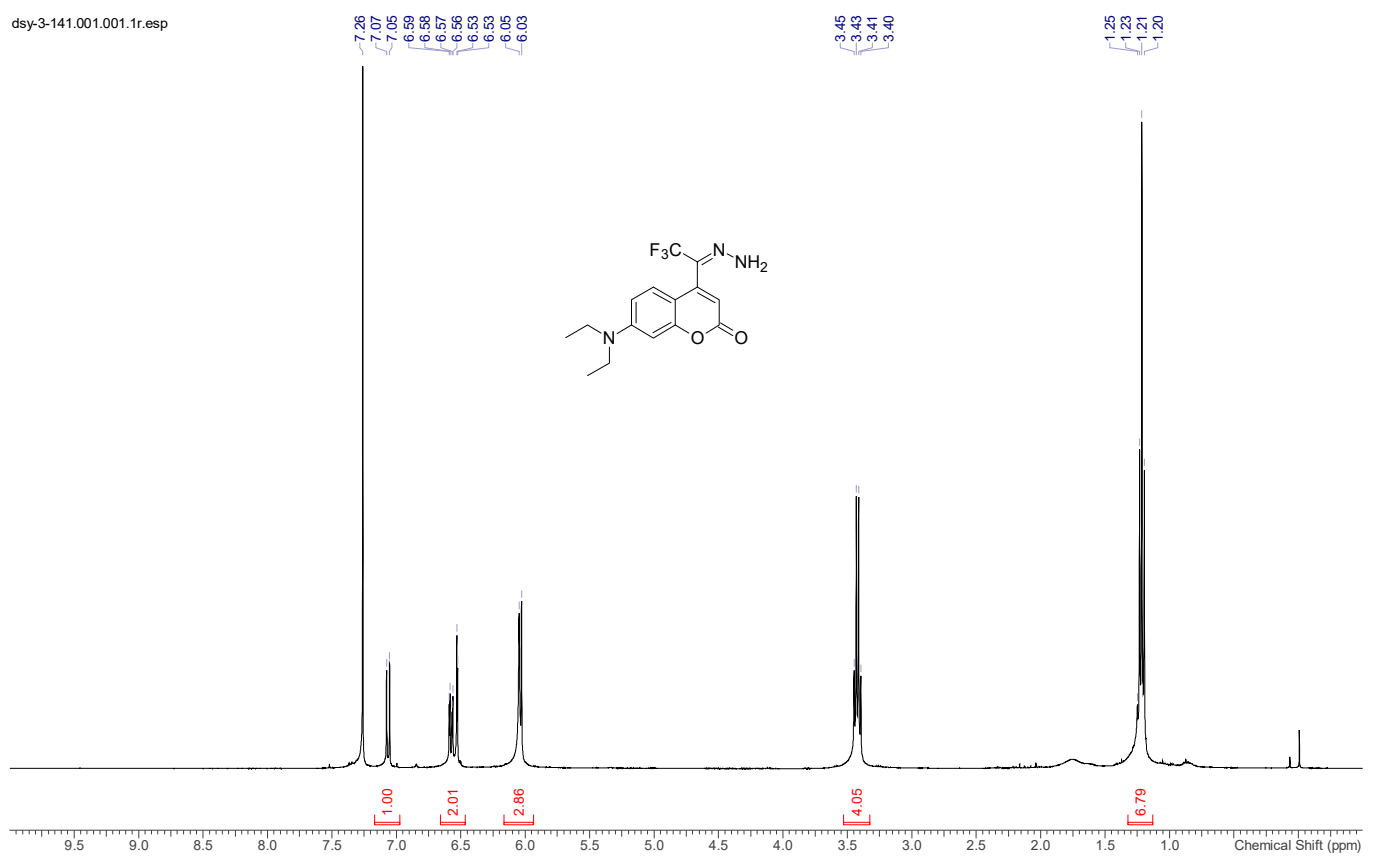

dsy-3-141.003.001.1r.esp

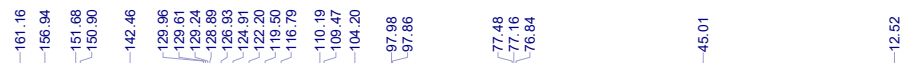

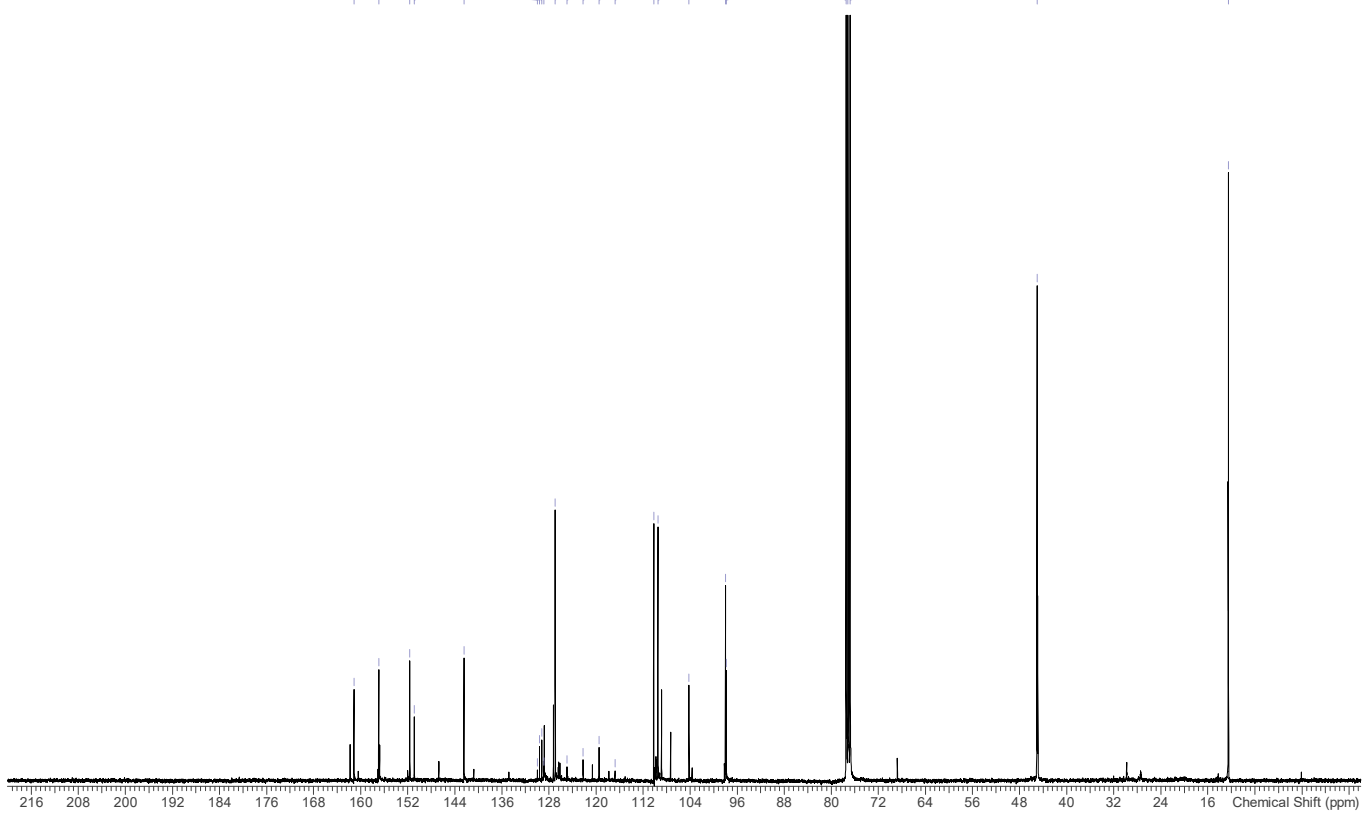




\section{Compound 2}
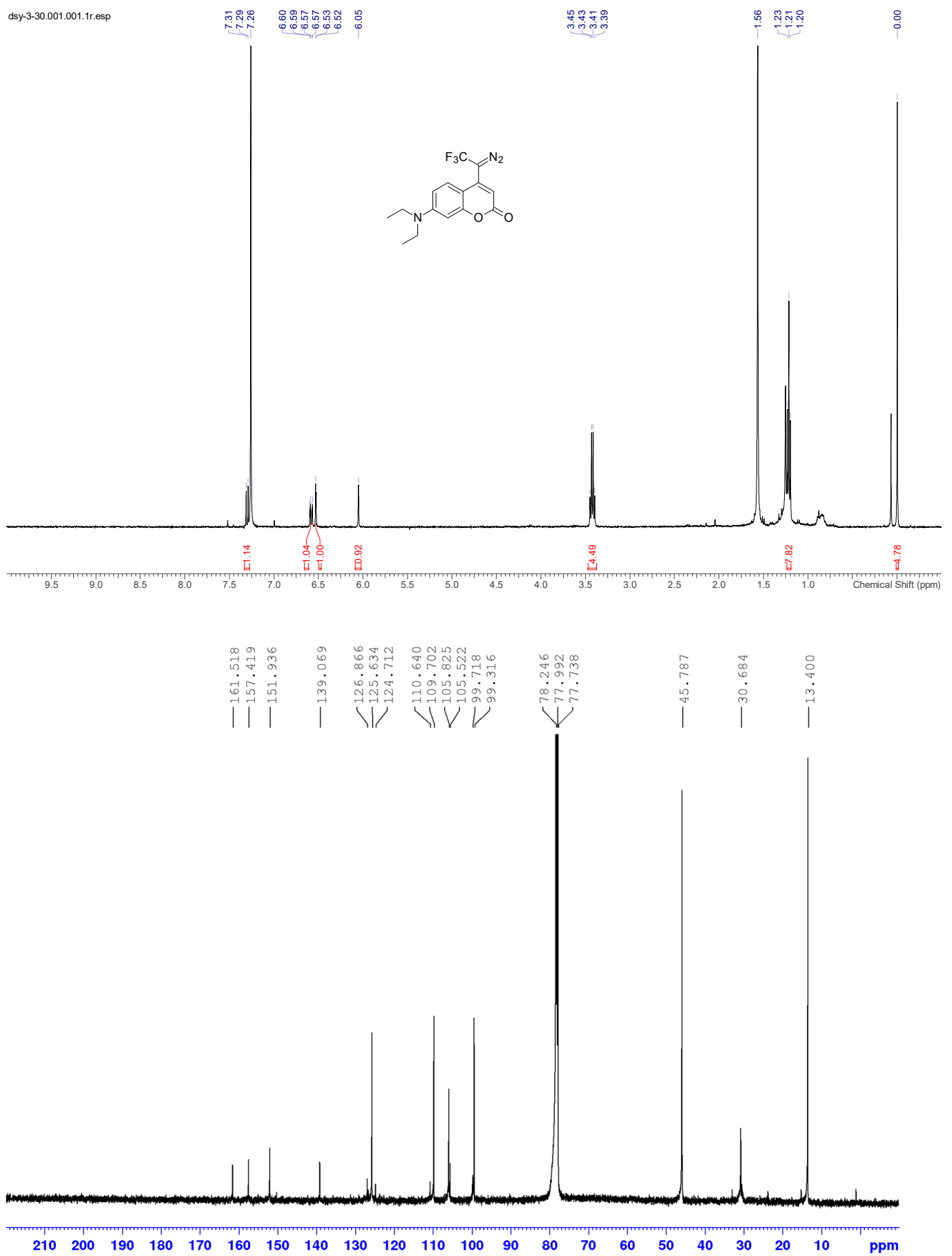


\section{Compound 1a}
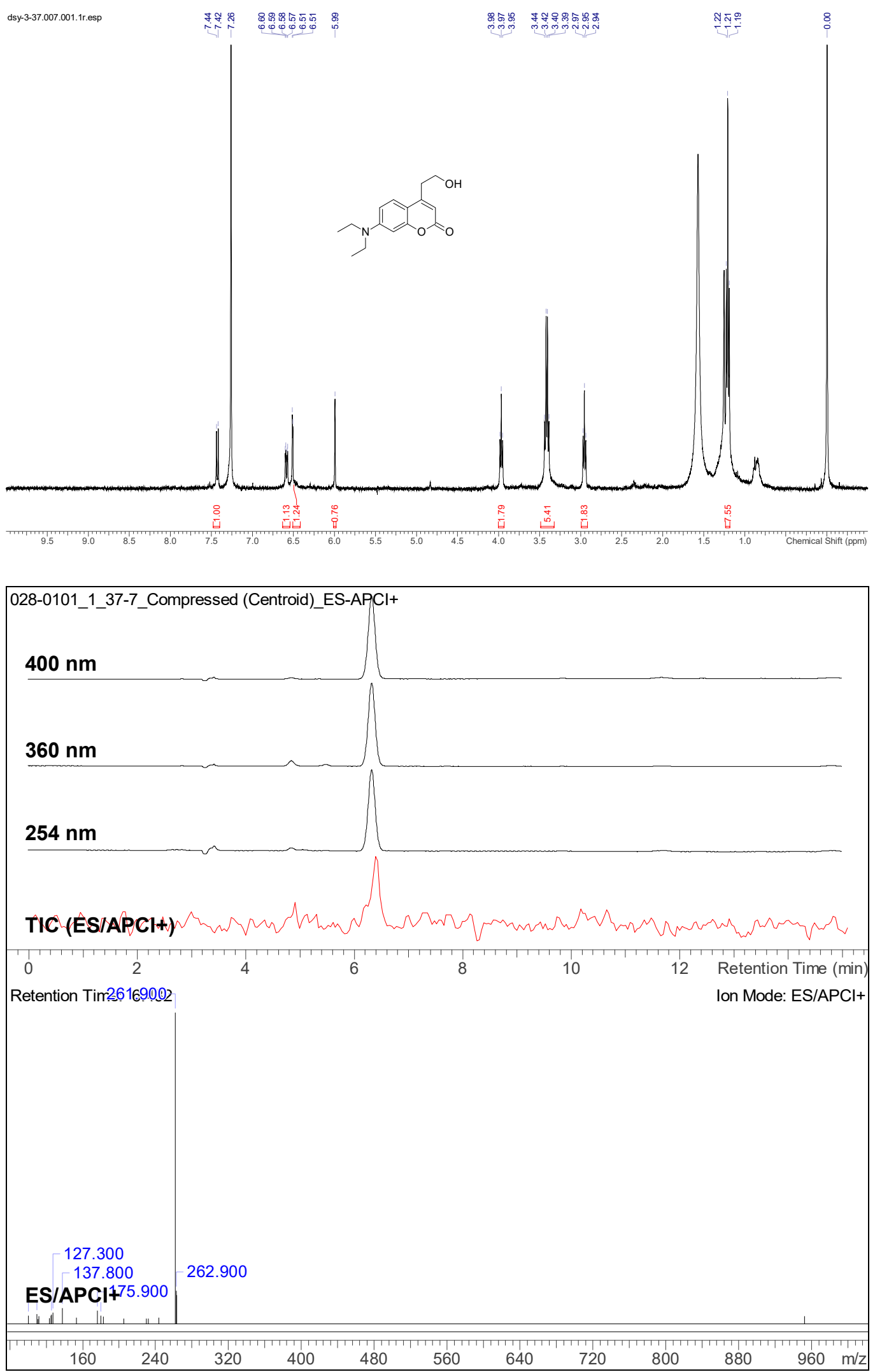


\section{Compound 1b}
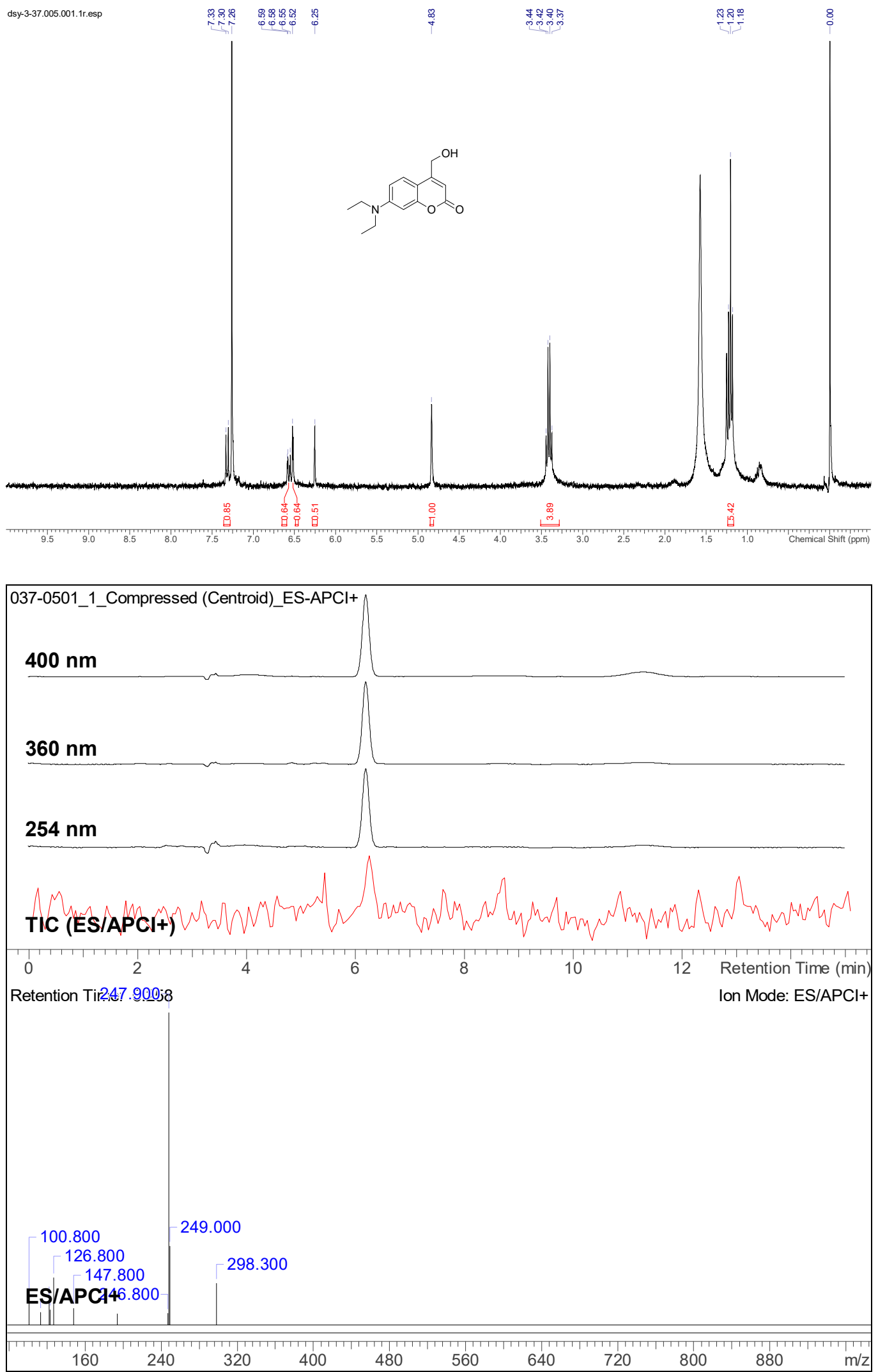


\section{Compound 1d}
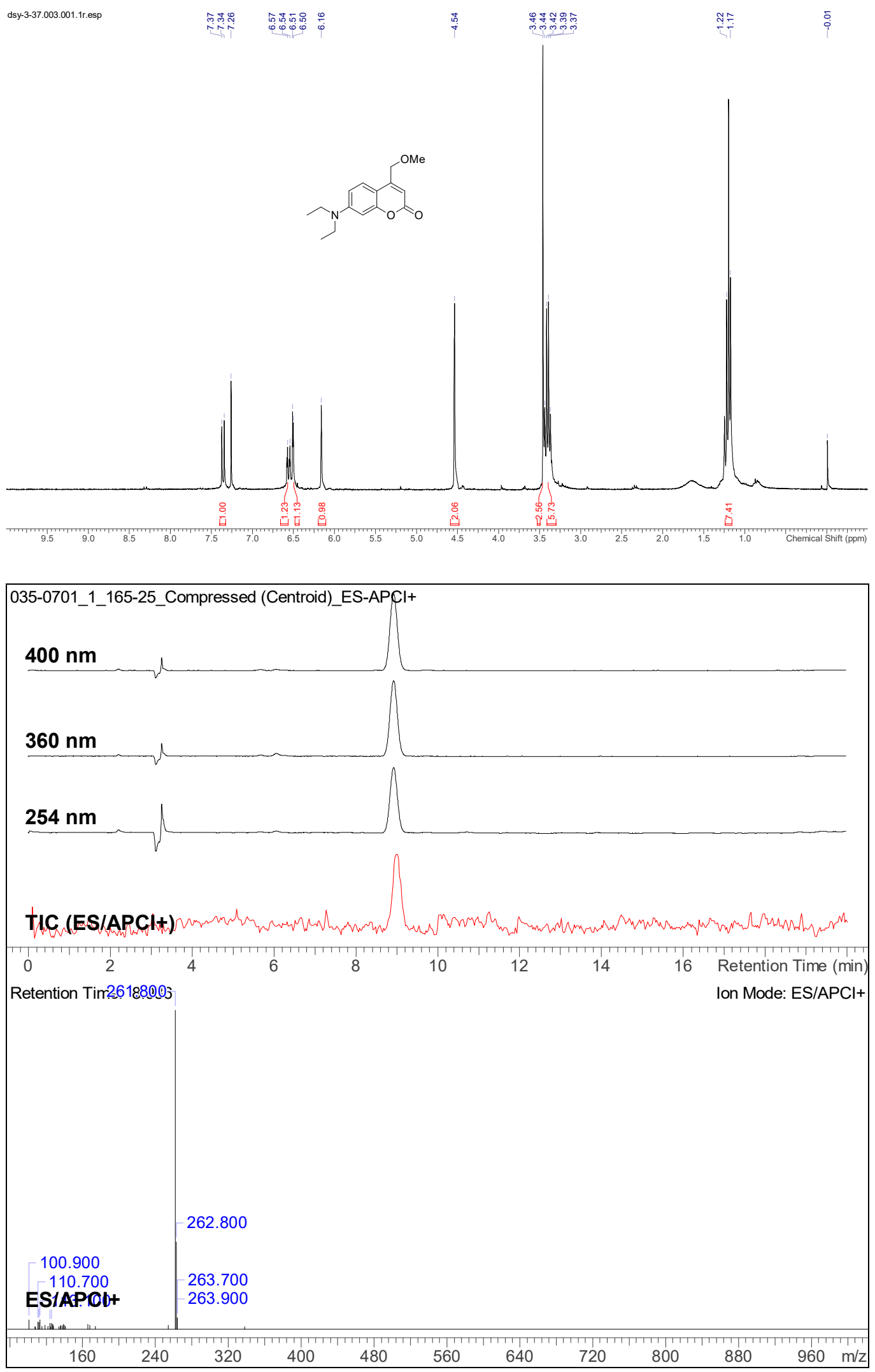


\section{Compound 1e}
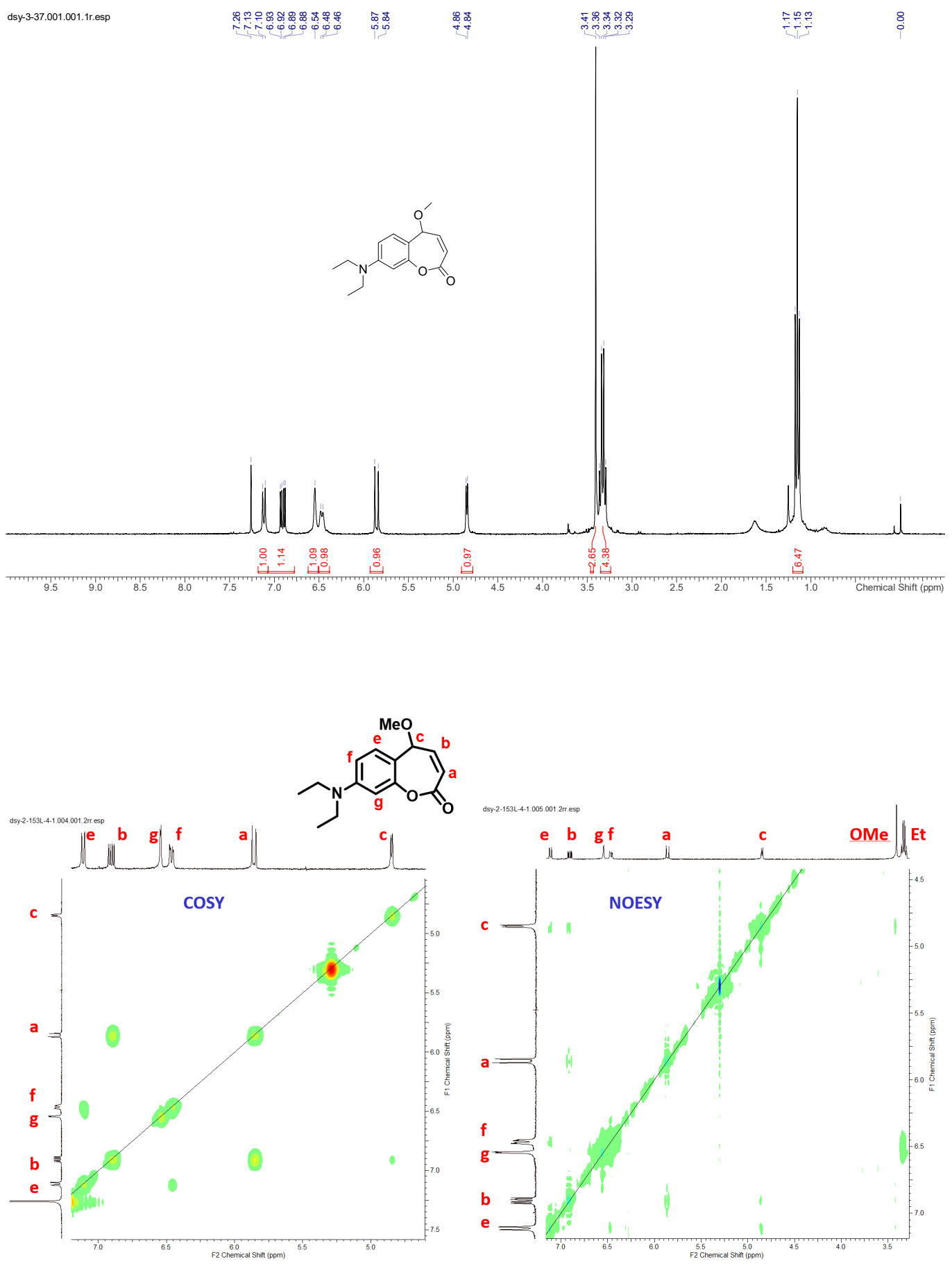


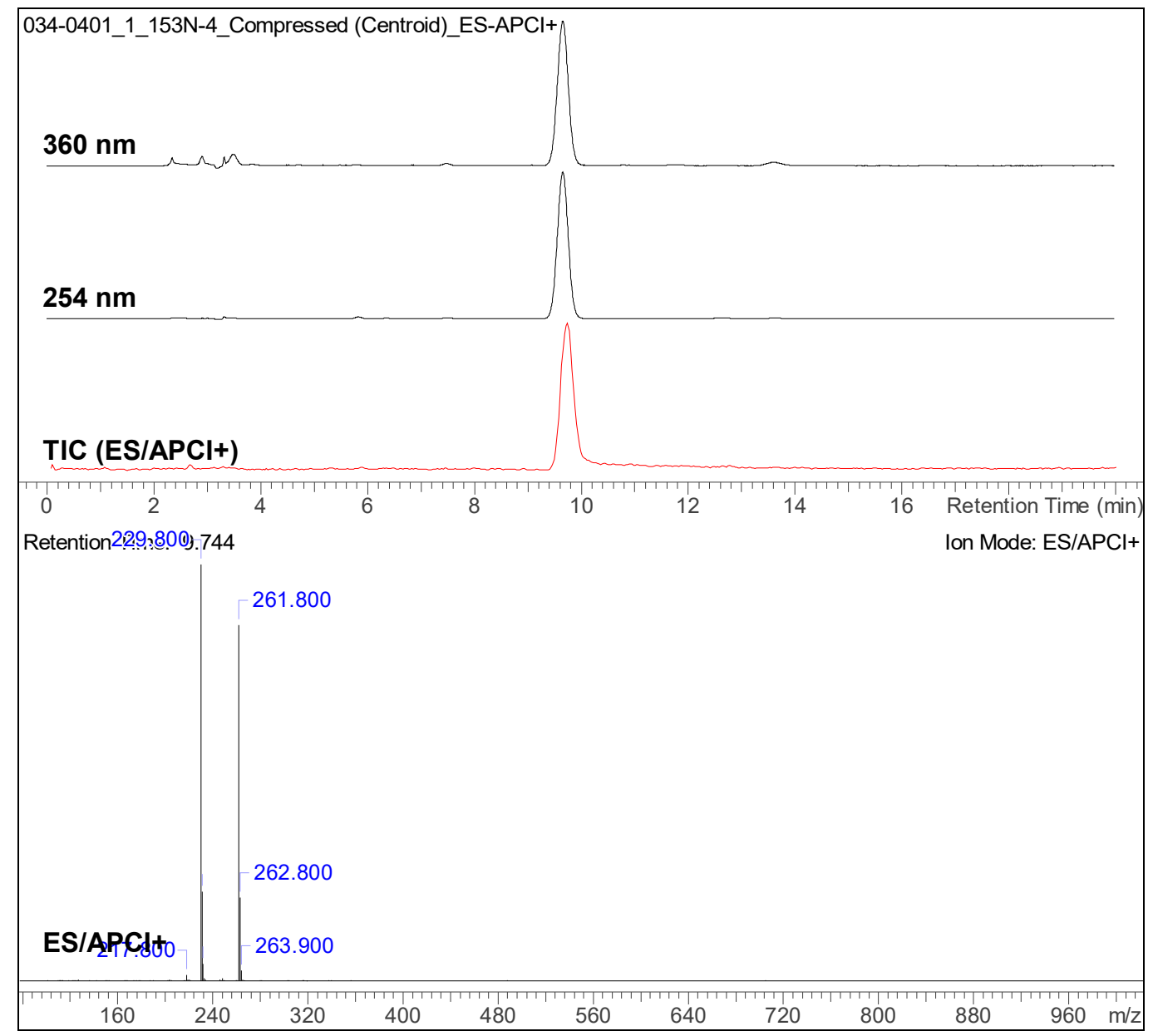

\section{Compound 2c}

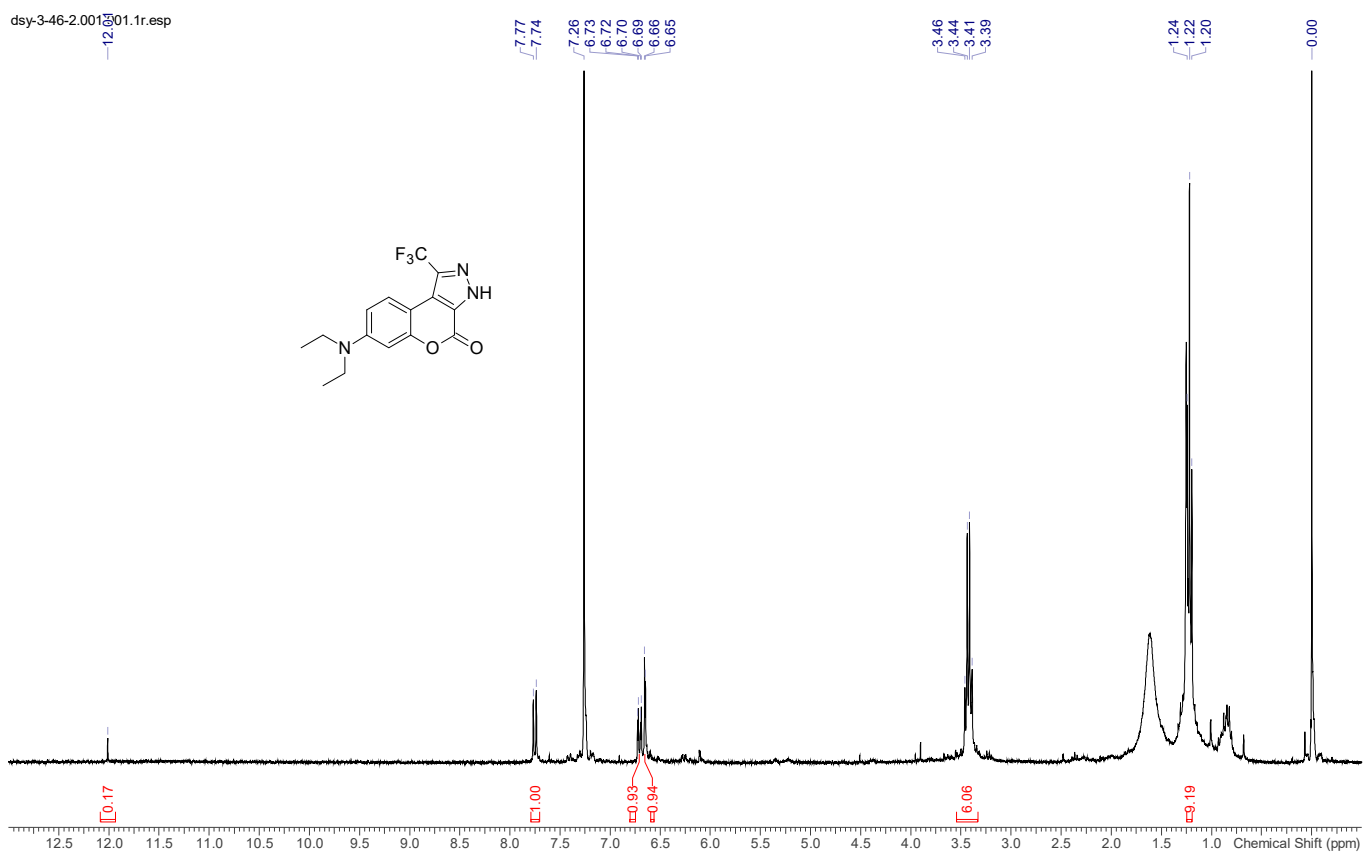




\section{Compound 2d}
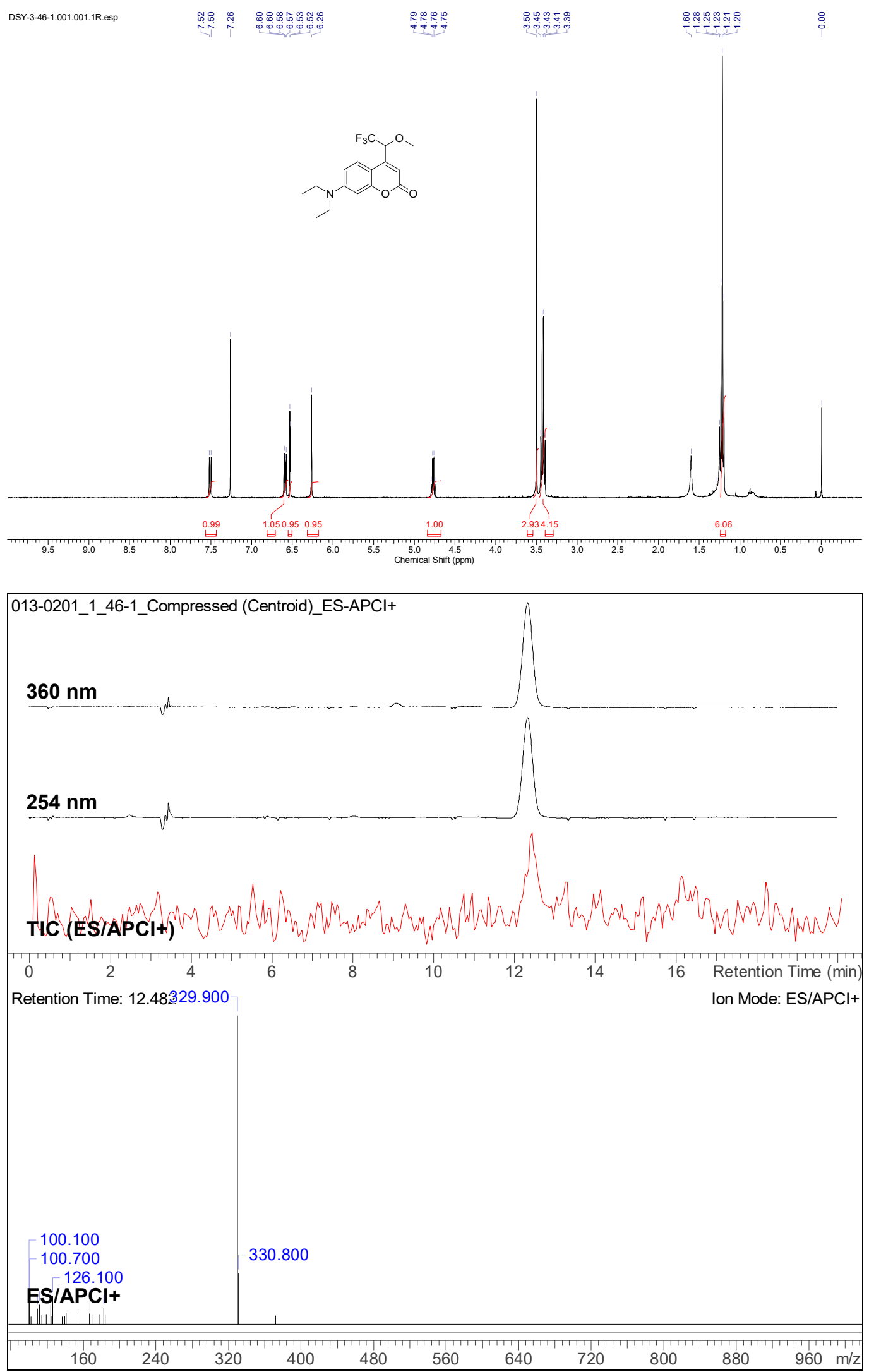


\section{Compound S8}
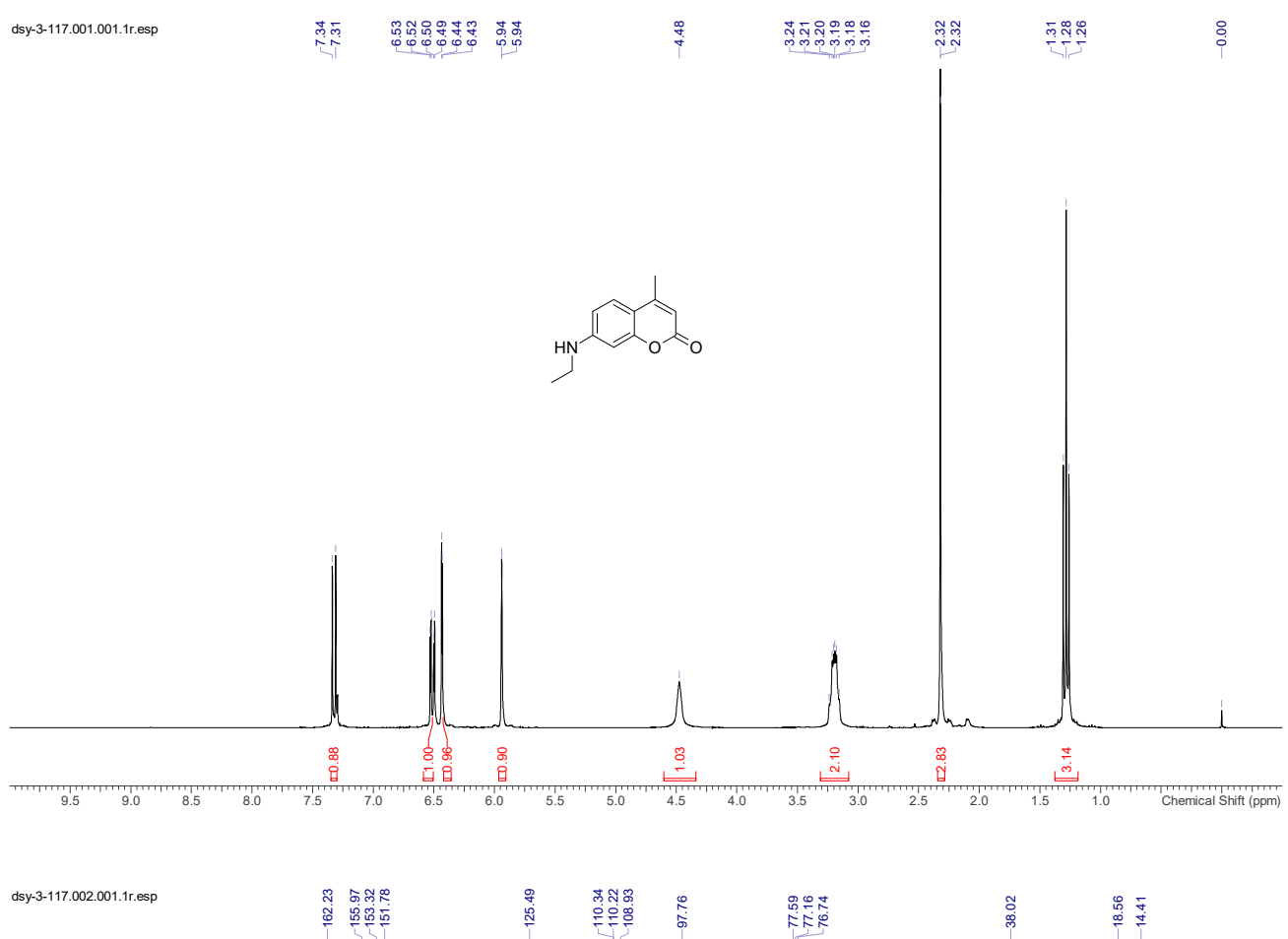

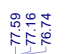

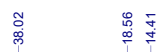

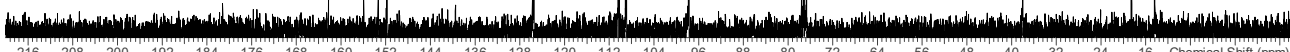

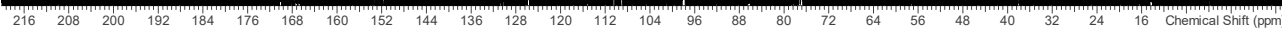




\section{Compound S9}

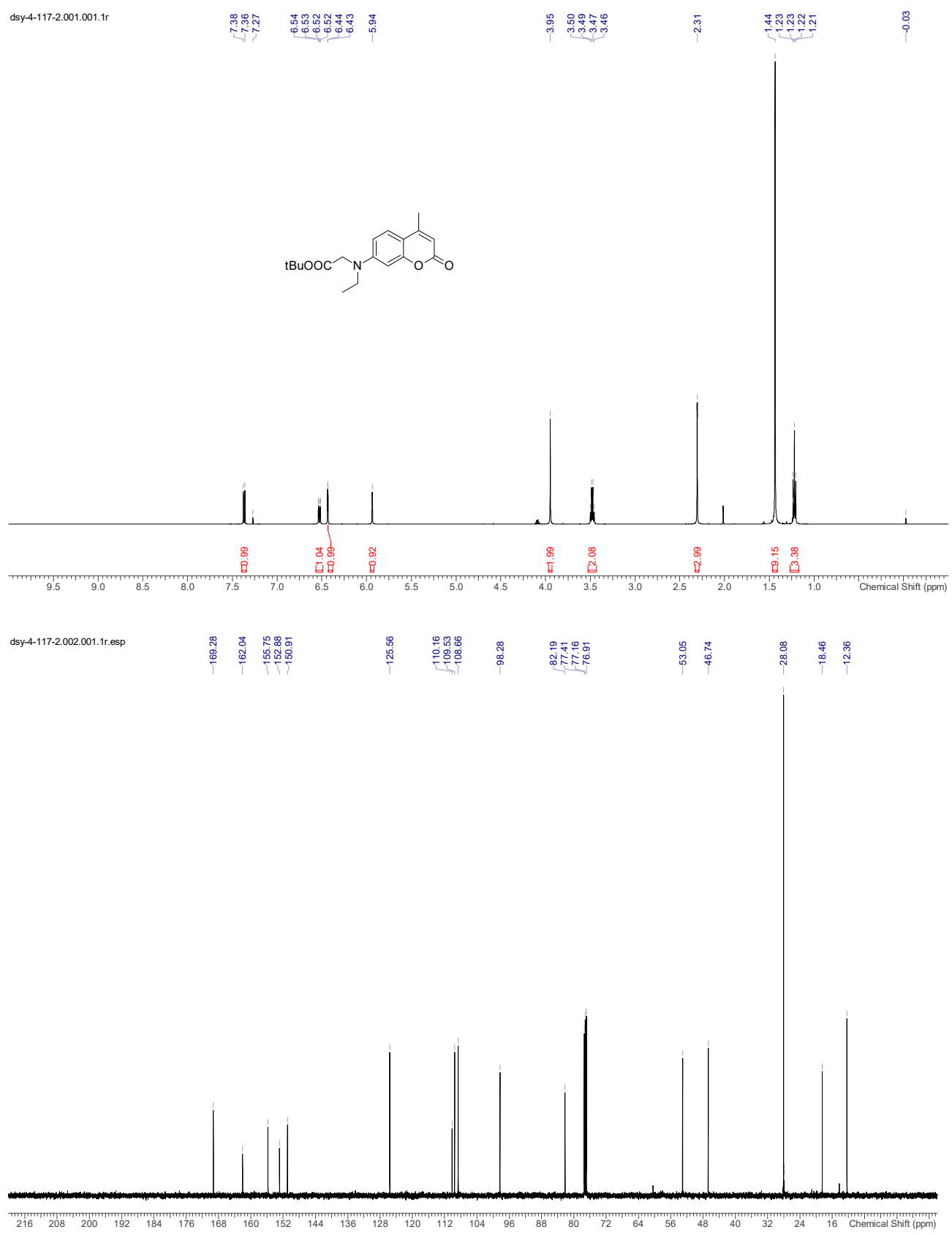




\section{Compound S10}

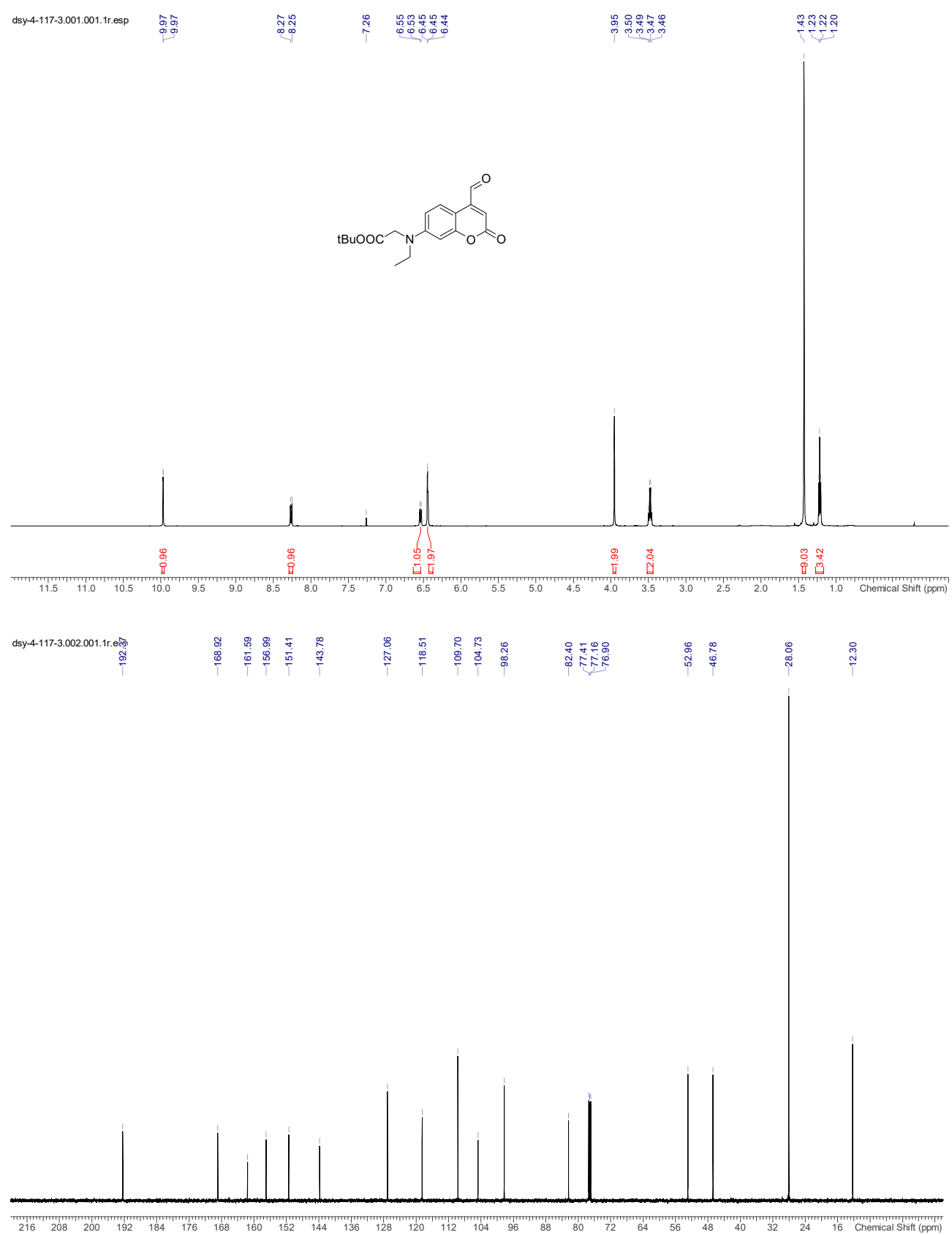




\section{$\underline{\text { Compound S11 }}$}

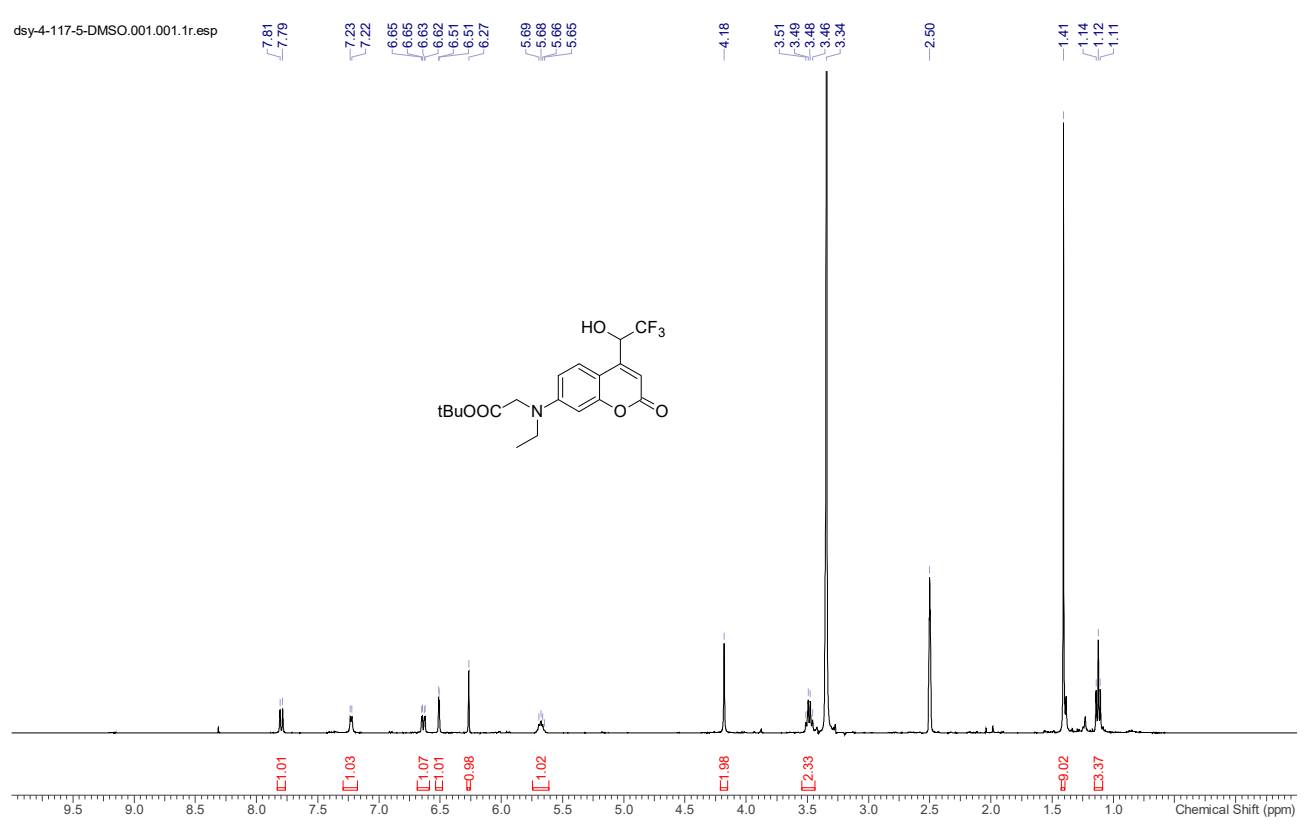

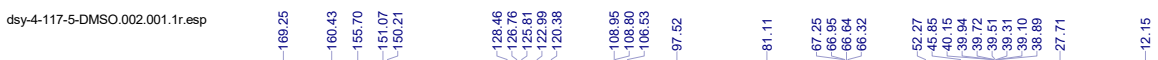

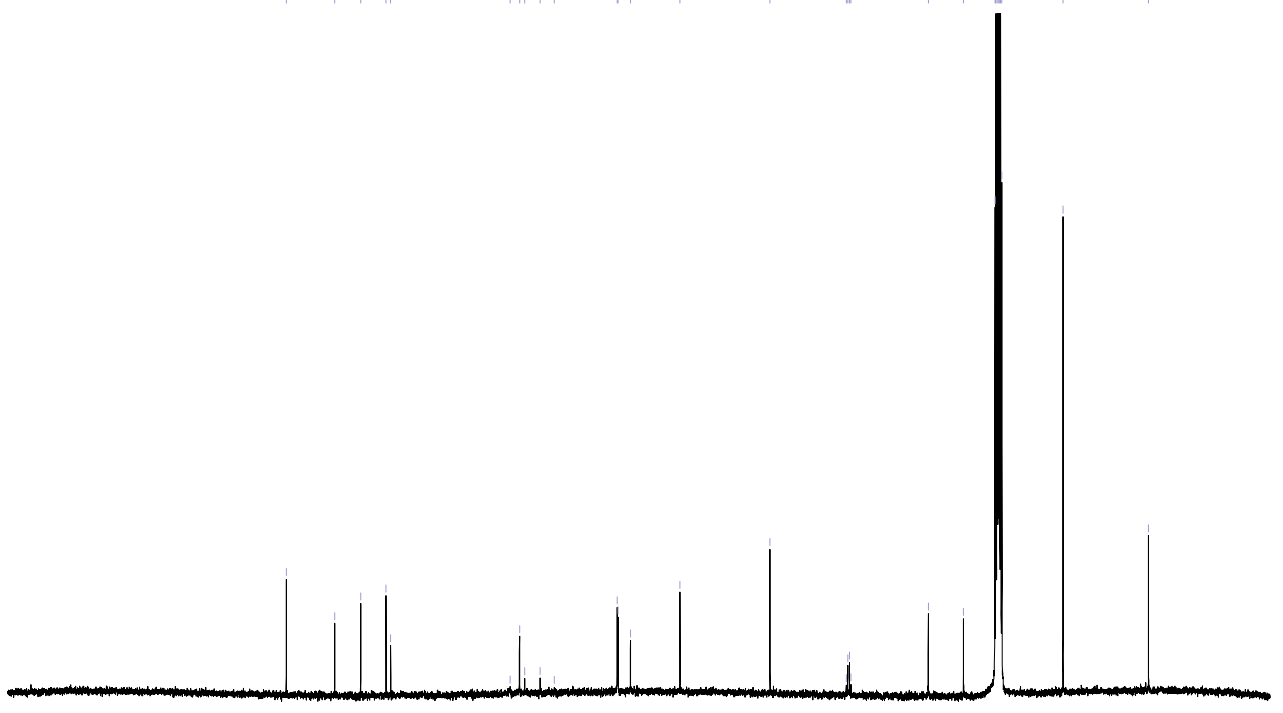

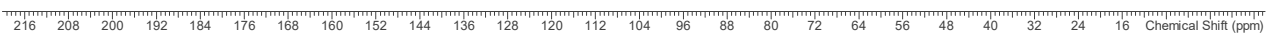




\section{Compound S12}

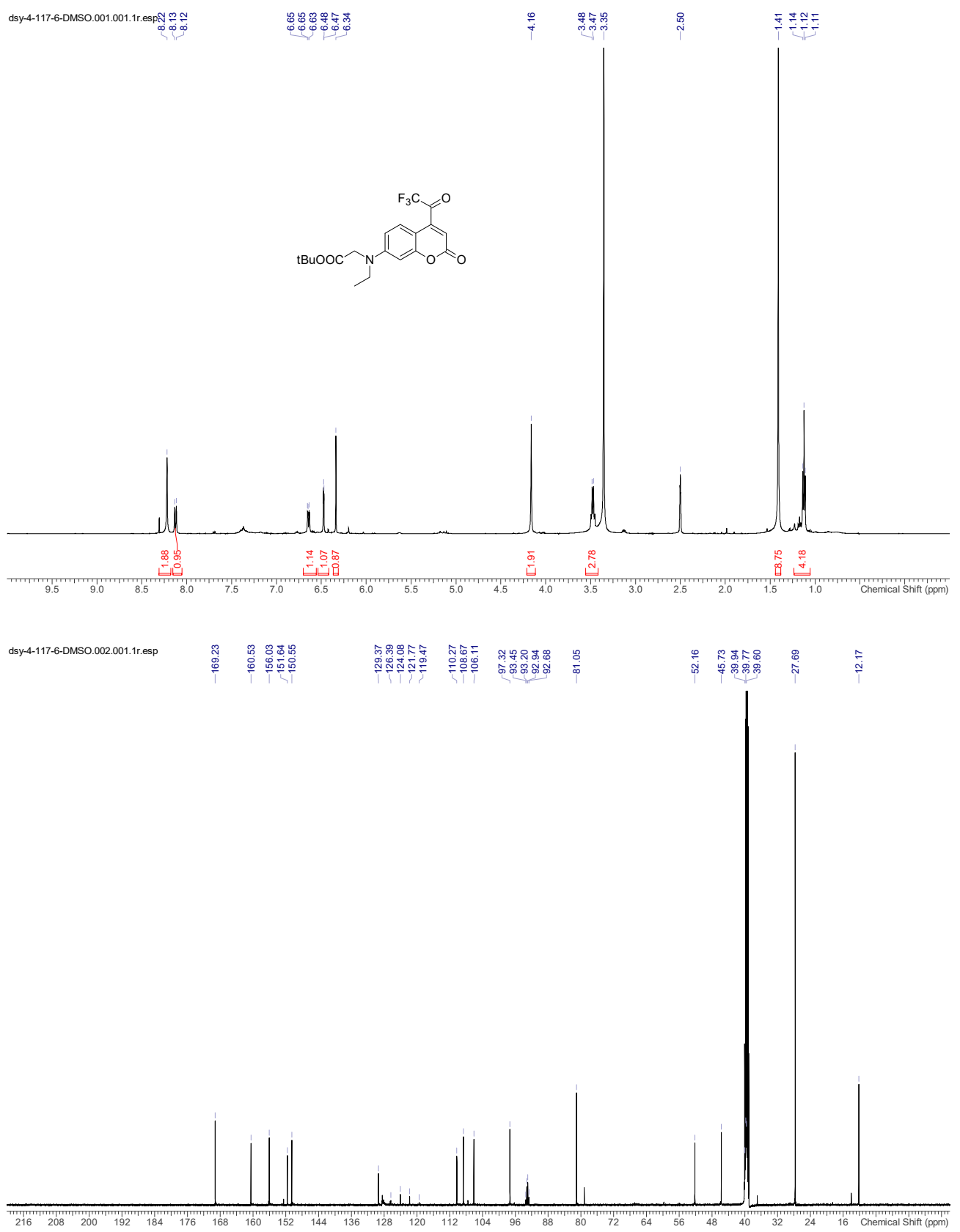




\section{$\underline{\text { Compound S13 }}$}

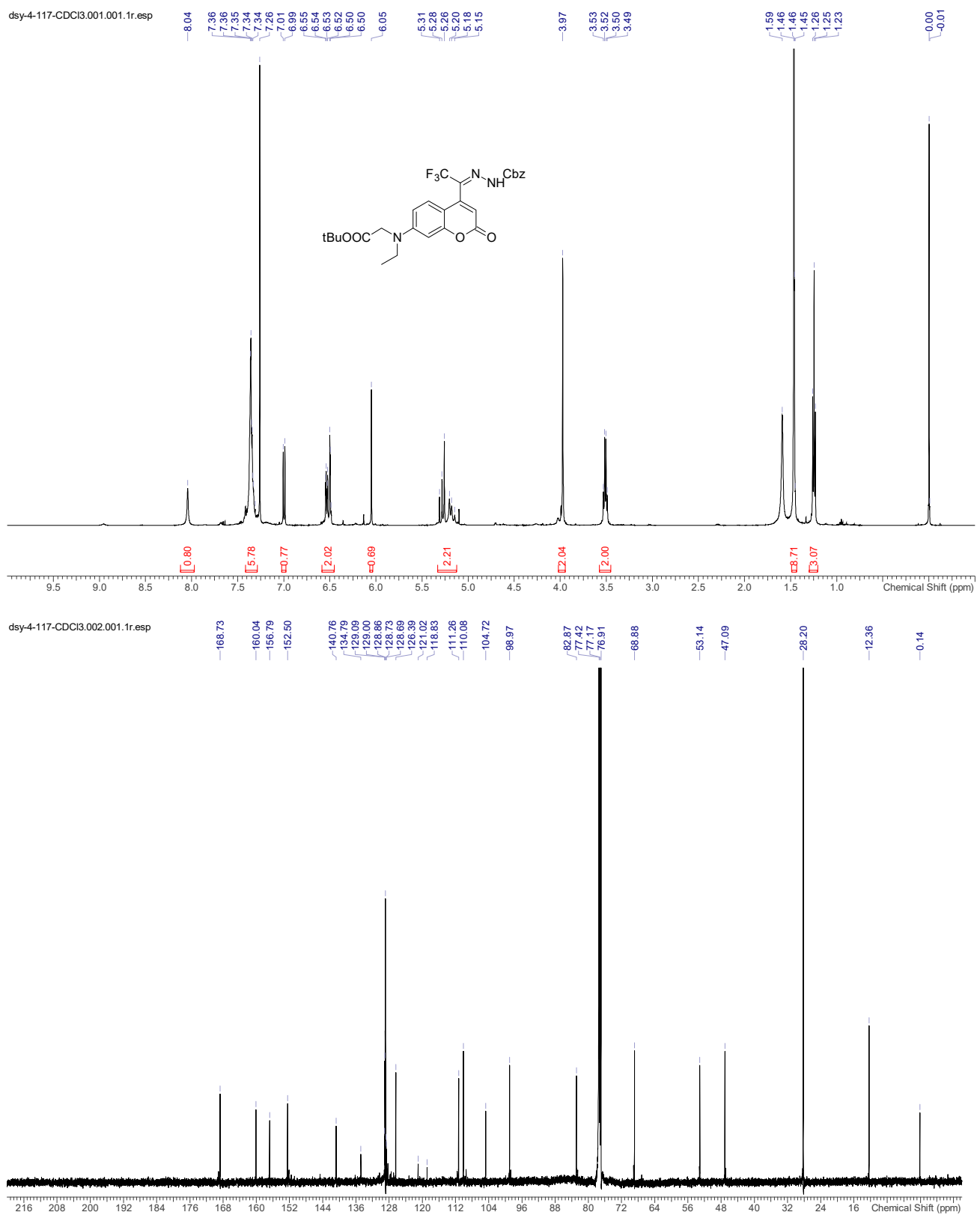




\section{Compound S16}
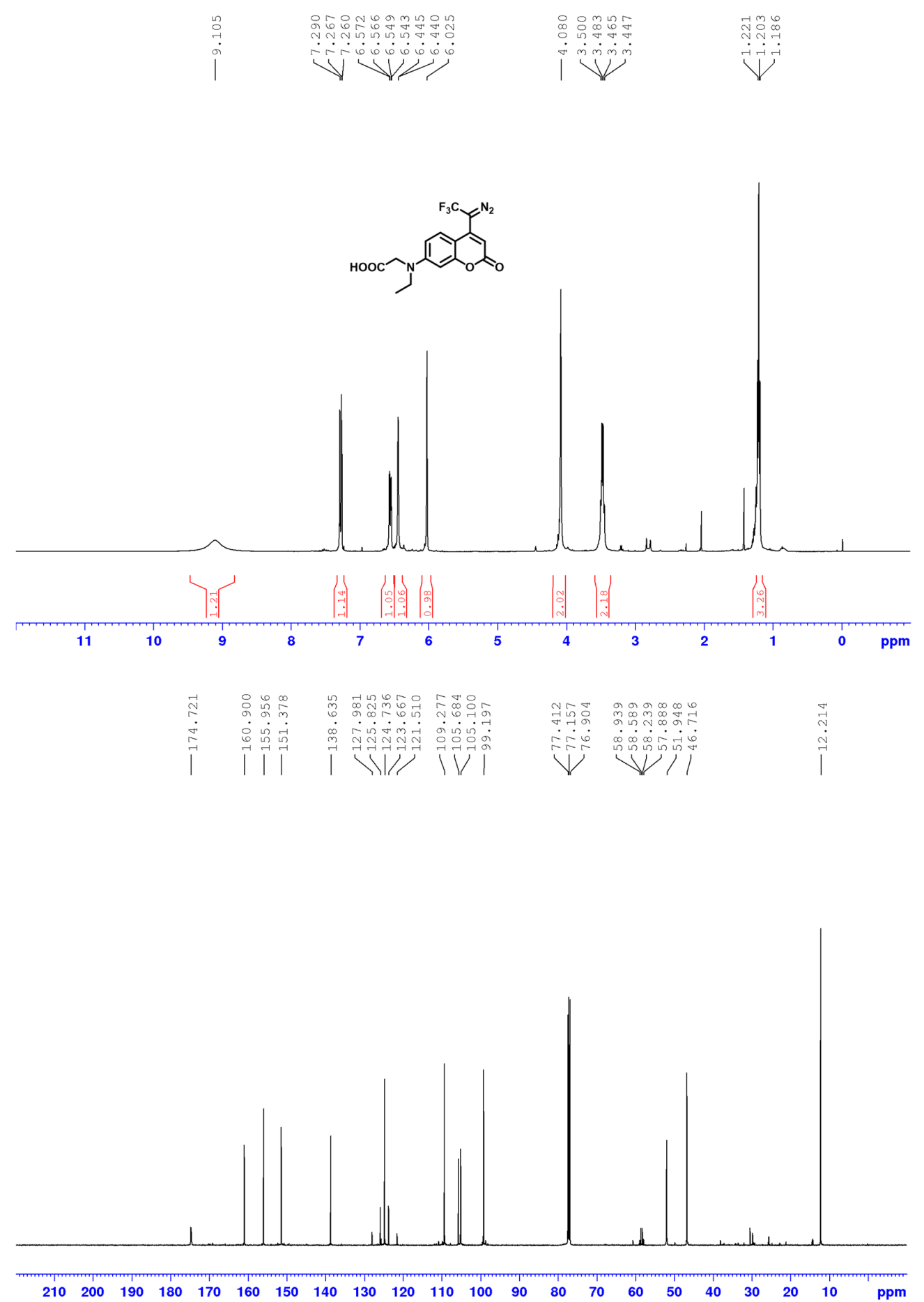


\section{Compound $\mathbf{3}$}
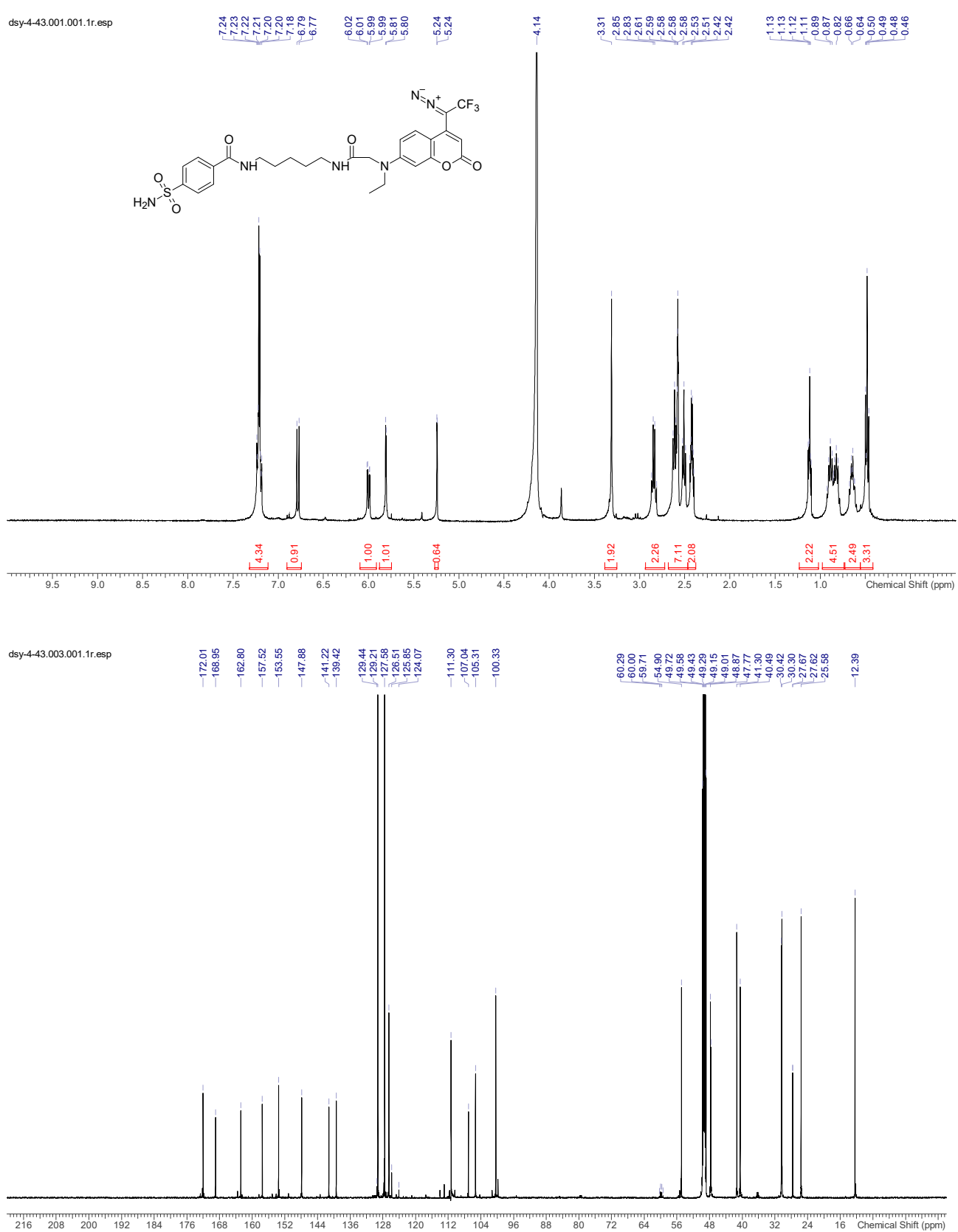


\section{Compound 4}

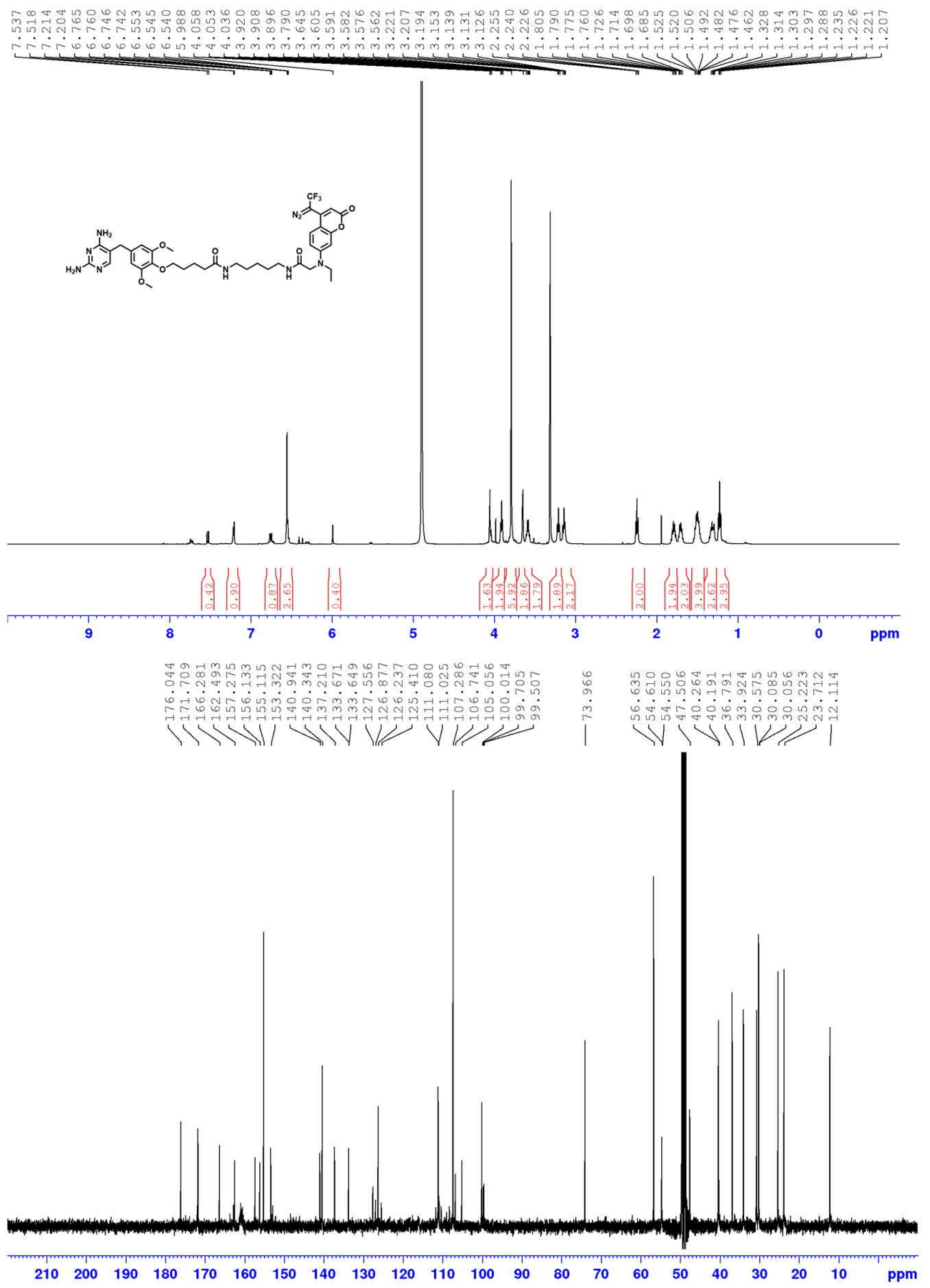




\section{References}

[1] K. Ito, J. Maruyama, Chem. Pharm. Bull. 1983, 31, 3012-3014.

[2] S. M. Nicolle, C. J. Moody, Chem. Eur. J. 2014, 20, 4420-4425.

[3] Q. Lin, Q. Huang, C. Li, C. Bao, Z. Liu, F. Li, L. Zhu, J. Am. Chem. Soc. 2010, 132, 10645-10647.

[4] K. Matsuo, Y. Kioi, R. Yasui, Y. Takaoka, T. Miki, S.-h. Fujishima, I. Hamachi, Chem. Sci. 2013, 4, 2573-2580.

[5] Y. Takaoka, Y. Nishikawa, Y. Hashimoto, K. Sasaki, I. Hamachi, Chem. Sci. 2015, 6, 3217-3224. 